\begin{abstract}
Análise multivariada no mapeamento genético de traços quantitativos
\end{abstract}

Nubia Esteban Duarte

\author{
DISSERTAÇÃO APRESENTADA \\ AO INSTITUTO DE MATEMÁTICA E ESTATÍSTICA \\ DA UNIVERSIDADE DE SÃO PAULO \\ PARA OBTENÇÃO \\ DO GRAU DE MESTRE EM CIÊNCIAS \\ Área de Concentração: Estatística \\ Orientadora: Profa. Dra. Júlia Maria Pavan Soler
}

Durante a elaboração deste trabalho a autora

recebeu apoio financeiro da CAPES e CNPq.

- São Paulo, Junho de 2007 - 


\title{
Análise multivariada no mapeamento genético de traços quantitativos
}

\author{
Este exemplar corresponde à redação \\ final da dissertação devidamente corrigida e \\ defendida por Nubia Esteban Duarte \\ e aprovada pela comissão julgadora.
}

São Paulo, 18 de Junho de 2007.

Comissão Julgadora:

- Titulares:

- Profa. Júlia Maria Pavan Soler (Orientadora) - IME/USP

- Prof. Antonio Augusto Franco Garcia - ESALQ/USP

- Profa. Lucia Pereira Barroso - IME/USP

- Suplentes:

- Profa. Mônica Carneiro Sandoval - IME/USP

- Prof. Heyder Diniz Silva - Monsato Company 
"O temor do Senhor é o princípio da sabedoria, têm bom entendimento todos os que cumprem os seus preceitos".

Salmo 111:10. 
À meu pai, in memoriam, minha mãe e irmãos, meus tios,

à Jorge, Eddy, Diana e Natalia. 


\section{Agradecimentos}

Acima de tudo, agradeço a Deus.

À minha mãe, meus irmãos, meus tios e primos pelo apoio incondicional e as forças que sempre me brindaram em todo momento.

À minha orientadora, Profa. Dra. Júlia M. Paván Soler, pela confiança em mim depositada, pela orientação que recebi ao longo do desenvolvimento deste trabalho.

Ao laboratório de Cardiologia e Genética Molecular do InCor/USP pela autorização na utilização dos dados reais.

Ao Dr Alexandre Pereira (InCor) pelas sugestões nas aplicações deste trabalho.

Aos meus colegas e amigos: Jacqueline, Luz Marina, Nelfi, Mary Luz, Paulo Tadeu, Betsabé e Eddy pela ajuda oportuna, respeito ao trabalho, sempre que precisei.

Aos meus professores do Departamento de Estatística do IME-USP pelos valiosos ensinamentos recebidos.

Aos membros da comissão examinadora por disponibilizarem seu tempo avaliando e dando valiosas sugestões para o trabalho.

À todos os meus amigos Colombianos, estudantes do IME, pela amizade e ajuda que sempre me ofereceram. Destacarei entre eles a Diana, Natalia, Paola, Sandra, Mary Luz, José Domingo, Mauricio, Luz Marina, Paula, Nelfi e Tabarez.

À todos os meus amigos que conheci em São Paulo, Brasileiros e de outros países (não os nomearei porque a lista sería muito grande), principalmente meus "grandes amigos" da turma de mestrado pelos quais tenho um carinho muito especial: Pedro, Augusto, Mariana, Juliana, Grazieli, Ela Cecilia, Fernando, Fernando Cordeiro, Joan, Iván, Jossivão, Marcelo entre outros.

Aos meus queridos amigos: Gleiciane, Adriana, Fernando, João, Luis, Rafael e Michel pela magnífica convivência. 
Aos meus amigos da igreja: senhora Emilia, Edwiges, Yamily, Guido e Paul pela amizade especial compartilhada.

Aos funcionários do IME-USP, pela colaboração em todo momento.

À CAPES e CNPq pelo apoio financeiro.

À todos, MUITO OBRIGADA. 


\section{Resumo}

Em pesquisa Genômica é de grande interesse o mapeamento de genes que controlam traços ou fenótipos quantitativos. Metodologias estatísticas para identificar genes que tenham efeitos sobre um único traço são bem conhecidas na literatura e têm sido exaustivamente aplicadas no mapeamento genético de muitas doenças. Porém, na prática, diferentes traços são correlacionados, como é o caso de hipertensão e obesidade, possivelmente, devido à ação de genes comuns envolvidos na sua regulação. Nestes casos, por meio de técnicas estatísticas multivariadas, que exploram a estrutura de covariância entre os traços, é possível identificar genes não detectados por análises univariadas, ganhar precisão nas estimativas dos efeitos e conhecer a posição desses genes, além de testar efeitos de pleiotropia (um mesmo gene controlando vários traços) e interações gene×ambiente (os genes que controlam a pressão antes e depois de dieta com sal).

Neste trabalho diferentes alternativas de análise estatística são consideradas para explorar a informação de vários traços conjuntamente: modelo de regressão intervalar multivariado (Jiang \& Zeng, 1995), mapeamento multivariado via a teoria espectral (Mangin et al.,1998), via medidas resumo relevantes (como a diferença entre respostas antes e depois de uma exposição) e via ajustes por covariáveis. Também são introduzidas algumas abordagens gráficas para o estudo do efeito de pleiotropia e interação gene×ambiente. As metodologias supracitadas são aplicadas a dados reais fornecidos pelo Laboratório de Cardiologia e Genética Molecular do InCor/USP, que consideram várias medidas de pressão arterial em ratos provenientes de uma população $F 2$. 


\section{Abstract}

In Genomic research, the mapping of genes which control quantitative traits has been of great interest. Statistical methods for detection of genes, influencing a single trait, are well known in the literature and they have been exhaustive used in the genetic mapping of many diseases. However, in real situations, different kind of traits are correlated, such as hypertention and obesity, that would be due to the action of a set of commom genes involved in the regulation of these traits. In these cases, through of multivariate statistical techniques, which explore the covariance structure between the traits, it is possible to identify genes that are not detected by univariated analysis. In addition multivariate analysis are useful to obtain accurate estimates and to know the position of these genes, besides testing effects of pleiotropic (a gene controlling several traits) and gene $\times$ environmental interations (genes that control the pressure before and after salt diet).

In this work different alternatives from statistical analysis are considered to explore information of several traits jointly: Interval multivariate regression models (Jiang and Zeng, 1995); multivariate mapping through the espectral theory (Mangin et al. 1998), summary measures (for example, models formulated in terms of the difference between two traits) and adjustments including covariates. Also, graphics procedures are introduced in order to study effects of pleiotropy and genexenvironmental interactions . The methodologies mentioned above are applied to real data set, supplied by the Cardiology and Molecular Genetic Laboratory of Heart institute (InCor-USP), that consider several measurements of blood pressure in rats that come from a $F 2$ population. 


\section{Índice}

Agradecimentos $\quad$ v

Resumo vii

Abstract viii

Lista de Tabelas $\quad$ xii

Lista de Figuras $\quad$ xiv

1 Introdução 1

2 Alguns conceitos em mapeamento genético $\quad 7$

2.1 Alguns conceitos básicos em Genética . . . . . . . . . . . . . 7

2.2 Dependência entre locos genéticos . . . . . . . . . . . . . . . . 9

2.2.1 Equilíbrio de Hardy- Weinberg . . . . . . . . . . . . . . . . 9

2.2.2 Desequilíbrio de ligação . . . . . . . . . . . . . . . . . . . . . . . . . 10

2.3 Eventos de recombinação . . . . . . . . . . . . . . . . . . . . . 12

2.4 Funções de distância citogenética . . . . . . . . . . . . . . . . . . . 14

2.4.1 Função de mapeamento de Haldane . . . . . . . . . . . . . . . 15

2.4.2 Função de mapeamento de Kosambi . . . . . . . . . . . . . . . . . . . 16

2.5 Efeitos genéticos . . . . . . . . . . . . . . . . . 17

2.6 Populações comumente utilizadas no mapeamento Genético . . . . . . . . . 19

2.7 Modelagem genética . . . . . . . . . . . . . . . . . 21 
2.7 .1 Efeitos pleiotrópicos . . . . . . . . . . . . . . . . . . . . 22

2.7 .2 Interações genexambiente . . . . . . . . . . . . . . . . . . . . 24

3 Métodos de Mapeamento genético $\quad 26$

3.1 Modelos de mapeamento genético . . . . . . . . . . . . . . . 27

3.1.1 Mapeamento utilizando um marcador por vez . . . . . . . . . . . . 28

3.1 .2 Mapeamento por Intervalo . . . . . . . . . . . . . . . . . . 30

3.1.3 Mapeamento por Intervalo Composto . . . . . . . . . . . . . . . 33

3.1 .4 Mapeamento por Múltiplos Intervalos . . . . . . . . . . . . . . . 36

3.1 .5 Modelos de Mistura . . . . . . . . . . . . . . . . . . 38

3.1.6 Hipóteses estatísticas sobre os efeitos do QTL . . . . . . . . . . . . . 40

3.1 .7 Estatística Lod Score . . . . . . . . . . . . . . . . . . . . . . . . . . . 41

3.2 Mapeamento de QTL's sob modelos multivariados . . . . . . . . . . . . . . 42

3.2.1 Modelo de Regressão Intervalar Multivariado . . . . . . . . . . . . . . 43

3.2.2 Testes de hipóteses dos efeitos de QTL's pleiotrópicos e interação gene $\times$ ambiente ........................ 46

3.2.3 Vantagens do mapeamento multivariado . . . . . . . . . . . . . . . . . 49

4 Modelos alternativos no mapeamento multivariado $\quad 51$

4.1 Análise da diferença entre dois fenótipos . . . . . . . . . . . . . . 51

4.2 Mapeamento usando ajuste por covariáveis . . . . . . . . . . . . . 53

4.3 Análise utilizando a decomposição espectral . . . . . . . . . . . . . . . 55

4.3.1 Teste para mapear QTL's com efeitos pleiotrópicos ou de interação gene $\times$ ambiente na análise canônica . . . . . . . . . . . . 58

5 Ferramentas gráficas no mapeamento genético $\quad 61$

5.1 Análise Univariada . . . . . . . . . . . . . . . . . . . 62

5.1.1 Visualização da variação quantitativa.

Histogramas e boxplots . . . . . . . . . . . . . . 62

5.1 .2 Gráfico de colunas ou de perfis de médias . . . . . . . . . . . . 65 
5.1 .3 Gráficos para detectar interações entre genes . . . . . . . . . . . 66

5.2 Análises bivariadas- Efeito de interação

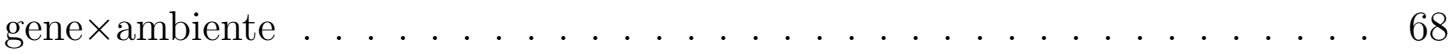

6 Aplicações $\quad 75$

6.1 Resultados da análise univariada . . . . . . . . . . . . . 76

6.2 Resultados da análise multivariada . . . . . . . . . . . . . . . 78

6.3 Análise da medida resumo diferença . . . . . . . . . . . . . . . 84

6.4 Influência de pontos atípicos sobre a pressão arterial . . . . . . . . . . . 86

6.5 Mapeamento usando ajuste por covariáveis . . . . . . . . . . . . . 87

6.6 Aplicação do método de decomposição espectral . . . . . . . . . . . . . . . . 95

6.7 Análise da resposta ao medicamento . . . . . . . . . . . . . . . . . . 97

7 Considerações finais $\quad 108$

A Banco de Dados do Delineamento F2 112

A.1 Delineamento $F 2 \ldots \ldots \ldots$. . . . . . . . . . . . . . . . . . . . 112

A.2 Banco de dados dos Marcadores Moleculares e Variáveis Genotípicas . . . 112

A.3 Banco de dados das variáveis Fenotípicas . . . . . . . . . . . . . . 114

B Enfoques referentes ao problema de múltiplos testes 116

B.1 Correção de Bonferroni . . . . . . . . . . . . . . . . . . . . . 117

B.2 Teste de Permutações . . . . . . . . . . . . . . . . . . . 117

B.3 FDR . . . . . . . . . . . . . . . . . . 118

$\begin{array}{ll}\text { Referências Bibliográficas } & 121\end{array}$ 


\section{Lista de Tabelas}

2.1 Relação entre probabilidades dos alelos e genótipos. . . . . . . . . . . . . . 10

3.1 Freqüências esperadas dos genótipos na geração F2, considerando três locos ligados, com freqüências de recombinação iguais a $\theta_{1}$ entre $M_{1}$ e $Q, \theta_{2}$ entre $Q$ e $M_{2}$ e $\theta$ entre $M_{1}$ e $M_{2} \ldots \ldots \ldots \ldots$. . . . . . . . . . . 32

3.2 Coeficientes de $a$ e $d$, para uma geração F2, no modelo de mapeamento por intervalo. . . . . . . . . . . . . . . . . . 32

3.3 Genótipos com sua probabilidade de ocorrência e componentes da função de densidade de probabilidade. . . . . . . . . . . . . . . 38

4.1 Testes estatísticos em cada posição de um determinado cromossomo . . . . 59

5.1 Classes genotípicas para dois locos cromossômicos, loco $A$ e loco $B$. . . . 68

6.1 Correlação entre os fenótipos da pressão sistólica. . . . . . . . . . . . . . 76

6.2 Testes da razão de verossimilhanças, estimativas dos efeitos aditivo e de dominância para $Y_{S B P}$ e $Y_{S B P S}$ no caso univariado. . . . . . . . . . 83

6.3 Testes da razão de verossimilhanças, estimativas dos efeitos aditivo e de dominância para $Y_{S B P}$ e $Y_{S B P S}$, sob o modelo multivariado. . . . . . . . . 83

6.4 Estatística da razão de verossimilhanças, estimativas dos efeitos aditivo e de dominância para o QTL sob o modelo univariado com alto sinal de ligação no cromossomo 5. . . . . . . . . . . . . . . . . . . 85

6.5 Teste da razão de verossimilhanças, estimativas dos efeitos aditivo e de dominância para as variáveis $Y_{D I F}, Y_{D I F 7}, Y_{D I F 14}$ e $Y_{D I F 21} \ldots \ldots$. . . . 89 
6.6 Testes da razão de verossimilhanças, estimativas dos efeitos aditivo e de

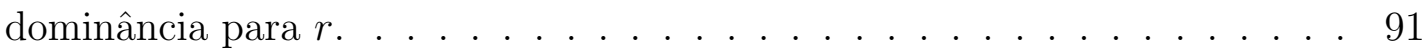

6.7 Testes da razão de verossimilhanças, estimativas dos efeitos aditivo e de dominância para os fenótipos formados por meio dos diferentes valores de $\beta$. 94

6.8 Correlação entre as variáveis canônicas e as originais. . . . . . . . . . . . . 96

6.9 Resultados dos testes estatísticos (mapeamento por intervalo). . . . . . . . 98

6.10 Teste da razão de verossimilhanças, estimativas dos efeitos aditivo e de dominância para $Y_{S B P}, Y_{S B P S}$ e $Y_{\text {Captopril }}$ no caso univariado. . . . . . . . . 101

6.11 Testes da razão de verossimilhanças, estimativas dos efeitos aditivo e de dominância para $Y_{S B P S}$ e $Y_{\text {Captopril }}$, sob o modelo multivariado. . . . . . . 102

6.12 Teste da razão de verossimilhanças, estimativas dos efeitos aditivo e de dominância para os fenótipos $Y_{S B P}, Y_{S B P S}$ e $Y_{\text {Captopril }}$ sob o modelo multivariado. . . . . . . . . . . . . . . . . . . . 103

6.13 Comparação dos testes da razão de verossimilhanças para as análises con-

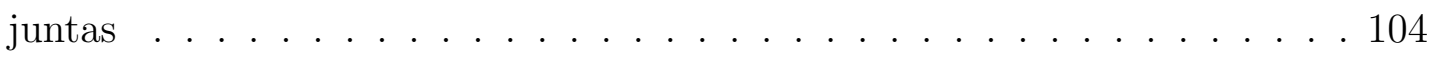

6.14 Estatísticas descritivas para as variáveis $Y_{S B P}, Y_{S B P S}$ e $Y_{C a p t o p r i l}$ em função dos genótipos. . . . . . . . . . . . . . . . . 105

6.15 Intervalos de confiança para contrastes entre médias genotípicas para cada variável. . . . . . . . . . . . . . . . . . . . . 107

6.16 Intervalos de confiança para contrastes entre médias dentro do grupo genotípico.107

7.1 Posições aproximadas dos genes que regulam a pressão arterial sistólica. . . 109

A.1 Número de marcadores moleculares em cada um dos 21 cromossomos. . . . 113

A.2 Localização dos marcadores moleculares e dados genotípicos dos ratos para o cromossomo 5. . . . . . . . . . . . . . . . . . 114

A.3 Codificação para os genótipos dos Marcadores Moleculares. . . . . . . . . 114

A.4 Dados fenotípicos para os 221 ratos. . . . . . . . . . . . . . 115

B.1 Número de erros cometidos ao se testarem $t$ hipóteses . . . . . . . . . . . 120 


\section{Lista de Figuras}

2.1 Ilustração do equilíbrio de Hardy-Weinberg. . . . . . . . . . . . . . . . . . 9

2.2 Composição dos alelos em dois locos genéticos. . . . . . . . . . . . . . . . 11

2.3 Eventos de recombinação. . . . . . . . . . . . . . . . . . . . . . 14

2.4 Comparação entre as funções de Morgan, Haldane e Kosambi. ..... . . 17

2.5 Representação de um gene com seus valores genotípicos. . . . . . . . . . . 18

2.6 Esquema representativo dos cruzamentos envolvidos na obtenção de uma geração de Retrocruzamento. . . . . . . . . . . . . . . . . . . . . 20

2.7 Esquema representativo dos cruzamentos envolvidos na obtenção de uma

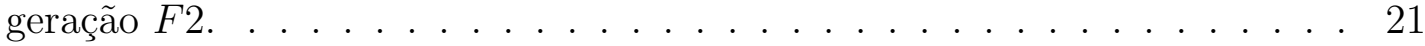

2.8 Padrões possíveis de variação genética . . . . . . . . . . . . . . . . 22

3.1 Mapa de marcadores moleculares úteis na identificação de QTL's. . . . . . 28

3.2 Representação do mapeamento de um QTL $\left(Q_{j}\right)$ condicionado à presença de dois locos marcadores $\left(M_{j}\right.$ e $\left.M_{j+1}\right) \ldots \ldots . \ldots . \ldots . . \ldots 31$

3.3 "QTL fantasma" devido a falso sinal de ligação. . . . . . . . . . . . . . . 34

3.4 Representação do método de mapeamento por intervalo composto que permite investigar o QTL $\left(Q_{j}\right)$ localizado entre os marcadores $\left(M_{j}\right.$ e $\left.M_{j+1}\right)$, considerando também outros marcadores como covariáveis. . . . . . . . . . 35

5.1 Variabilidade fenotípica segundo as categorias genotípicas $(m m, M m$ e $M M)$. 63

5.2 Modelos de mistura. . . . . . . . . . . . . . . . . 65

5.3 Perfis de médias para um loco cromossômico codominante, com genótipos $(m m, M m, M M) . \ldots \ldots \ldots 6$ 
5.4 Interações epistáticas entre dois locos cromossômicos. . . . . . . . . . . . 67

5.5 Diagramas de dispersão e gráfico de perfis indicando correlação positiva entre fenótipos. ........................... 70

5.6 Perfis individuais de resposta para fenótipos com correlação positiva. . . . 71

5.7 Diagramas de dispersão e gráfico de perfis indicando correlação negativa entre fenótipos. . . . . . . . . . . . . . . . . . . 72

5.8 Perfis individuais de resposta para fenótipos com correlação negativa. . . . 73

6.1 Perfis da estatística Lod score sob o modelo univariado para $Y_{S B P}$. . . . 78

6.2 Perfis da estatística Lod score sob o modelo univariado para $Y_{S B P S}$. . . . . 78

6.3 Perfis da estatística Lod score sob o modelo univariado para $Y_{\text {Captopril }}$. . 79

6.4 Perfis individuais de resposta para a pressão sistólica antes e depois da exposição ao sal. . . . . . . . . . . . . . . . . . . . . . . . . 80

6.5 Perfis da estatística Lod score para efeitos marginais e conjuntos sob o modelo multivariado . . . . . . . . . . . . . . . . . . 81

6.6 Perfis da estatística Lod score sob o modelo univariado para $Y_{D I F}$. . . . . . 85

6.7 Perfis da estatística Lod score sob o modelo univariado para $Y_{D I F}, Y_{D I F 7}$, $Y_{D I F 14}$ e $Y_{D I F 21} \ldots \ldots \ldots \ldots \ldots \ldots$

6.8 Perfis da estatística Lod score sob o modelo univariado para $r$. . . . . . . 90

6.9 Perfis da estatística Lod score para todos os fenótipos obtidos mediante variações nos valores de $\beta$. . . . . . . . . . . . . . . . . . . . . . . 93

6.10 Representação gráfica da tendência dos efeitos aditivos, de dominância e da estatística do teste da razão de verossimilhanças de acordo com $\beta$. . . . 94

6.11 Perfis da estatística Lod score sob o modelo univariado para as variáveis

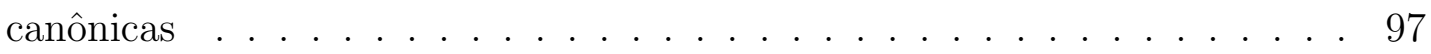

6.12 Perfis individuais de resposta para a pressão arterial medida em três etapas 98

6.13 Perfis da estatística Lod score sob o modelo multivariado para $Y_{S B P S}$ e $Y_{\text {Captopril. } \ldots \ldots \ldots \ldots} \ldots \ldots \ldots \ldots \ldots$

6.14 Perfis da estatística Lod score sob o modelo univariado para $Y_{\text {DIFcapt }} \quad$. . . 101 
6.15 Perfis da estatística Lod score sob o modelo multivariado para $Y_{S B P}, Y_{S B P S}$

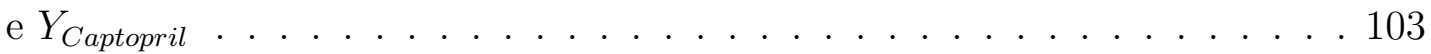

6.16 Perfis de médias para as classes genotípicas $m m, M m, M M$ dentro de cada fenótipo para a posição específica do cromossomo 5 marcador R589. . . . . 105

A.1 Delineamento F2. Projeto InCor. . . . . . . . . . . . . . . . . . 113 


\section{Capítulo 1}

\section{Introdução}

A genética é o ramo da biologia que estuda a transferência das características físicas, químicas e biológicas de geração para geração. Nesta área, a identificação ou mapeamento de genes que regulam ou estão envolvidos no processo de regulação de muitas doenças tais como hipertensão, obesidade, diabetes, está sendo o tema principal de muitas pesquisas. Graças a estes estudos, é possível descobrir a causa de muitas doenças e assim mecanismos de prevenção poderão ser desenvolvidos a partir das informações obtidas sobre os genes que as afetam (Farah, 1997).

Sabe-se que muitos genes estão envolvidos na regulação de fenótipos ou características nos seres vivos como, por exemplo, altura, pressão arterial, obesidade, diabetes entre outras. Em geral, em textos da área de Genética e Estatística aplicada à Genética essas características são denominadas traços ou fenótipos quantitativos os quais num contexto específico são variáveis aleatórias com distribuição contínua. Neste trabalho usa-se os termos variável, característica, fenótipo ou traço indistintamente. O loco ${ }^{1}$ genético, isto é, uma região cromossômica específica associada à regulação de fenótipos quantitativos é amplamente conhecido como QTL (do inglês, Quantitative Trait Locus) (Falconer \& Mackay, 1996). O procedimento de identificar e localizar essas regiões cromossômicas bem como de estimar seus efeitos (aditivos e de interação) sobre os fenótipos é conhecido como mapeamento genético de QTL's. Tal procedimento envolve a estimação de efeitos adi-

${ }^{1}$ Loco: região cromossômica, vem de locus (com plural loci) em latim. No presente trabalho usa-se o termo loco. 
tivos dos possíveis genes envolvidos assim como possíveis efeitos de interação entre os genes (epistasia), efeitos de interação dos genes com o ambiente e, finalmente, identificar possíveis genes comuns envolvidos na regulação de um mesmo traço (efeito de pleiotropia). A base fundamental do mapeamento genético consiste em utilizar a informação observável de pontos de referência do genoma e, a partir disso predizer QTL's e seus efeitos associados. Esses pontos de referência são denominados marcadores moleculares ou locos cromossômicos cuja posição é conhecida e são passíveis de genotipagem, isto é, para tais posições cromossômicas a constituição genotípica do indivíduo pode ser identificada. Os marcadores moleculares constituem uma amostra de locos genéticos estrategicamente dispostos ao longo do genoma e a hipótese empregada para a localização de QTL's é que algum marcador estará próximo e, portanto, suficientemente ligado (do inglês, linkage) ao QTL de interesse (Lynch \& Walsh, 1998; Zeng, 1994), de tal forma que os dados do marcador oferecem informação sobre o QTL.

Uma das aplicações mais importantes do mapeamento genético é localizar genes de interesse específico tais como aqueles que causam doenças em humanos (hipertensão, diabetes, depressão, obesidade) ou, genes que controlam fenótipos de importância econômica em plantas (produção, resistência a pragas, tamanho dos frutos) e animais (produção de leite, peso, qualidades nutricionais dos ovos) (Liu, 1998). Com esse objetivo o avanço biotecnológico veio possibilitar o uso de marcadores genéticos para diferentes populações e, atualmente, mapas de marcadores moleculares estão disponíveis para mapeamento de genes de muitas espécies (humanos, macacos, ratos, cãos, trigo, milho, soja, bactérias, entre tantas outras) com o intuito de localizar com maior precisão locos genéticos envolvidos com a regulação de traços ou fenótipos de interesse.

O procedimento mais comum no mapeamento genético tem sido a procura por QTL's considerando um traço de cada vez (Lander \& Botstein, 1989; Knapp, Bridges \& Birkes, 1990; Haley \& Knott, 1992; Zeng, 1994). Mediante estes procedimentos univariados, vários estudos têm obtido sucesso, identificando genes que influenciam um fenótipo, por exemplo, genes reguladores da pressão sangüínea (Samani, 2003). No entanto, os enfoques de mapeamento mediante os métodos univariados não tomam vantagem da estrutura de 
correlação entre os fenótipos, podendo acarretar limitações no mapeamento genético de QTL's e também no entendimento da correlação genética entre fenótipos que sejam controlados por conjuntos comuns de genes.

Na prática, os traços ou características quantitativas, observadas no mesmo indivíduo, são geralmente correlacionados, possivelmente, devido à ação de genes comuns envolvidos na sua regulação (pleiotropia), além disso tal correlação pode ser gerada entre traços controlados por genes diferentes mas ligados (não pleiotrópicos), isto é, localizados em regiões cromossômicas muito próximas. Este último caso pode ser pesquisado por meio de análises posteriores ao mapeamento que envolvam mapas de marcadores mais densos que refinem a região cromossômica identificada previamente. Em humanos existem milhões de traços quantitativos que são regulados por muitos genes, se cada gene regulasse só um traço, deveriam existir também milhões de genes, mas, é conhecido que nos humanos existem entre 30.000 e 35.000 genes. Assim é lógico pensar que existem genes que regulam dois ou mais traços simultaneamente (Venter, 2001; Balding, 2002). O efeito com que um gene regula vários traços ou fenótipos simultaneamente é conhecido como efeito de pleiotropia. Ressalta-se, que além dos fenótipos serem regulados por genes, grande parte de sua regulação pode ser influenciada por fatores ambientais bem como pode acontecer um importante efeito de interação entre gene e ambiente conhecido como efeito de interação gene $\times$ ambiente. $O$ fato dos traços quantitativos serem na maioria das vezes influenciados por muitos genes, além de fatores ambientais e interações, faz com que seu estudo seja não trivial. Isto porque características poligênicas dificultam o isolamento e a caracterização de cada um dos fatores que controlam o traço (Schork et al. 1995).

A análise multivariada provê um enfoque para identificar genes que influenciam dois ou mais fenótipos correlacionados. Vários métodos de mapeamento multivariado têm sido desenvolvidos na literatura (Jiang \& Zeng, 1995; Weller, Wiggans \& VanRaden, 1996; Mangin et al. 1998). Os autores argumentam que considerando a estrutura de correlação entre múltiplos traços ou fenótipos, pode-se obter um aumento no poder de detecção de QTL's e na precisão do mapeamento genético quando comparado às análises realizadas com caracteres isolados. Mediante a abordagem multivariada é possível o estudo do efeito 
de pleiotropia e a interação gene× ambiente que serão o motivo de análise principal do presente trabalho.

Na literatura são encontradas algumas aplicações de mapeamento genético multivariado, por exemplo, Arya et al. (2003) examinou a obesidade e níveis de HDL de colesterol em humanos (dois fenótipos diferentes avaliados simultaneamente nos indivíduos) e, mediante uma análise bivariada foi identificado um loco no cromossomo 6 influenciando os dois traços. Eles argumentam que a análise univariada mostrou evidências do QTL, mas foi a análise bivariada que forneceu fortes evidências da presença do QTL naquela região. Kraft et al. (2003) apresentaram um estudo de análise de QTL's, univariado e bivariado, sobre fenótipos de pressão sangüínea em um estudo longitudinal (o mesmo fenótipo avaliado em diferentes tempos). Foram realizadas análises univariadas em diferentes classes de faixa etária e análises longitudinais, concluiram que, para esse caso específico, a análise univariada apresentou mais evidências da presença de um QTL no cromossomo 17 do genoma humano, comparado com a análise multivariada que apresentou resultados não estáveis.

Os exemplos anteriores ilustram o fato que tem sido discutido na literatura de que as metodologias estatísticas multivariadas, aplicadas ao mapeamento genético de QTL's, ainda não são suficientemente claras sobre como abordar os problemas de análises conjuntas gerais, entre eles o mapeamento de QTL's com efeitos pleiotrópicos e interações gene $\times$ ambiente. Vários métodos univariados alternativos à análise multivariada para o esclarecimento dos padrões de regulação gênica têm sido apresentados na literatura, tais como a análise mediante a decomposição espectral (Mangin et al. 1998), análise da diferença entre dois fenótipos de interesse (Soler et al. 2005) e modelos mediante o ajuste por covariáveis (Turner et al. 2004). No contexto destes problemas de abordagem multivariada surgiu a motivação para o desenvolvimento do presente trabalho cujos objetivos são:

- Explorar diferentes modelos de mapeamento genético univariados e multivariados para estudar o efeito de pleiotropia e interação gene×ambiente; 
- Aplicar tais modelos de mapeamento genético na análise de um conjunto de dados reais com o intuito de procurar QTL's reguladores da pressão arterial, encontrar a posição aproximada destes no mapa cromossômico e, tanto quanto possível, caracterizar seus efeitos nos diferentes grupos genotípicos de indivíduos.

Como motivação, as aplicações consideradas são baseadas em dados reais coletados no Laboratório de Cardiologia e Genética Molecular do Instituto do Coração de São Paulo (InCor-USP). O estudo é baseado em uma população de 221 ratos $F 2$ resultante do cruzamento controlado entre uma linhagem de animais normotensos e outra de hipertensos (ver Apêndice A1), desenvolvidas de forma que o background genético ${ }^{2}$ da geração de filhos possua características praticamente idênticas, diferindo apenas nos determinantes genéticos da pressão arterial. Foram coletadas 23 variáveis fenotípicas, entre elas: pressão basal, pressão sistólica antes e pós-sal, pressão diástólica antes e pós-sal, pressão após o uso de medicamentos como o Captopril e o peso do animal. Além disso, os 221 animais foram genotipados considerando um mapa com 182 marcadores moleculares espalhados nos 21 cromossomos dos ratos (ver Figura 3.1).

No Capítulo 2 são introduzidos conceitos de genética que são fundamentais no desenvolvimento das metodologias estatísticas para o mapeamento de QTL's. Muitas metodologias para o mapeamento genético são baseadas em modelos de regressão univariados e multivariados destacando-se que existem vantagens do procedimento multivariado com respeito ao univariado. A descrição dos métodos e os respectivos modelos são apresentados no Capítulo 3. Para se esclarecer os padrões de regulação genética nos modelos multivariados, são considerados três modelos univariados alternativos de mapeamento genético no Capítulo 4 (análise mediante a decomposição espectral, diferença entre dois fenótipos e modelos e mediante o ajuste por covariáveis). Com o intuito de se explorar descritivamente um conjunto de dados genéticos para verificar se há evidência de locos genéticos participando da regulação de fenótipos, são apresentadas algumas ferramentas gráficas conhecidas na literatura, e são sugeridos alguns diagramas de perfis individuais

\footnotetext{
2 Background genético: é o conjunto de muitos genes, cada um com pequeno efeito.
} 
úteis no estudo do efeito da interação gene×ambiente; a descrição dessas ferramentas está organizada no Capítulo 5.

As aplicações da metodologia descrita no trabalho são realizadas para um conjunto de dados reais sobre a pressão arterial de ratos $F 2$. Os fenótipos analisados são: pressão arterial sistólica basal, pressão arterial sistólica pós-sal e pressão arterial sistólica pósremédio. Os resultados encontrados estão descritos no Capítulo 6. Finalmente, no Capítulo 7 são apresentadas algumas conclusões obtidas juntamente com sugestões para pesquisas futuras no contexto de mapeamento genético multivariado de QTL's. 


\section{Capítulo 2}

\section{Alguns conceitos em mapeamento genético}

Neste capítulo serão introduzidos conceitos importantes de Genética, os quais ajudarão na compreensão e desenvolvimento da teoria abordada neste trabalho aplicada ao mapeamento genético de múltiplos traços.

\subsection{Alguns conceitos básicos em Genética}

O DNA ou ácido desoxirribonucleico, é a molécula que armazena a informação genética e está organizado em forma de Cromossomos no núcleo das células dos organismos. Esta molécula especifica as funções que serão realizadas pelas células que compõem o organismo e determina, juntamente com o ambiente, suas características físicas nos diferentes níveis (bioquímico, fisiológico, etc). Ao longo do cromossomo, de forma linear, estão distribuídos os genes os quais correspondem a seqüências de DNA que codificam proteínas. Cada gene ocupa uma região no cromossomo conhecida como loco (Farah, 1977).

Gene é um termo geral que significa a entidade física transmitida de pai para filho, durante o processo de reprodução, que influencia características hereditárias (Falconer \& Mackay, 1996). Formas alternativas de um gene que podem ocorrer em um determinado loco são chamados de alelos. O grupo de alelos de diferentes genes no mesmo cromossomo recebidos de um dos pais do indivíduo é chamado de haplótipo. O conjunto dos diferentes cromossomos de um indivíduo é conhecido como cariótipo e o conjunto formado por uma das cópias de todos os cromossomos é o Genoma. 
A constituição genética de um indivíduo definida pelo material recebido dos dois pais, é conhecida como o Genótipo. O genótipo não é observável, porém pode ser deduzido por meio de processos indiretos (de cruzamentos laboratoriais entre outros), é definido no momento da fecundação e não se altera, salvo alguma mutação, durante toda a vida do indivíduo. Já o conjunto de características observáveis nesse indivíduo no nível bioquímico, fisiológico ou morfológico é conhecido como o fenótipo. Este é a "aparência" do indivíduo, ou seja, tudo aquilo que é visível ou detectável de alguma forma e que está associado a alguma característica do indivíduo, sendo que alguns fenótipos podem se alterar com o passar do tempo.

É importante chamar a atenção para o fato de que nem sempre as características fenotípicas são visíveis, sendo necessário, às vezes, exames especiais para serem mensurados. O tipo sangǘneo (Sistema ABO) e o fator Rh se enquadram nesse caso. O mesmo ocorre com o indivíduo diabético, hemofílico, hipertenso entre outros, cujos fenótipos não são visíveis, mas apenas detectados. Na maioria dos casos, as manifestações fenotípicas dependem das relações entre o genótipo e o meio ambiente com o qual o indivíduo interage. Os filhos herdam dos pais um certo genótipo, que tem a potencialidade de expressar vários fenótipos, muitas vezes dependendo de sua interação com o ambiente.

Um indivíduo diplóide tem dois alelos em um determinado loco, (os alelos denotam-se com letras maiúsculas, com os respectivos sub-índices, $A_{i}$ e $A_{j}$, por exemplo). Quando um indivíduo possui alelos idênticos para um dado loco, $\left(A_{1} A_{1}\right)$ ou $\left(A_{2} A_{2}\right)$ diz-se que ele é homozigoto. Caso apresente no mesmo loco alelos diferentes, $\left(A_{1} A_{2}\right)$, em cada cromossomo homólogo, chama-se heterozigoto. Se indivíduos com genótipo $A_{1} A_{2}$ são fenotipicamente iguais a indivíduos com genótipo $A_{1} A_{1}$, mas diferentes de indivíduos com genótipo $A_{2} A_{2}$, então o alelo $A_{1}$ é dominante para o alelo $A_{2}$, ou, equivalentemente, $A_{2}$ é recessivo para o alelo $A_{1}$. No caso dominante basta uma cópia do alelo para a caractarística se expressar. No caso recessivo a expressão do fenótipo só ocorre na presença de duas cópias do alelo. Se o genótipo $\left(A_{1} A_{2}\right)$ conduz a fenótipo que é diferente do fenótipo $\left(A_{1} A_{1}\right)$ que por sua vez é diferente de $\left(A_{2} A_{2}\right)$, então os alelos $A_{1}$ e $A_{2}$ são chamados Codominantes e tem-se três classes fenotípicas definidas. 


\subsection{Dependência entre locos genéticos}

Para descrever a configuração genética de uma população, deve-se primeiramente especificar seus possíveis genótipos e, então, as probabilidades genotípicas (probabilidades dos indivíduos serem portadores de cada genótipo) e as probabilidades alélicas (probabilidades de ocorrência de cada alelo nessa população). A estimação dessas probabilidades, assim como a interação de diferentes alelos no mesmo ou em diferentes locos e o grau com o qual tais interações governam as probabilidades genéticas, são de grande interesse para a análise de populações. A seguir são apresentados dois conceitos fundamentais envolvidos com a estrutura de dependência entre alelos e genótipos nos locos genéticos.

\subsubsection{Equilíbrio de Hardy- Weinberg}

Um conceito importante em Genética é o equilíbrio de Hardy-Weinberg, (EHW), que descreve as probabilidades genotípicas em termos das probabilidades alélicas, supondo independência na combinação dos alelos paternos que definem o genótipo (ver Figura 2.1). Sob condições de cruzamentos aleatórios e ausência de processos como migração, mutação, seleção e oscilação, a população é esperada estar em equilíbrio de Hardy-Weinberg (Hartl \& Clark, 1997).

Figura 2.1 Ilustração do equilíbrio de Hardy-Weinberg.

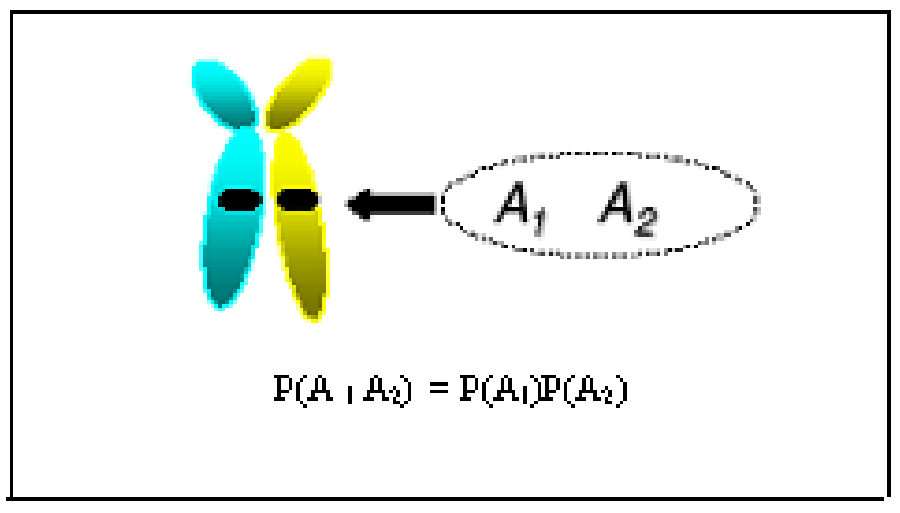

Um sistema genético com $r$ alelos em um loco ocorrendo com probabilidades $p_{i}, i=$ 
$1,2, \ldots, r$, diz-se em equilíbrio de Hardy-Weinberg se as $(r+1) r / 2$ probabilidades genotípicas $p_{i j}, i<j$ são dadas por:

$$
p_{i j}=p_{i} p_{j}[\mathbb{1}(i=j)+2 \mathbb{1}(i<j)]
$$

onde $\mathbb{1} C$ representa a função indicadora do conjunto $C$. Considerando locos dialélicos, segue na Tabela 2.1 a relação entre probabilidades dos alelos e genótipos sob EHW (Falconer e Mackay, 1996). Por exemplo, a probabilidade que um indivíduo na população possua o genótipo $A_{1} A_{1}$ é $p^{2}$. De maneira geral, pode-se dizer que o EHW é uma medida de associação entre alelos em um único loco. Existem possibilidades de desvios deste equilíbrio, uma delas é a estratificação da população, em que os cruzamentos são não aleatórios, ou seja, a união entre indivíduos de estratos diferentes são menos prováveis de ocorrer do que cruzamentos entre indivíduos de mesmo estrato, além disso a endogamía pode conduzir a desvios do equilíbrio (Sham, 1998).

Tabela 2.1 Relação entre probabilidades dos alelos e genótipos.

\begin{tabular}{lccccc}
\hline \hline & \multicolumn{2}{c}{ Alelos } & \multicolumn{3}{c}{ Génotipos } \\
\cline { 2 - 6 } & $A_{1}$ & $A_{2}$ & $A_{1} A_{1}$ & $A_{1} A_{2}$ & $A_{2} A_{2}$ \\
\hline Probabilidades & $\mathrm{p}$ & $\mathrm{q}$ & $\mathrm{p}^{2}$ & $2 \mathrm{pq}$ & $\mathrm{q}^{2}$ \\
\hline \hline
\end{tabular}

\subsubsection{Desequilíbrio de ligação}

A análise da distribuição dos alelos em um único loco pode ser estendida para mais de um loco. O desequilíbrio de ligação $(D)$ é definido como qualquer desvio das probabilidades alélicas conjuntas em relação às probabilidades alélicas esperadas sob independência, indicando a existência de uma associação entre dois locos. Esses desvios podem ser representados por:

$$
D=P\left(A_{i} B_{j}\right)-P\left(A_{i}\right) P\left(B_{j}\right)
$$

onde $P\left(A_{i} B_{j}\right)$ representa a probabilidade conjunta do haplótipo $A_{i} B_{j} ; P\left(A_{i}\right)$ e $P\left(B_{j}\right)$ representam as probabilidades marginais dos alelos $A_{i}$ e $B_{j}$, respectivamente. 
Se $D=0$ então $P\left(A_{i} B_{j}\right)=P\left(A_{i}\right) P\left(B_{j}\right)$ e, nesse caso, a população é dita estar em equilíbrio de ligação. Este equilíbrio define independência probabilística na constituição dos alelos em locos do mesmo cromosssomo chamado de independência vertical (entre locos) para diferenciar do EHW, uma independência horizontal (na constituição dos alelos dentro do loco).

Considerando o modelo de desequílíbrio baseado em dois locos, na Figura 2.2 são representados os alelos $A_{1}$ e $A_{2}$ no loco $L_{1}$, os alelos $B_{1}$ e $B_{2}$ no loco $L_{2}$ e os possíveis haplótipos $A_{1} B_{1}, A_{1} B_{2}, A_{2} B_{1}, A_{2} B_{2}$. Ao considerar o haplótipo $A_{1} B_{1}$, a medida do desequilíbrio gamético é dada por:

$$
D_{A_{1} B_{1}}=P\left(A_{1} B_{1}\right)-P\left(A_{1}\right) P\left(B_{1}\right)
$$

Figura 2.2 Composição dos alelos em dois locos genéticos.

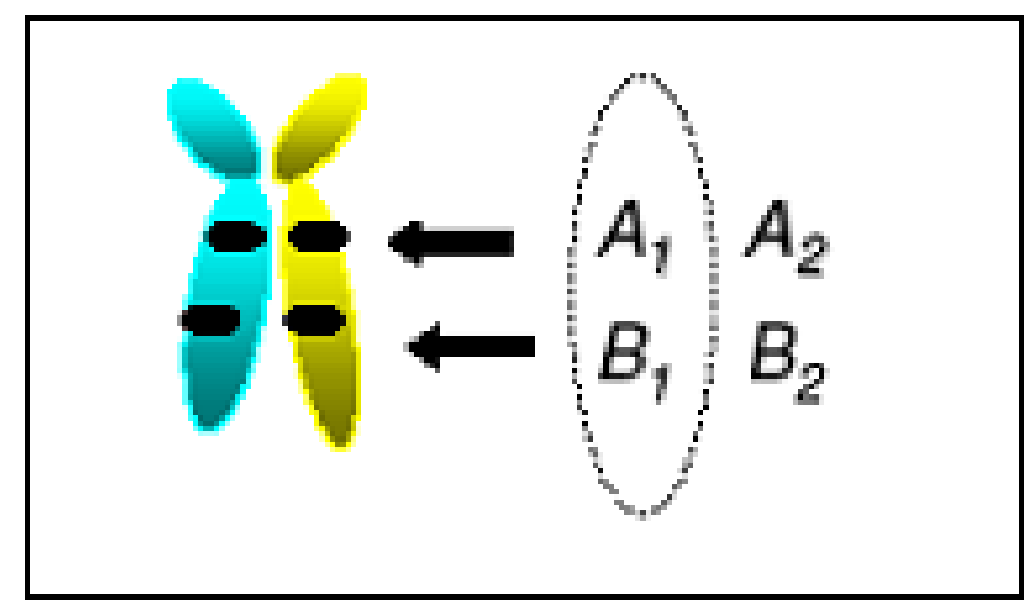

O parâmetro de desequilíbrio de ligação pode ser positivo ou negativo, sendo que sua amplitude depende das probabilidades alélicas nos dois locos:

$$
-\operatorname{máx}\left[P_{A_{1}} P_{B_{1}},\left(1-P_{A_{1}}\right)\left(1-P_{B_{1}}\right)\right]<D_{A_{1} B_{1}}<\min \left[\left(1-P\left(B_{1}\right) P_{A_{1}},\left(1-P_{A_{1}}\right) P_{B_{1}}\right]\right. \text {. }
$$

Este parâmetro de desequilíbrio de ligação (D) é também uma medida de dependência alélica entre locos no mesmo cromossomo e tem sido explorado em estudos de ligação genéticos. Assim, quando o objetivo é encontrar genes que regulam um fenótipo (por 
exemplo, encontrar os genes que regulam doenças cardíacas, pressão arterial) é útil garantir que a população esteja em desequilíbrio de ligação pois, neste caso, a informação de um loco conhecido (marcador) ligado a um QTL poderá ser usada com maior precisão na predição do QTL. As populações derivadas de cruzamentos controlados são as mais adequadas para este tipo de estudo, pois nelas o desequilíbrio de ligação atinge o ponto máximo e, como conseqüência, a capacidade para detectar genes que estejam "muito próximos" também é máxima, permitindo o acompanhamento da segregação de um dado alelo de interesse (QTL) por meio da segregação de um gene (marcador) de manifestação conhecida (Tanksley, 1993 e Liu, 1998).

\subsection{Eventos de recombinação}

A meiose é o processo de divisão celular que origina os gametas. Nesse processo, as cromátides homólogas ou irmãs se duplicam e se emparelham, podendo partir-se em determinados pontos e juntar-se novamente, porém com as porções dos filamentos trocados, formando assim um cromossomo híbrido em lugar do original. Este mecanismo é conhecido como Recombinação genética ou Crossing-over (Farah, 1997). A transmissão de locos como eventos independentes é geralmente verdadeira para genes que estão em diferentes cromossomos, mas quando os locos são fisicamente ligados no mesmo cromossomo, uma dependência dentro do modo de segregação dos genes incorporados dentro de gametas que tendem a ser transmitidas de forma integra, isto é, não recombinante,

pode existir entre os genes incorporados dentro de gametas. Genes ligados no mesmo cromossomo tendem a ser herdados e transmitidos como um grupo sem a ocorrência de recombinação entre as cromátides homólogas, uma tendência que diminui com o aumento da distância entre locos. Deste modo, o mecanismo de recombinação é função da distância entre locos responsável por esta diminuição (Lynch \& Walsh, 1998). Na Figura 2.3 ilustrase este mecanismo de recombinação $(A, B$ representam os alelos no primeiro cromossomo paterno e $a, b$ os alelos no segundo cromossomo paterno).

A probabilidade de que ocorra evento de recombinação entre dois locos quaisquer na 
meiose é conhecida como fração de recombinação e será representada por $\theta$. A fração de recombinação está diretamente relacionada à distância (citogenética) entre locos num mesmo cromossomo, isto é, quanto mais próximos dois locos estão, menor é a probabilidade de ocorrência de recombinação entre eles (Ott, 1991). O parâmetro $\theta$ pode ser expresso pela fórmula de Mather, como a seguir (Lange, 1997):

$$
\theta=\frac{1}{2} P(N>0)=\frac{1}{2}[1-P(N=0)]
$$

onde $N$ indica o número de eventos de recombinação entre dois locos no mesmo cromossomo.

O intervalo dentro do qual $\theta$ pode variar é de 0 a 0,5 . Da expressão 2.3 tem-se que $\theta$ é igual a 0,5 na ocorrência de pelo menos um evento de recombinação, isto é, $P(N=$ $0)=0$. Do mesmo modo $\theta$ assume o valor 0 quando a probabilidade de nenhum evento de recombinação é 1 , ou seja, $P(N=0)=1$. No procedimento de inferência estatística sobre o parâmetro $\theta$ é usual definir a hipótese nula como $H_{0}: \theta=0,5$ (não ligação entre locos) e a hipótese alternativa como $H_{1}: \theta<0,5$. No teste da hipótese $H_{0}$, se a evidência amostral apontar para a rejeição de $H_{0}$, conclui-se que há ligação entre os locos sob análise.

Existe uma relação entre fração de recombinação $\theta$ e o desequilíbrio de ligação. Quando dois locos estão ligados com uma fração de recombinação $\theta$, os coeficientes de desequilíbrio decrescem por um fator $(1-\theta)$ a cada geração em cruzamentos aleatórios. A expressão do desequilíbrio na $g$-ésima geração é dada por:

$$
D_{A_{1} B_{1}}^{g}=(1-\theta)^{g} D_{A_{1} B_{1}}^{0}
$$

onde,

$D_{A_{1} B_{1}}^{0}$ : é a medida de desequilíbrio na geração inicial,

$D_{A_{1} B_{1}}^{g}$ : desequilíbrio na geração $g$,

$\theta$ : fração de recombinação. 
Figura 2.3 Eventos de recombinação.

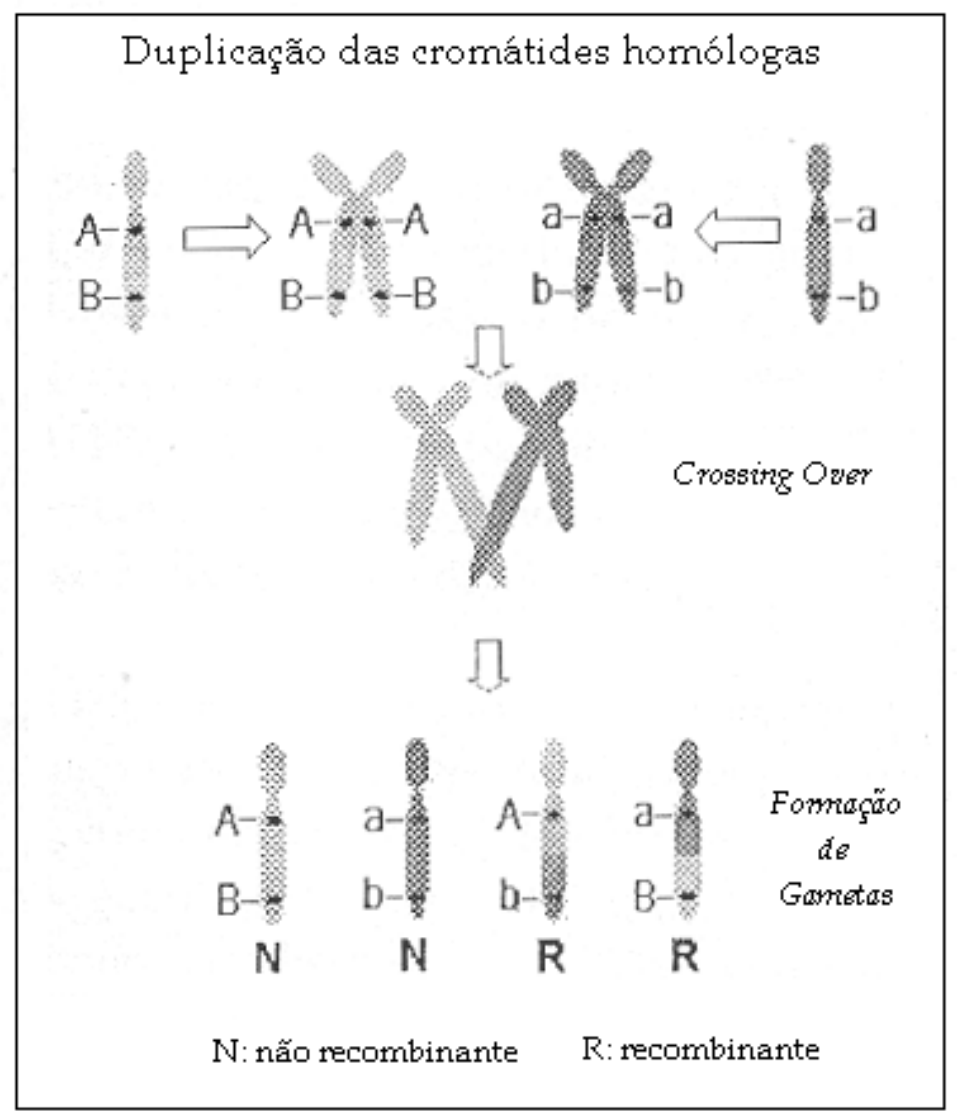

\subsection{Funções de distância citogenética}

Embora o método para medir distância entre dois locos seja definido em termos da probabilidade de recombinação, $\theta$, nem sempre tais probabilidades fornecem medidas diretas dessas distâncias. A presença de um crossing-over, ou permuta de material genético, numa determinada região pode diminuir a probabilidade de ocorrência de permutas em outras regiões e, conseqüentemente, diferentes modelos têm sido adotados para estimar a distância dos locos em função de $\theta$. Além disso, as probabilidades de recombinação não têm a propriedade de serem aditivas em relação à soma e por isso, faz-se necessária uma transformação de escala (Lynch \& Walsh, 1998).

A falta de aditividade das distâncias entre locos levou ao desenvolvimento das funções de mapeamento. Estas funções são utilizadas para converter as probabilidades de recom- 
binação em medidas de distância entre locos genéticos cujas propriedades permitem o ordenamento de locos no cromossomo.

A medida de distância (citogenética) será denotada por $\lambda$ e é definida como o número médio de pontos de permuta genética no segmento cromossômico sob estudo. A unidade dessa escala de medida foi denominada Morgan (M), de forma que um Morgan (1M) corresponde a um segmento cromossômico no qual ocorre, em média, uma permuta genética por gameta em cada geração, sendo comum utilizar a medida em centimorgans $(\mathrm{cM})^{1}$.

As informações de interesse, ao se consultar um mapa de ligação, ${ }^{2}$ é a probabilidade de recombinação $\theta$ existente entre os locos bem como a posição dos locos; portanto é preciso que exista uma relação que permita obter $\theta$ a partir de $\lambda$ e vice-versa. Essa regra de associação é chamada de função de mapeamento. A função de distância citogenética mais simples (função identidade $\theta=\lambda$ ) foi proposta por Morgan (1928), apropriada para intervalos curtos. Outras funções matemáticas de mapeamento têm sido desenvolvidas (Haldane, 1919; Kosambi, 1944; Carter \& Falconer, 1951; Rao et al. 1977; Karlin, 1984; Ott, 1991), sendo as funções de Haldane e Kosambi as mais utilizadas para se relacionar distância genética $\lambda$ entre dois locos no mapa e a probabilidade de recombinação $\theta$, contornando o problema de aditividade.

\subsubsection{Função de mapeamento de Haldane}

Para obter a função de mapeamento de Haldane, são admitidas duas pressuposições básicas:

- As ocorrências de permutas genéticas são independentes (não há interferência);

- As permutas genéticas ocorrem ao acaso, ao longo do cromossomo.

Assim, o número de permutas genéticas pode ser modelado segundo uma distribuição de Poisson. Para que haja recombinação entre dois locos separados por uma distância $\lambda$

${ }^{1}$ Um centimorgan é definido como a distância entre dois locos cuja recombinação ocorre em $1 \%$ dos casos. Logo $1 \mathrm{cM}=0,01 \mathrm{M}$.

${ }^{2}$ Um mapa de ligação genética mostra a ordem dos locos em um cromossomo. A ordem está baseada nos dados de frequência de recombinação entre os locos. 
é necessário que ocorra um número ímpar de permutas genéticas, pois, com a ocorrência de um número par de permutas genéticas a configuração original é restaurada. Como o número de crossing - over's em um segmento de tamanho $\lambda$ pode ser modelado segundo a distribuição de Poisson, com média $\lambda$, tem-se:

$$
\begin{aligned}
\theta & =P(\text { número impar de permutas gênicas }) \\
& =\sum_{y-i m p a r} \frac{\lambda^{y} e^{-\lambda}}{y !} \\
& =e^{-\lambda}\left[\frac{\lambda}{1 !}+\frac{\lambda^{3}}{3 !}+\frac{\lambda^{5}}{5 !}+\ldots\right] \\
& =e^{-\lambda} \frac{\left(e^{\lambda}-e^{-\lambda}\right)}{2} \\
& =\frac{1}{2}\left(1-e^{-2 \lambda}\right)
\end{aligned}
$$

cuja função inversa é: $\lambda=-\ln (1-2 \theta) / 2$.

\subsubsection{Função de mapeamento de Kosambi}

Ao contrário da função de Haldane, a função de Kosambi admite interferência, ou seja, que a possibilidade de ocorrências de permutas genéticas não sejam eventos independentes. (Weir, 1996; Liu, 1998). Neste caso, a relação entre a distância $\lambda$ com a probabilidade de recombinação $\theta$ pode ser expressa como sendo:

$$
\theta=\frac{1}{2}\left(\frac{e^{4 \lambda}-1}{e^{4 \lambda}+1}\right)=\frac{1}{2} \tanh (2 \lambda)
$$

em que tanh é a tangente hiperbólica, e cuja função inversa é:

$$
\lambda=\frac{1}{4} \ln \left(\frac{1+2 \theta}{1-2 \theta}\right) .
$$

Bearzoti (2000) e Lynch \& Walsh (1998) comparam as funções de mapeamento de Haldane e de Kosambi e afirmam que, para pequenos valores de $\theta(\theta<0,15)$, ambas funções fornecem estimativas de $\lambda \cong \theta$, diferindo para freqüências de recombinação maiores e tornando-se a aproximar para valores altos de $\theta(\theta \cong 0,5)$. Este comportamento pode ser 
Figura 2.4 Comparação entre as funções de Morgan, Haldane e Kosambi.

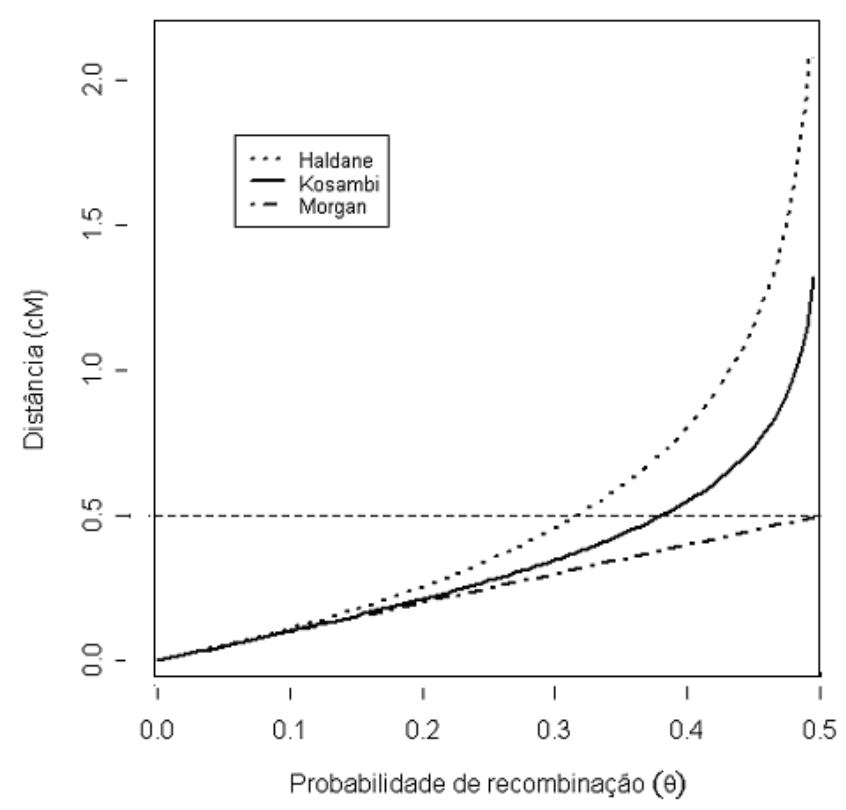

observado na Figura 2.4 na qual estão apresentadas as distâncias em centimorgans (cM), obtidas pelas funções de mapeamento de Morgan, Haldane e Kosambi para probabilidades de recombinação variando de 0 a 0,5 .

\subsection{Efeitos genéticos}

O fenótipo é uma (ou conjunto de) característica(s) que um indivíduo possui e, em geral, ele é o resultado de interações entre o genótipo (constituição genética do indivíduo) e o ambiente (Falconer \& Mackay, 1996). Expressa-se este relacionamento mediante a equação:

$$
Y=\mu+G+E
$$

onde, $Y$ representa os valores fenotípicos,

$\mu$ é a média populacional da resposta,

$G$ é o valor ou efeito genotípico e

$E$ é o componente residual, que representa a contribuição ao fenótipo de fatores não descrito por $\mu$ e $G$ 
Os valores $Y, G$ e $E$ podem ser expressos em qualquer unidade que represente uma propriedade biológica que possa ser medida de forma discreta ou contínua, tal como peso, altura, teor de gordura, pressão arterial, etc. Quando não existe efeito do ambiente (modelado no fator $E$ ) sobre determinada característica o fenótipo apresentado é idêntico para todos os indivíduos que possuem o mesmo genótipo, diferindo pelos locos em $G$.

É importante destacar que o efeito genético de um gene pode ser decomposto em dois componentes: efeito genético aditivo e efeito genético de dominância. $O$ efeito genético aditivo é o valor fenotípico que pode ser predito linearmente por meio do número de alelos de um certo tipo que definem o genótipo, enquanto que o efeito de dominância é o valor fenotípico que não pode ser explicado linearmente (resíduo genético devido ao efeito de interação entre os alelos $A_{1}$ e $A_{2}$ no mesmo loco). O valor genotípico de um indivíduo não é mensurável na prática, exceto quando estamos interessados em um loco onde os genótipos são fenotípicamente distinguíveis.

Figura 2.5 Representação de um gene com seus valores genotípicos.

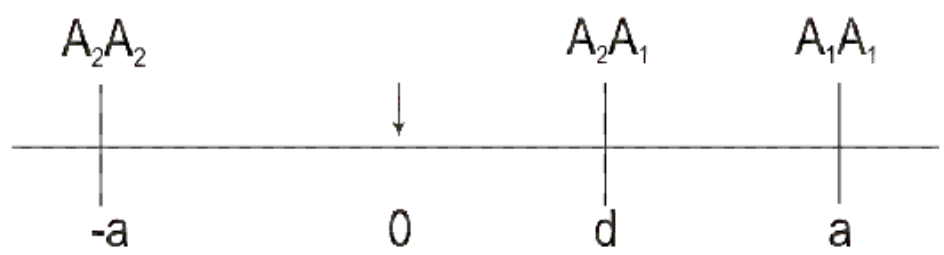

Considerando que uma população esteja classificada segundo as classes genotípicas $A_{2} A_{2}, A_{2} A_{1}$ e $A_{1} A_{1}$, e que a média para cada classe genotípica seja $\mu_{A_{2} A_{2}}, \mu_{A_{2} A_{1}}$ e $\mu_{A_{1} A_{1}}$, respectivamente, então os efeitos aditivos e de dominância em função das médias são dados pelos seguintes contrastes ortogonais (Lynch \& Walsh, 1998):

$$
\begin{aligned}
a & =\frac{\mu_{A_{1} A_{1}}-\mu_{A_{2} A_{2}}}{2} \\
d & =\frac{\left(2 \mu_{A_{2} A_{1}}-\mu_{A_{1} A_{1}}-\mu_{A_{2} A_{2}}\right)}{2} \\
& =\mu_{A_{2} A_{1}}-\left(\frac{\mu_{A_{1} A_{1}}+\mu_{A_{2} A_{2}}}{2}\right)
\end{aligned}
$$




\subsection{Populações comumente utilizadas no mapeamento Genético}

Existem basicamente dois tipos de populações quando fazemos referência ao mapeamento genético:

- Populações Experimentais: são as populações cujos cruzamentos são controlados e ocorrem entre indivíduos do mesmo grupo ou até de mesma família, comuns em experimentos envolvendo o manejo de plantas e de animais de laboratório (como ratos, por exemplo);

- Populações Naturais: são caracterizadas pelos cruzamentos aleatórios que nela ocorrem. A população humana é um exemplo de população natural.

Em cruzamentos controlados, os genótipos paternos são conhecidos de modo que os indivíduos das próximas gerações podem ser considerados como vindos de uma mesma grande família (compartilham os mesmos genótipos paternos). Também, estes cruzamentos podem gerar um desequilíbrio de ligação entre os genes. O desequilíbrio de ligação é bastante elevado nas populações derivadas de cruzamentos controlados e como conseqüência, é possível detectar a ligação entre dois locos cromossômicos.

Nas Figuras 2.6 e 2.7 são apresentados dois esquemas de populações obtidas de cruzamentos controlados. Para a formação de cada uma das populações, parte-se de duas linhagens parentais homozigotas, o genitor $1, P_{1}$, com genótipo $A_{1} A_{1}$ e o genitor $2, P_{2}$, com genótipo $A_{2} A_{2}$. A geração $F_{1}$ (primeira geração de descendentes) é composta exclusivamente por indivíduos idênticos, todos heterozigotos, $A_{1} A_{2}$, mostrando um completo desequilíbrio de ligação nos genes (dos mesmos cromossomos) que diferem entre as linhagens, isto é, os genes não segregam independentemente.

No delineamento Backcross (retrocruzamento), os indivíduos da geração $F_{1}$ são cruzados com um dos genitores $P_{1}$ ou $P_{2}$, originando indivíduos cujos genótipos são $A_{1} A_{2}$ ou $A_{1} A_{1}$ se o cruzamento é com o genitor $P_{1}$, também $A_{1} A_{2}$ ou $A_{2} A_{2}$ se o cruzamento é com o genitor $P_{2}$ (ver Figura 2.6). 
No delineamento $F_{2}$ (ver Figura 2.7) um indivíduo da geração $F_{1}$ é cruzado com outro indivíduo da geração $F_{1}$ dando origem a indivíduos com genótipos $A_{1} A_{1}, A_{1} A_{2}$ e $A_{2} A_{2}$, ou seja, dois homozigotos e um heterozigoto. Os dados reais analisados neste trabalho foram gerados de um cruzamento controlado para obtenção de uma geração $F 2$.

Figura 2.6 Esquema representativo dos cruzamentos envolvidos na obtenção de uma geração de Retrocruzamento.

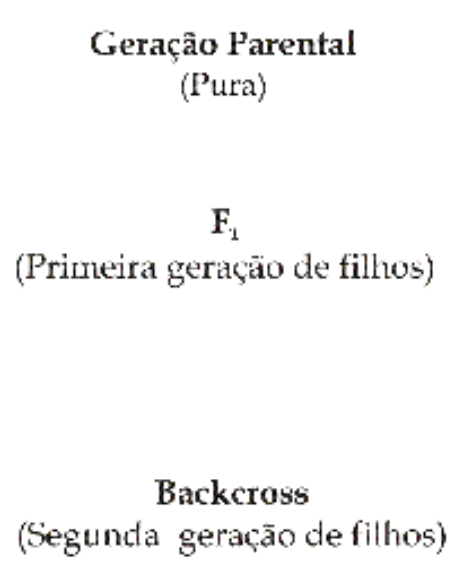

\section{Geraçâo Parental}

(Pura)

Geraçào de filhos)

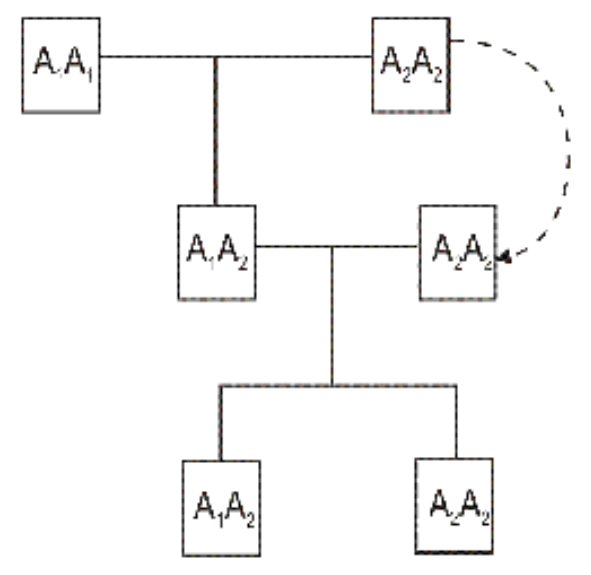

Razão 1 : 1

Nota-se que a variabilidade genotípica obtida por meio do delineamento Backcross é menor, fazendo com que o delineamento $F_{2}$, para muitas finalidades, seja mais útil, afinal, este delineamento gera três genótipos para cada loco cromossômico o que permite a estimação do grau de dominância associado a cada gene detectado, além de seu efeito aditivo (Lynch \& Walsh, 1998). Ressalta-se que a idéia chave dos cruzamentos controlados é permitir que linhagens homozigotas, com fenótipos de interesse diferentes (por exemplo, normotenso $\times$ hipertenso, resistente $\times$ suscetível, obeso $\times$ não obeso), sejam cruzadas a fim de que originem gerações cuja variação genética esteja relacionada com o gene controlador do traço em questão.

As populações derivadas de cruzamentos controlados são interessantes devido à flexibilidade na escolha dos pais e na determinação do esquema do cruzamento. Quando o objetivo do estudo é encontrar genes controladores de um traço em particular, as variações 
Figura 2.7 Esquema representativo dos cruzamentos envolvidos na obtenção de uma geração F2.

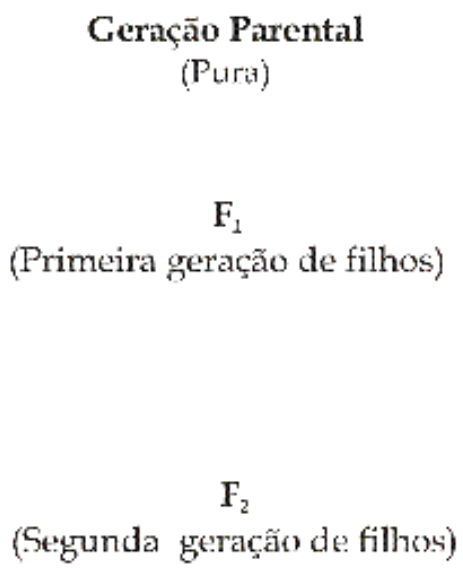

Geração Parental

$F_{1}$

(Primeira geração de filhos)

(Segunda geração de filhos)

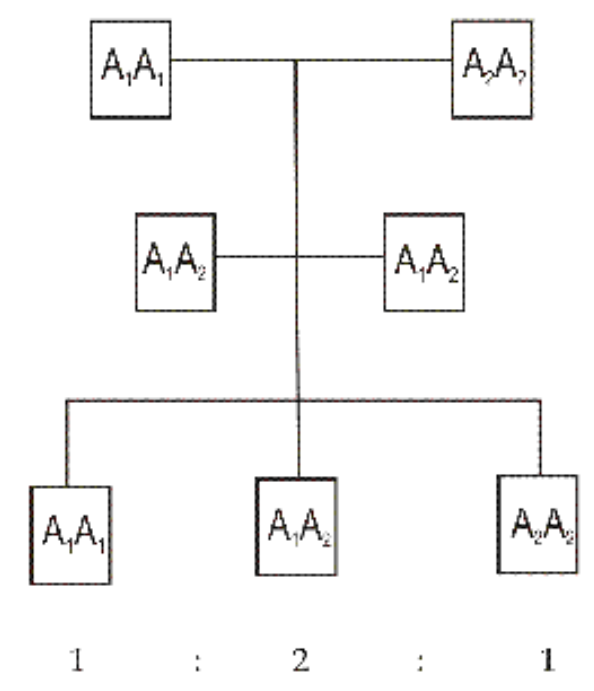

Razăo $1: 2 \quad: \quad 1$

genéticas do traço entre os pais é crucial. Se os pais forem completamente diferentes em um nível fenotípico para o traço de interesse, existe uma chance razoável de que exista uma variação genética entre eles. Mesmo ao levarmos em consideração que efeitos do meio ambiente não controlados podem causar uma grande variação fenotípica sem base genética alguma, ainda assim a chance de haver variação genética é considerável (Liu, 1998; Doerge et al. 1997).

\subsection{Modelagem genética}

A Figura 2.8 apresenta diferentes modelos que explicam a variação de fenótipos em função de variáveis genéticas e ambientais (residuais) tal como foi indicado na expressão 2.6. Observa-se, em primeiro lugar, um modelo no qual apenas um gene controla um traço de interesse (flecha branca). Estes tipos de modelos são conhecidos na literatura como modelos Mendelianos de regulação monogênica. Em seguida, tem-se o caso em que um único gene regula ou influencia mais de um fenótipo (flecha escura), esse fenômeno é 
conhecido como pleiotropia. Finalmente observa-se o caso em que dois genes (ou mais) controlam um traço ou fenótipo, este modelo é denominado de regulação multilocos e, no caso em que há interação entre os genes tem-se epistasia. O modelo de epistasia trata da situação na qual diferentes locos estão envolvidos na regulação de um mesmo traço quantitativo, em que um gene de um determinado loco interfere na manifestação dos genes de outro loco, caracterizando um efeito de interação entre eles. No processo de regulação celular das características dos organismos é esperado que esteja envolvida uma complexa rede funcional em que todos estes modelos (multilocos, pleiotrópicos e epistáticos) estejam presentes (Balding, 2002).

Figura 2.8 Padrões possíveis de variação genética

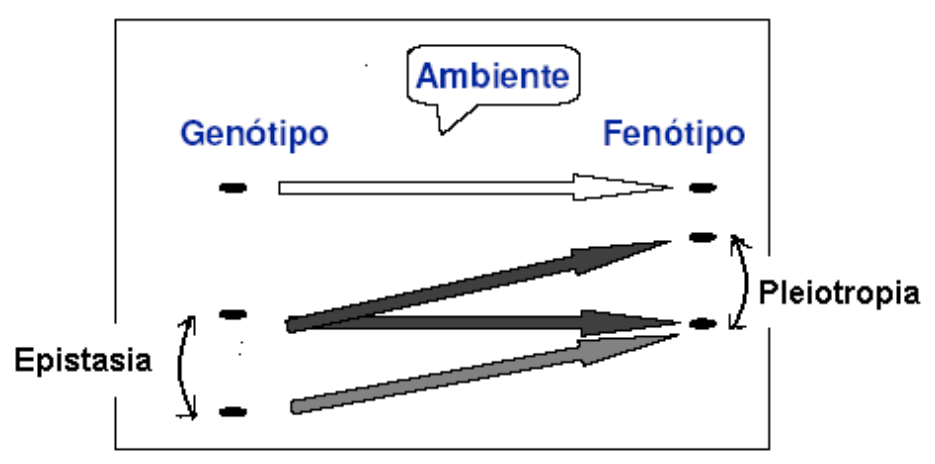

\subsubsection{Efeitos pleiotrópicos}

Neste trabalho, explora-se a utilidade de diferentes modelos estatísticos no estudo da covariância entre fenótipos, em particular, a covariância pode ser gerada devido a efeitos pleiotrópicos. Um gene tem efeito pleiotrópico quando influencia mais do que uma característica fenotípica simultaneamente. Então se um mesmo gene está associado a mais de um caráter, isto pode gerar uma estrutura de covariância entre fenótipos devido ao gene comum. Como exemplo do efeito de pleiotropia encontra-se o albinismo, onde a presença de um único gene defeituoso, altera a cor dos olhos, a cor da pele, dos cabelos etc. 
Um outro exemplo citado em Amabis \& Martho (1994) faz referência a ervilhas, em que um único par de alelos condiciona simultaneamente três traços fenotípicos: cor de flores (branca ou vermelha), cor da semente (cinza ou parda) e presença ou ausência de manchas roxas nas axilas das folhas. Turner et al. (2004) consideram o efeito de pleiotropia no estudo da pressão sistólica, pressão diastólica e índice de massa corporal. Note que o delineamento experimental associado a estes casos considera a medição de vários fenótipos em cada indivíduo da amostra. Muitas vezes trata-se de estudos transversais, nos quais em um corte (ou momento) vários fenótipos são observados simultaneamente em indivíduos da população.

Acredita-se que a maior parte dos genes tenha efeito pleiotrópico. O que ocorre na prática é que, usualmente, é percebido apenas seus efeitos fenotípicos mais marcantes, possivelmente, devido a limitação de modelagem estatística. Deve haver inúmeros casos em que características completamente diferentes sejam reguladas pelo mesmo gene ou conjunto comum de genes, e a relação passa desapercebida. Deste modo, somente por meio de modelos estatísticos sofisticados que incorporem a informação de vários fenótipos simultaneamente, aliados a planejamentos experimentais apropriados, é que se obtém sucesso na estimação de efeitos pleiotrópicos.

A utilidade de se detectar pleiotropia é que muitos QTL's somente são identificados ao se explorar a estrutura de covariância entre múltiplos traços. É necessário, no entanto, que se tenha cuidado para não confundir efeitos de pleiotropia com efeitos de um agrupamento de locos bem próximos uns dos outros mas cada um influenciando um único traço, a saber o efeito de ligação genética (Falconer \& Mackay, 1996). Nesta direção, há de se ter cuidado também com a possibilidade de correlações fenotípicas devido ao desequilíbrio de ligação entre diferentes genes associados aos fenótipos. A literatura não é conclusiva sobre os procedimentos específicos de análise que sejam protegidos de tais efeitos, assim o resultado de uma análise de mapeamento particular deve ser sempre usado como uma indicação de região funcional candidata que merece ser ainda mais refinada e validada por meio de análises alternativas e delineamentos experimentais independentes. Na Seção 3.2 .2 retoma-se este tópico. 


\subsubsection{Interações gene $\times$ ambiente}

O estudo do efeito de pleiotropia (um mesmo gene controlando vários traços) pode ser estendido (ou tem um paralelo) ao estudo de interações entre gene e ambiente. O fenótipo de um indivíduo depende de componentes genéticos e residuais (incluindo o ambiente) como representado na expressão 2.6. Os fatores ambientais apesar de não serem transmitidos através das gerações, devem ser considerados para a determinação precisa do valor genético do indivíduo, pois a ação de muitos genes é disparada a partir da exposição ao ambiente. A influência de fatores ambientais pode ser menor ou maior, dependendo da caraterística em questão. No caso do sistema sangüíneo $A B O$, os fatores ambientais têm importância desprezível, entretanto, um indivíduo que, por exemplo, tenha predisposição genética para doenças cardíacas, poderá evitar um infarto de coração se mantiver uma dieta saudável, baixa em colesterol e praticar exercícios (Farah, 1997).

Um mesmo genótipo pode responder de maneira diferenciada de acordo com o ambiente em que se encontra. Essa resposta diferencial dos efeitos genotípicos em resposta ao ambiente no desenvolvimento dos organismos dá origem ao importante conceito conhecido como interação gene×ambiente. Quando existe interação entre genes e fatores ambientais o efeito do gene sobre o fenótipo na presença de uma condição ambiental específica pode ser inibido, ativado, reduzido ou potencializado.

Para medir essa sensibilidade do gene ao ambiente é que os fenótipos são avaliados em diferentes condições ambientais de interesse. Sabe-se que ambientes específicos devem ser mais ou menos favoráveis para a expressão de fenótipos (Falconer \& Mackay, 1996). Como exemplo desta interação pode-se citar o estudo da altura de uma variedade específica de plantas cultivadas em diferentes climas, em diferentes lugares e sob diferentes condições nutricionais do solo, neste caso cada condição ambiental pode interferir de maneira específica no efeito do gene sobre a altura da planta. Um outro exemplo é a situação de dados gerados de delineamentos longitudinais onde o interesse é entender como o gene responde por exemplo à modificação na idade do indivíduo. Estes casos refletem situações de mapeamento onde modela-se interações gene×ambiente. Fazendo um paralelo com 
os delineamentos comumente usados para o estudo de pleiotropia (avaliação de muitos fenótipos em um único corte da população), no caso de interação gene×ambiente podese ter o seguimento de um único fenótipo nos mesmos indivíduos em diferentes cortes transversais da população (perfil longitudinal).

No presente estudo trata-se, especificamente, de como o sal pode interferir nos efeitos dos genes que regulam a pressão arterial assim como também se o medicamento Captopril interfere ou não na expressão dos genes reguladores da pressão arterial sistólica.

Uma ampla variedade de novos métodos estatísticos em genética estão sendo desenvolvidos (em resposta à necessidade de ferramentas analíticas adequadas) para as análises genéticas das características complexas dos indivíduos, contemplando tanto estudos de pleiotropia como de interação gene×ambiente, além de epistasia. Estima-se que uma alta porcentagem dos indivíduos da população geral sofram de uma ou mais doenças complexas durante suas vidas e muitas das doenças comuns, tais como hipertensão, doença coronária, depressão, esquizofrenia, diabetes, etc, constituem exemplos de doenças com componentes genéticos comuns e interações entre os genes e de genes com o ambiente (Almasy \& Blangero, 2000).

Neste trabalho serão apresentados modelos estatísticos que podem ser adotados tanto para o estudo de pleiotropia como de interação gene×ambiente e também explora-se o uso de alguns modelos mais específicos como é o caso da análise medida resumo diferença entre fenótipos que é mais apropriada para o caso de interação gene×ambiente. 


\section{Capítulo 3}

\section{Métodos de Mapeamento genético}

Uma vez que cada gene ocupa uma determinada posição dentro do genoma, a qual é conhecida como loco, é possível, então, construir uma identidade genômica localizando cada gene pelo seu "endereço", ou seja, conhecer exatamente sua posição no genoma. Contudo, lembrando que os genes nas diversas espécies representam uma porcentagem pequena do genoma (de 3 a $5 \%$ da molécula de DNA é constituída por genes), podese vislumbrar a dificuldade enfrentada para se localizar precisamente um gene em uma posição específica. Mesmo assim, o mapeamento genético é uma área que tem evoluído muito nos últimos anos. Tamanho esforço, colocado nesse tipo de pesquisa, deve-se aos benefícios que poderão ser colhidos em relação ao diagnóstico, prevenção e cura de doenças genéticas, ao isolamento de genes de importância na agricultura e agropecuária e, em geral, à compreensão do papel de cada gene na organização geral do organismo (Farah, 1997).

Os estudos para o mapeamento de QTL's são realizados através das estimativas obtidas da informação de locos marcadores, os quais correspondem a seqüências de DNA cuja localização e genotipagem pode ser obtida por meio de técnicas moleculares. Os locos marcadores são geralmente neutros, não prejudicam qualquer função vital nem apresentam efeito sobre o fenótipo de um indivíduo (Farah, 1997).

A informação de marcadores moleculares é descrita na forma de mapa genético ${ }^{1}$ as- $^{-}$ sociado ao genoma de um organismo, com a finalidade de detectar regiões reguladoras de uma característica específica de interesse. O genoma para cada espécie é diferente,

\footnotetext{
${ }^{1}$ Formado pela seqüência ordenada dos marcadores moleculares e genes conhecidos de uma espécie, assim como por todas as distâncias que existem entre eles. Os mapas genéticos são específicos relativamente a espécies e, muitas vezes, também ao fenótipo de interesse.
} 
por exemplo, o genoma nos humanos contém 23 pares de cromossomos, o genoma dos ratos é formado por 21 pares de cromossomos, entre outras muitas espécies. Os avanços de técnicas moleculares têm possibilitado a obtenção de mapas de marcadores das mais variadas espécies, os quais são a base fundamental para o mapeamento genético de QTL's. Como ilustração, na Figura 3.1 é apresentado um mapa de marcadores moleculares do genoma dos ratos composto por 20 cromossomos (na figura não está incluído o cromossomo sexual). Observa-se que cada cromossomo é representado por um arranjo linear de marcadores cuja distância entre eles é dada em cM, cada marcador ocupa um posição fixa no cromossomo e tem um nome específico.

Nas seções seguintes deste capítulo são descritos alguns modelos e métodos estatísticos nos quais a utilização de um mapa de marcadores é relevante na identificação de genes (QTL's) reguladores de fenótipos de interesse. Neste trabalho será utilizado o mapa de marcadores apresentado na Figura 3.1 com o intuito de encontrar genes (QTL's) reguladores da pressão arterial de ratos.

\subsection{Modelos de mapeamento genético}

As metodologias estatísticas utilizadas no mapeamento de QTL's exploram os conceitos de desequilíbrio de ligação e de ligação entre os locos marcadores e os possíveis QTL's dispersos em posições específicas ao longo do mapa.

Nesta seção, serão revisadas da literatura várias técnicas utilizadas na formulação de modelos e procedimentos de inferências no mapeamento de QTL's. Dentre os diversos métodos de mapeamentos propostos, destacam-se: a análise utilizando um marcador de cada vez, o mapeamento por intervalo, o mapeamento por intervalo composto (Lander \& Botstein, 1989; Jansen \& Stam, 1994; Zeng, 1994) e mapeamento por intervalo múltiplo (Kao et al. 1999). 
Figura 3.1 Mapa de marcadores moleculares úteis na identificação de QTL's.

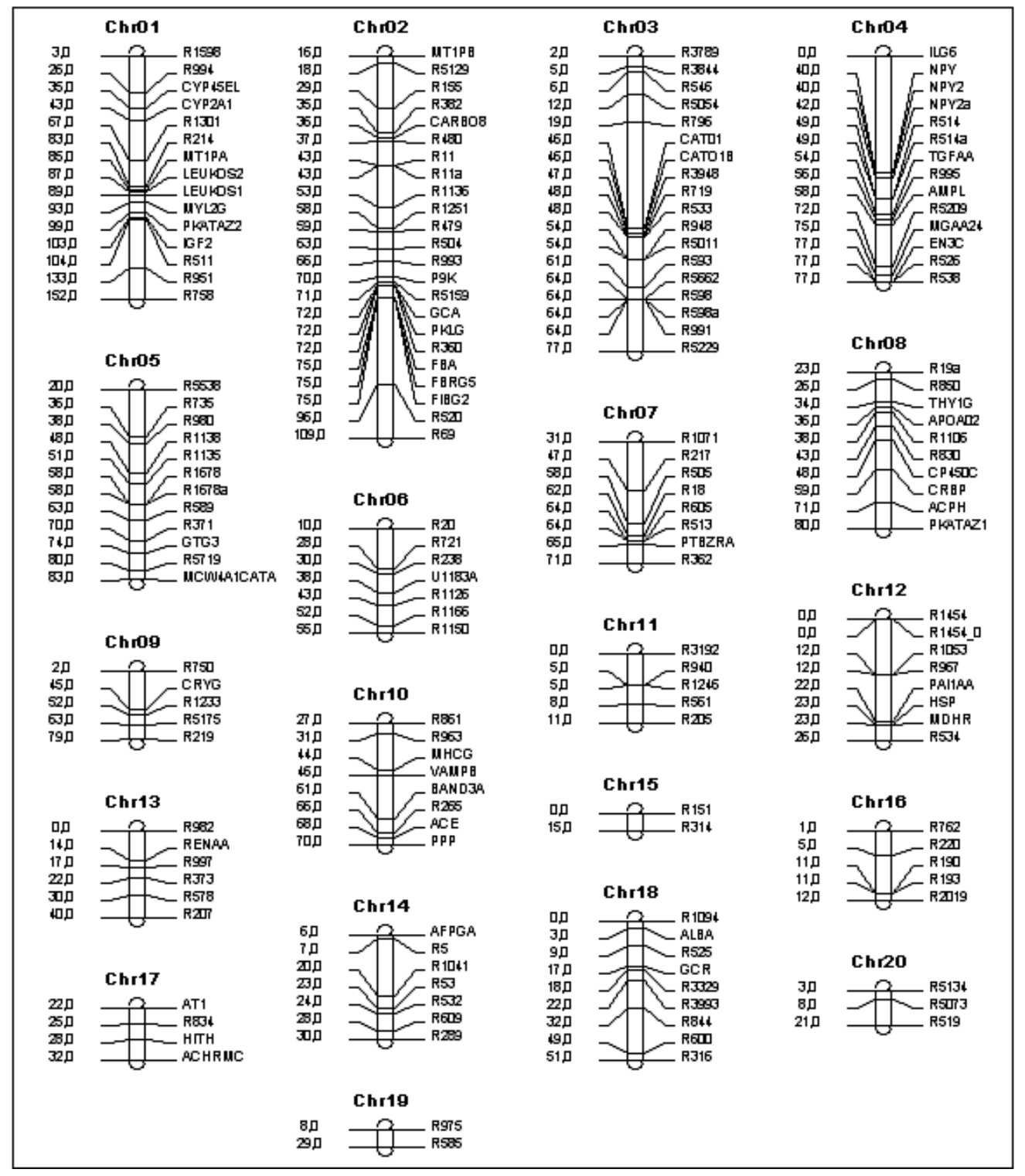

\subsubsection{Mapeamento utilizando um marcador por vez}

O método estatístico baseado nas análises com um marcador por vez (do inglês, Single Marker Analysis), é proposto como uma análise inicial prévia para investigar a utilidade da informação do mapa de marcadores para detectar QTL's. A presença do QTL é assumida na região próxima ao marcador ou também é possível que o QTL procurado seja o próprio marcador. $\theta$ denotará a fração de recombinação entre o marcador e o QTL (ver expressão 2.3). Nas análises realizadas mediante este método, investiga-se se há diferenças 
significativas entre os valores fenotípicos dos indivíduos, classificados segundo os genótipos que possuem. Por exemplo, considere que indivíduos de uma geração $F 2$ estejam classificados de acordo com seu genótipo em um loco de marcador como $M M, M m$ ou $\mathrm{mm}$. A comparação das médias fenotípicas $\left(\mu_{M M}, \mu_{M m}, \mu_{m m}\right)$ permite que sejam realizadas inferências indiretas sobre os QTL's. Essas comparações são realizadas para cada loco marcador separadamente, sem considerar as informações de outros locos (daí o nome); uma diferença significativa entre as médias é tomada como evidência de ligação entre o QTL $(Q)$ e o marcador $(M)$.

Seja $T$ o número total de marcadores em um mapa genético; assim, um mapa com $T$ marcadores permite que sejam realizados $T$ testes e cada teste em um loco marcador é independente da informação dos demais locos (Zeng, 1993, 1994). O modelo linear de efeito genético aditivo adotado nas análises pode ser representado por :

$$
y_{i}=\mu+\beta x_{i}+e_{i}
$$

em que,

$y_{i}:$ valor fenotípico do $i$-ésimo indivíduo ;

$\mu$ : média esperada da resposta para indivíduos com genótipo heterozigoto $M m$ (no caso do delineamento $F 2$ e da específica parametrização adotada para $x_{i}$ );

$\beta$ : efeito aditivo do genótipo marcador;

$x_{i}$ : variável indicadora, tal que, para o $i$-ésimo indivíduo

$$
x_{i}=\left\{\begin{array}{l}
-1, \text { se o genótipo do marcador é } m m \\
0, \text { se o genótipo do marcador é } M m \\
1, \text { se o genótipo do marcador é } M M
\end{array}\right.
$$

$e_{i}$ : resíduo aleatório para o $i$-ésimo indivíduo. Comumente os $e_{i}^{\prime} s$ são assumidos como independentes e normalmente distribuídos com média zero e variância comum $\sigma^{2}$.

O modelo 3.1 é formulado como um modelo linear clássico, e a presença de um QTL é detectada quando as diferenças entre as médias dos diferentes grupos alélicos homozigotos são significativas isto é quando rejeita-se a hipótese $H_{0}: \beta=0$. Desde que o mapa contém $T$ marcadores, são ajustados $T$ modelos 3.1 separadamente. 
A aplicação deste método no mapeamento genético apresenta várias limitações, uma delas é que não há distinção entre a ocorrência de um QTL de pequeno efeito situado bem próximo ao marcador ou de um QTL de grande efeito situado mais longe; em outras palavras, há confundimento entre as estimativas dos efeitos dos QTL's e a fração de recombinação entre os locos de marcador e QTL (Falconer \& Makay, 1996). Também, em regiões onde o mapa de marcadores não é denso (há grandes distâncias entre marcadores) tal mapeamento é pouco preciso. Contudo, esta metodologia é util como um passo inicial ao se realizar o mapeamento, uma vez que permite, por exemplo, detectar e eliminar marcadores não informativos. Estes métodos de mapeamento foram os primeiros a serem utilizados e fornecem a base para o desenvolvimento de outras metodologias de mapeamento mais refinadas (Lynch \& Walsh, 1998).

\subsubsection{Mapeamento por Intervalo}

Visando o desenvolvimento de metodologias mais precisas para o mapeamento de QTL's, o método de mapeamento por intervalo (do inglês, Interval Mapping) foi proposto por Lander \& Botstein (1989). O mapeamento por intervalo tem por objetivo percorrer todo o genoma, fixando posições entre os marcadores em um mapa, na busca por evidências da presença de possíveis QTL's. Este mapeamento utiliza a informação de dois marcadores por vez, para definir o intervalo no qual será procurado o QTL. O método apresenta um aumento no poder de detecção do QTL e também fornece estimativas mais precisas da sua posição e efeitos que o método de um marcador por vez (Haley \& Knott, 1992).

A metodologia envolvida é ilustrada na Figura 3.2 onde, os marcadores $M_{j}$ e $M_{j+1}$ representam o intervalo que será mapeado e estão separados por uma distância $\lambda$. O QTL é suposto estar localizado entre estes marcadores a uma distância $\lambda_{1}$ com o marcador $M_{j} \mathrm{e}$ $\lambda_{2}$ com o marcador $M_{j+1}$. Mediante uma função de mapeamento essas distâncias $\lambda, \lambda_{1} \mathrm{e} \lambda_{2}$ podem ser transformadas em probabilidades de recombinação $\theta, \theta_{1}$ e $\theta_{2}$, respectivamente (ver Seção 2.4), como apresentado na Figura 3.2.

Na geração $F 2$, considerando um único QTL presente entre os dois marcadores flan- 
queadores $^{2}$ do intervalo de pesquisa, cada um dos três locos pode estar definido para uma das três constituições genéticas possíveis (dois homozigotos e um heterozigoto), por exemplo, sendo $M_{1}$ e $M_{2}$ os marcadores flanqueadores do intervalo de pesquisa, os genótipos para o primeiro marcador serão $M_{1} M_{1}, M_{1} m_{1}$ ou $m_{1} m_{1}$ e os genótipos para o segundo serão $M_{2} M_{2}, M_{2} m_{2}$ ou $m_{2} m_{2}$ e no loco do QTL os indivíduos podem ter os genótipos $Q Q, Q q$ ou $q q$. Assim, tem-se um total de 27 classes genotípicas possíveis.

Figura 3.2 Representação do mapeamento de um $Q T L\left(Q_{j}\right)$ condicionado à presença de dois locos marcadores $\left(M_{j}\right.$ e $\left.M_{j+1}\right)$.

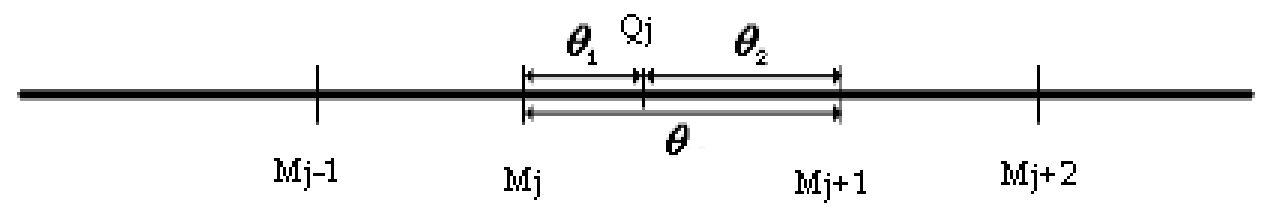

Com o intuito da formulação do modelo de mapeamento por intervalo, considera-se que o valor esperado para um determinado traço $Y$, para os três genótipos possíveis do QTL $\left(\mu_{Q Q}, \mu_{Q q}, \mu_{q q}\right)$ na geração $F 2$, são:

$$
\mu_{Q Q}=\mu+a, \quad \mu_{Q q}=\mu+d, \quad \mu_{q q}=\mu-a,
$$

onde $\mu$ é a média do traço (média das médias dos homozigotos, isto é, $\frac{\mu_{Q Q}+\mu_{q q}}{2}$ ), a e $d$ são os desvios de aditividade e de dominância do QTL (ver Seção 2.5). O valor esperado do traço $Y$ considerando o efeito do QTL flanqueado pelos marcadores $M_{i}$ e $M_{i+1}$ (cujos possíveis genótipos denotam-se como $G_{M i}$ e $G_{M_{i+1}}$, respectivamente), é dado por:

$$
\begin{aligned}
E\left(Y \mid G_{M_{i}}, G_{M_{i+1}}\right) & =\mu_{Q Q} P\left(Q Q \mid G_{M_{i}}, G_{M_{i+1}}\right)+\mu_{Q q} P\left(Q q \mid G_{M_{i}}, G_{M_{i+1}}\right)+\mu_{q q} P\left(q q \mid G_{M_{i}}, G_{M_{i+1}}\right) \\
& =(\mu+a) P\left(Q Q \mid G_{M_{i}}, G_{M_{i+1}}\right)+(\mu+d) P\left(Q q \mid G_{M_{i}}, G_{M_{i+1}}\right)+(\mu-a) P\left(q q \mid G_{M_{i}}, G_{M_{i+1}}\right) \\
& =\mu+a X_{a g}+d X_{d g},
\end{aligned}
$$

onde $X_{a g}=P\left(Q Q \mid G_{M_{i}}, G_{M_{i+1}}\right)-P\left(q q \mid G_{M_{i}}, G_{M_{i+1}}\right)$ e $X_{d g}=P\left(Q q \mid G_{M_{i}}, G_{M_{i+1}}\right)$ são os valores preditos do QTL associados aos efeitos aditivo e de dominância, respectivamente. Estes são calculados por meio das informações genotípicas dos marcadores flanqueadores

\footnotetext{
2 Marcadores flanqueadores são aqueles que delimitan a localização de um suposto QTL.
} 
do suposto QTL e por meio das correspondentes frações de recombinação $\left(\theta, \theta_{1}\right.$ e $\left.\theta_{2}\right)$ associadas às distâncias entre os marcadores e a posição fixada do QTL.

As probabilidades genotípicas do QTL preditas dos dados de marcadores e as variáveis preditoras, $X_{a g}$ e $X_{d g}$, calculadas para cada um dos 9 genótipos possíveis para os marcadores flanqueadores $M_{1}$ e $M_{2}$, em uma população $F 2$, são dados nas Tabelas 3.1 e 3.2 , respectivamente. O procedimento para o cálculo dos respectivos valores encontram-se detalhados em Haley \& Knott (1992).

Tabela 3.1 Freqüências esperadas dos genótipos na geração F2, considerando três locos ligados, com freqüências de recombinação iguais a $\theta_{1}$ entre $M_{1}$ e $Q, \theta_{2}$ entre $Q$ e $M_{2}$ e $\theta$ entre $M_{1}$ e $M_{2}$.

\begin{tabular}{llll}
\hline \hline & \multicolumn{3}{c}{ Genótipo do QTL } \\
\cline { 2 - 4 } Genótipo dos marcadores & QQ & Qq & qq \\
\hline$M_{1} M_{1} M_{2} M_{2}$ & $\frac{1}{4}\left(1-\theta_{1}\right)^{2}\left(1-\theta_{2}\right)^{2}$ & $\frac{1}{2}\left(1-\theta_{1}\right) \theta_{2} \theta_{1}\left(1-\theta_{2}\right)$ & $\frac{1}{4} \theta_{1}^{2} \theta_{2}^{2}$ \\
$M_{1} M_{1} M_{2} m_{2}$ & $\frac{1}{4}\left(1-\theta_{1}\right)^{2}\left(1-\theta_{2}\right) \theta_{2}$ & $\frac{1}{4}\left(1-\theta_{1}\right) \theta_{2}^{2} \theta_{1}$ & $\frac{1}{4} \theta_{1}^{2}\left(1-\theta_{2}\right) \theta_{2}$ \\
$M_{1} M_{1} m_{2} m_{2}$ & $\frac{1}{4}\left(1-\theta_{1}\right)^{2} \theta_{2}^{2}$ & $\frac{1}{2}\left(1-\theta_{1}\right) \theta_{2} \theta_{1}\left(1-\theta_{2}\right)$ & $\frac{1}{4} \theta_{1}^{2}\left(1-\theta_{2}\right)^{2}$ \\
$M_{1} m_{1} M_{2} M_{2}$ & $\frac{1}{4}\left(1-\theta_{1}\right)\left(1-\theta_{2}\right)^{2} \theta_{1}$ & $\frac{1}{4} \theta_{1}^{2}\left(1-\theta_{2}\right) \theta_{2}$ & $\frac{1}{4}\left(1-\theta_{1}\right) \theta_{2}^{2} \theta_{1}$ \\
$M_{1} m_{1} M_{2} m_{2}$ & $\frac{1}{4}\left(1-\theta_{1}\right) \theta_{2} \theta_{1}\left(1-\theta_{2}\right)$ & $\frac{1}{4} \theta_{1}^{2}\left(1-\theta_{2}\right)^{2}$ & $\frac{1}{4}\left(1-\theta_{1}\right) \theta_{2} \theta_{1}\left(1-\theta_{2}\right)$ \\
$M_{1} m_{1} m_{2} m_{2}$ & $\frac{1}{4}\left(1-\theta_{1}\right) \theta_{2}^{2} \theta_{1}$ & $\frac{1}{4} \theta_{1}^{2}\left(1-\theta_{2}\right)^{2} \theta_{2}$ & $\frac{1}{4}\left(1-\theta_{1}\right)\left(1-\theta_{2}\right)^{2} \theta_{1}$ \\
$m_{1} m_{1} M_{2} M_{2}$ & $\frac{1}{4} \theta_{1}^{2}\left(1-\theta_{2}\right)^{2}$ & $\frac{1}{2}\left(1-\theta_{1}\right) \theta_{2} \theta_{1}\left(1-\theta_{2}\right)$ & $\frac{1}{4}\left(1-\theta_{1}\right)^{2} \theta_{2}^{2}$ \\
$m_{1} m_{1} M_{2} m_{2}$ & $\frac{1}{4} \theta_{1}^{2}\left(1-\theta_{2}\right) \theta_{2}$ & $\frac{1}{4}\left(1-\theta_{1}\right) \theta_{2}^{2} \theta_{1}$ & $\frac{1}{4}\left(1-\theta_{1}\right)^{2}\left(1-\theta_{2}\right) \theta_{2}$ \\
$m_{1} m_{1} m_{2} m_{2}$ & $\frac{1}{4} \theta_{1}^{2} \theta_{2}^{2}$ & $\frac{1}{2}\left(1-\theta_{1}\right) \theta_{2} \theta_{1}\left(1-\theta_{2}\right)$ & $\frac{1}{4}\left(1-\theta_{1}\right)^{2}\left(1-\theta_{2}\right)^{2}$ \\
\hline \hline
\end{tabular}

Tabela 3.2 Coeficientes de a e d, para uma geração F2, no modelo de mapeamento por intervalo.

\begin{tabular}{lll}
\hline \hline Genótipo dos marcadores & $X_{a}$ & \multicolumn{1}{c}{ Coeficientes de $a$ e $d$} \\
\cline { 2 - 3 }$M_{1} M_{1} M_{2} M_{2}$ & $\frac{\left(1-\theta_{1}\right)\left(1-\theta_{2}\right)-\theta_{1}^{2} \theta_{2}^{2}}{(1-\theta)^{2}}$ & $\frac{2 \theta_{1}\left(1-\theta_{1}\right) \theta_{2}\left(1-\theta_{2}\right)}{(1-\theta)^{2}}$ \\
$M_{1} M_{1} M_{2} m_{2}$ & $\frac{\left(1-\theta_{1}\right)^{2} \theta_{2}\left(1-\theta_{2}\right)}{\theta(1-\theta}$ & $\frac{\theta_{1}\left(1-\theta_{1}\right)\left(1-\theta_{2}\right)^{2}+\theta_{1}\left(1-\theta_{1}\right) \theta_{2}^{2}}{\theta(1-\theta)}$ \\
$M_{1} M_{1} m_{2} m_{2}$ & $\frac{\left(1-\theta_{1}\right)^{2} \theta_{2}^{2}-\theta_{1}^{2}\left(1-\theta_{2}\right)^{2}}{\theta^{2}}$ & $\frac{2 \theta_{1}\left(1-\theta_{1}\right) \theta_{2}\left(1-\theta_{2}\right)}{\theta^{2}}$ \\
$M_{1} m_{1} M_{2} M_{2}$ & $\frac{\theta_{1}\left(1-\theta_{1}\right)\left(1-\theta_{2}\right)^{2}-\theta_{1}\left(1-\theta_{1}\right) \theta_{2}^{2}}{\theta(1-\theta)}$ & $\frac{\left(1-\theta_{1}\right)^{2} \theta_{2}\left(1-\theta_{2}\right)}{\theta(1-\theta)}$ \\
$M_{1} m_{1} M_{2} m_{2}$ & 0 & $\theta_{1}^{2} \theta_{2}^{2}+\theta_{1}^{2}\left(1-\theta_{2}\right)^{2}$ \\
$M_{1} m_{1} m_{2} m_{2}$ & $\frac{\theta_{1}\left(1-\theta_{1}\right) \theta_{2}^{2}-\theta_{1}\left(1-\theta_{1}\right)\left(1-\theta_{2}\right)^{2}}{\theta(1-\theta)}$ & $\frac{\left(1-\theta_{1}\right)^{2} \theta_{2}\left(1-\theta_{2}\right)+\theta_{1}^{2} \theta_{2}\left(1-\theta_{2}\right)}{\theta(1-\theta)}$ \\
$m_{1} m_{1} M_{2} M_{2}$ & $\frac{\theta_{1}^{2}\left(1-\theta_{2}\right)-\left(1-\theta_{1}\right)^{2} \theta_{2}^{2}}{\theta^{2}}$ & $\frac{2 \theta_{1}\left(1-\theta_{1}\right) \theta_{2}\left(1-\theta_{2}\right)}{\theta^{2}}$ \\
$m_{1} m_{1} M_{2} m_{2}$ & $\frac{\theta_{1}^{2} \theta_{2}\left(1-\theta_{2}\right)-\left(1-\theta_{1}\right)^{2} \theta_{2}\left(1-\theta_{2}\right)}{\theta(1-\theta)}$ & $\frac{\theta_{1}\left(1-\theta_{1}\right)^{2}\left(1-\theta_{2}\right)^{2}+\theta_{1}\left(1-\theta_{1}\right) \theta_{2}^{2}}{\theta(1-\theta)}$ \\
$m_{1} m_{1} m_{2} m_{2}$ & $\frac{\theta_{1}^{2} \theta_{2}^{2}-\left(1-\theta_{1}\right)^{2}\left(1-\theta_{2}\right)^{2}}{(1-\theta)^{2}}$ & $\frac{2 \theta_{1}\left(1-\theta_{1}\right) \theta_{2}\left(1-\theta_{2}\right)}{(1-\theta)^{2}}$ \\
\hline \hline
\end{tabular}

Conhecendo as expressões para as variáveis preditoras $X_{a g}$ e $X_{d g}$ apresentadas na Tabela 
3.2, o modelo de regressão linear múltipla dado em 3.2 pode ser ajustado via a teoria de modelos lineares clássicos da seguinte maneira: dado um intervalo entre dois marcadores e um suposto QTL fixado em posições intermediárias entre eles, $X_{a g}$ e $X_{d g}$ são calculadas para todos os indivíduos da amostra e inferências ( $s o b e_{i}^{\prime} s$ independentes, normais e homocedásticos) podem ser feitas para os coeficientes de regressão $\mu, a$ e $d$ por meio de procedimentos de estimação e testes destes parâmetros genéticos (Haley \& Knott, 1992). Um ajuste alternativo é apresentado por Zeng (1994) que assume um modelo de mistura de normais para a distribuição dos resíduos. Este último tem se mostrado superior ao ajuste clássico devido à sua flexibilidade em acomodar diferentes classes de distribuições e será apresentado na Seção 3.1.5.

O desenvolvimento e aplicação do mapeamento por intervalo ocorreu paralelamente ao surgimento de mapas de marcadores moleculares para diferentes espécies, o que permitiu sua utilização em larga escala e sob diferentes delineamentos experimentais. O aumento na precisão das análises, decorrente de mapas de marcadores cada vez mais densos, e os avanços computacionais, ocorridos para tratamento de grandes bancos de dados, também contribuíram na disseminação de sua utilização. Foi baseado nesse método que surgiu o MAPMARKER/QTL, primeiro programa computacional específico para o mapeamento de QTL's (Lander \& Botstein, 1989; Lincon et al. 1992), inaugurando uma nova era de pesquisa em genética quantitativa. A principal desvantagem do método do mapeamento por intervalo está em não isolar o intervalo analisado do efeito do restante do genoma, ou seja, as inferências feitas podem sofrer influência dos efeitos de outros QTL's sobre o intervalo de pesquisa.

\subsubsection{Mapeamento por Intervalo Composto}

No mapeamento de QTL's, o método por intervalo não considera as regiões adjacentes ao intervalo de pesquisa. É claro que o objetivo é testar o efeito do QTL fixado nas diferentes posições dentro do intervalo, mas as estimativas dos efeitos do QTL podem ser influenciadas pelo efeito de outros possíveis QTL's em regiões adjacentes. Por exemplo, imagine que existam dois QTL's $\left(Q T L_{1}, Q T L_{2}\right)$ próximos ao intervalo no qual está 
sendo realizado o mapeamento. Esses QTL's podem influenciar a estimação do efeito do possível QTL dentro do intervalo intermediário, às vezes, detectando QTL's inexistentes, dando lugar a falsos positivos ou "QTL's fantasma", como ilustrado na Figura 3.3. Nesta figura o gráfico indicando o "QTL fantasma" representa os resultados baseados no perfil da estatística razão de verossimilhanças para o teste do efeito de QTL's mediante o mapeamento por intervalo. Observa-se o aparecimento de um "QTL fantasma" no intervalo mapeado (entre os marcadores $M_{2}$ e $M_{3}$ ) devido à presença dos dois QTL's ligados, $Q T L_{1}$ e $Q T L_{2}$, localizados nos intervalos adjacentes.

Figura 3.3 "QTL fantasma" devido a falso sinal de ligação.

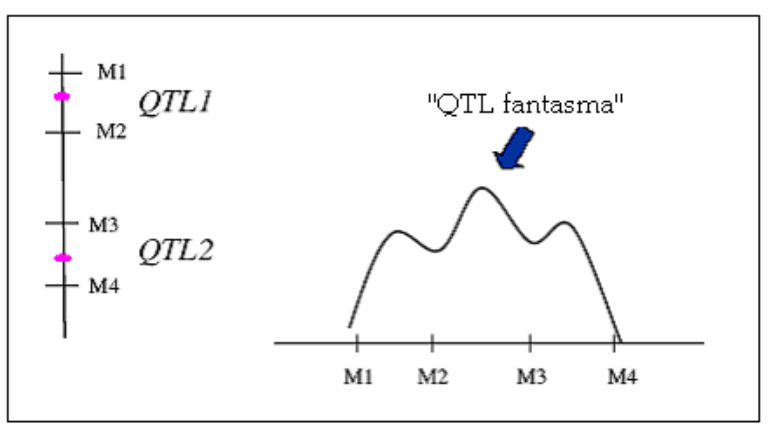

Com o objetivo de eliminar os efeitos de QTL's inexistentes, controlar o erro tipo I, foi proposta, de forma independente, por Jansen $(1993)$ e Zeng $(1993,1994)$ a utilização de um modelo de regressão linear múltipla, denominado mapeamento por intervalo composto (do inglês, Composite Interval Mapping). Este consiste em considerar não apenas um intervalo entre dois marcadores, mas também alguns outros marcadores que são utilizados como cofatores (covariáveis) para controlar o que é chamado de background genético por meio de análises de regressão múltipla.

Ilustram-se as considerações feitas sobre mapeamento intervalar composto mediante o segmento cromossômico esquematizado na Figura 3.4. Suponha que o intervalo analisado pelo método de mapeamento por intervalo composto esteja entre os marcadores $M_{j}$ e $M_{j+1}$, considera-se como cofatores os marcadores adjacentes ao intervalo de pesquisa para impedir que os efeitos dos possíveis QTL's ligados ou não ligados ao possível QTL $\left(Q_{j}\right)$ mapeado, interfiram na sua deteç̧ão no intervalo de interesse. Além disso, com o objetivo 
de ganhar precisão na análise, adiciona-se como covariáveis outros marcadores em posições distantes ou em cromossomos diferentes do intervalo mapeado, que, possivelmente tenham algum efeito (Lynch \& Walsh, 1998).

Figura 3.4 Representação do método de mapeamento por intervalo composto que permite investigar o QTL $\left(Q_{j}\right)$ localizado entre os marcadores $\left(M_{j}\right.$ e $\left.M_{j+1}\right)$, considerando também outros marcadores como covariáveis.

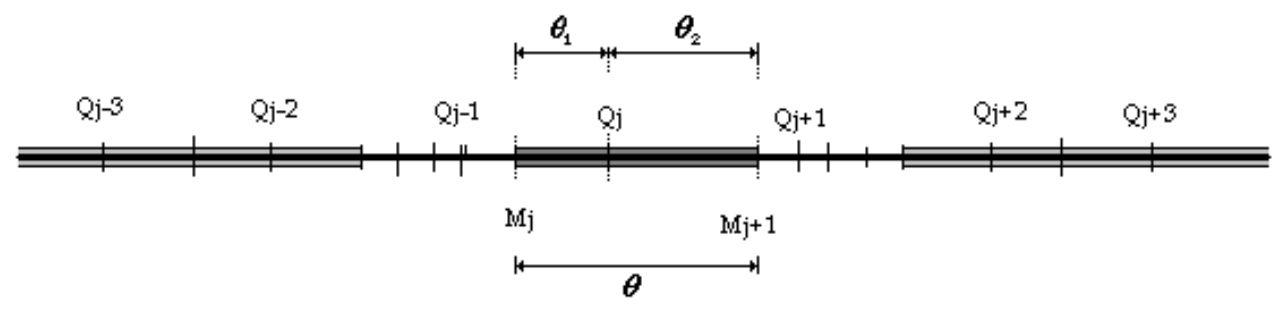

Sendo $T$ o número total de marcadores no mapa genético e $t(t<T)$ o número de marcadores que são utilizados como cofatores, para uma amostra de $n$ indivíduos avaliados para um fenótipo quantitativo, o modelo para o mapeamento por intervalo composto, considerando que o intervalo de pesquisa seja $(j, j+1)$ é dado por:

$$
y_{i}=\mu+\underbrace{a X_{a i}+d X_{d i}}_{\text {Intervalo }}+\underbrace{\sum_{\substack{l=1 \\ l \neq j, l \neq j+1}}^{t}\left(a_{l} x_{a i l}+d_{l} x_{d i l}\right)}_{\text {Cofatores }}+e_{i},
$$

onde,

$\mu$ : média geral;

$y_{i}$ : fenótipo avaliado no indivíduo $i, i=1,2, \ldots, n$;

$a$ : coeficiente de regressão dos efeitos aditivos do QTL;

$d$ : coeficiente de regressão dos efeitos de dominância do QTL;

$a_{l}$ e $d_{l}$ : coeficientes de regressão associados ao l-ésimo marcador;

$X_{a i}$ e $X_{d i}$ : valores preditos para os efeitos aditivos e de dominância do QTL. São calculados por meio de informações genotípicas dos marcadores flanqueadores e por meio das probabilidades associadas aos coeficientes dos valores de $a$ e $d$ apresentados na Tabela 3.2; $x_{a i l}$ e $x_{d i l}$ : variáveis indicadoras do genótipo do $l$-ésimo marcador no $i$-ésimo indivíduo, explicitamente: 


$$
x_{a i l}=\left\{\begin{array}{l}
-1, \text { se o genótipo do marcador é } m m \\
0, \text { se o genótipo do marcador é } M m \\
1, \text { se o genótipo do marcador é } M M
\end{array}\right.
$$

$x_{d i l}$ : variável indicadora da heterozigosidade do marcador;

$$
x_{d i l}=\left\{\begin{array}{l}
1, \quad \text { se o genótipo do marcador é heterozigoto }(M m) \\
0, \text { se o genótipo do marcador é homozigoto }(m m \text { ou } M M)
\end{array}\right.
$$

$e_{i}$ : o resíduo aleatório.

Sob as considerações dadas em Haley \& Knott (1992) os resíduos são assumidos normais com média 0 e variância $\sigma^{2}\left(e_{i} \sim N\left(0, \sigma^{2}\right)\right)$. Segundo o enfoque de Zeng (1994), os resíduos do modelo seguem uma distribuição de mistura de normais. O modelo de mistura será tratado na próxima seção.

Como é observado, a primeira parte na expressão 3.3 estima o efeito do QTL no intervalo analisado, já os termos dentro do somatório referem-se ao ajuste dos marcadores como covariáveis para remoção dos efeitos de outros possíveis QTL's ligados e não ligados ao QTL mapeado. Em resumo, as razões para incluir múltiplos marcadores no modelo de regressão são principalmente duas:

- Ganhar precisão: pois ao incluir no modelo os marcadores não ligados é esperado que o resíduo seja diminuído;

- Controle de falso positivo (efeitos "fantasma"): os marcadores ligados que são utilizados como cofatores, bloqueiam os efeitos de possíveis QTL's pertencentes a regiões adjacentes ao intervalo de pesquisa.

Ressalta-se que a principal dificuldade deste modelo reside justamente em encontrar o subconjunto de marcadores genéticos ideal para o ajuste e, para tanto, é comum a utilização de métodos stepwise (Draper \& Smith, 1981).

\subsubsection{Mapeamento por Múltiplos Intervalos}

A técnica de mapeamento por múltiplos intervalos (do inglês, Multiple Interval Map- 
ping) foi apresentada por Kao et al. (1999). A idéia geral deste método é ajustar diretamente em um único modelo tanto os efeitos dos supostos QTL's quanto o possíveis efeitos epistáticos associados, considerando múltiplos intervalos simultaneamente.

A seguir apresenta-se o modelo com epistasia para 2 QTL's, incluindo o ajuste para marcadores de controle do background genético:

$$
\begin{aligned}
y_{i} & =\mu+\underbrace{a_{1} X_{a 1 i}+d_{1} X_{d 1 i}}_{Q T L 1}+\underbrace{a_{2} X_{a 2 i}+d_{2} X_{d 2 i}}_{Q T L 2} \\
& +\underbrace{i_{a a} X_{a 1 i} * X_{a 2 i}}_{\text {aditivo-aditivo }}+\underbrace{i_{d d} X_{d 1 i} * X_{d 2 i}}_{\text {dominância-dominância }} \\
& +\underbrace{i_{a d} X_{a 1 i} * X_{d 2 i}+i_{d a} X_{d 1 i} * X_{a 2 i}}_{\text {aditivo-dominância }}+\underbrace{\sum_{\substack{l=1 \\
\neq \neq, l \neq j+1}}^{t}\left(a_{l} x_{a i l}+d_{l} x_{d i l}\right)}_{\text {Cofatores }}+e_{i},
\end{aligned}
$$

onde,

$y_{i}$ : fenótipo avaliado no indivíduo $i, i=1,2, \ldots, n$;

$\mu$ : média geral;

$a_{1}, d_{1}$ : coeficientes de regressão dos efeitos aditivo e de dominância do QTL1;

$a_{2}, d_{2}$ : coeficientes de regressão dos efeitos aditivo e de dominância do QTL2;

$X_{a 1 i}, X_{d 1 i}, X_{a 2 i}$ e $X_{d 2 i}$ : valores preditos para os efeitos aditivos e de dominância do QTL1

e QTL2. São calculados por meio de informações genotípicas dos marcadores flanqueadores e por meio das probabilidades associadas aos coeficientes de regressão apresentados na Tabela 3.2 ;

$i_{a a}, i_{d d}, i_{a d}$ e $i_{d a}$ : são os efeitos epistáticos entre os dois QTL's definidos em termos dos componentes aditivos e de dominância dos QTL's;

$x_{a i l}$ e $x_{d i l}$ : variáveis indicadoras do genótipo do $l$-ésimo marcador no $i$-ésimo indivíduo. $e_{i}$ : o resíduo aleatório do modelo. Para os procedimentos inferenciais, assume-se que os erros podem seguir as premissas clássicas, isto é, independentes e normalmente distribuídos com média zero e variância comum $\sigma^{2}$ ou, o modelo de mistura de distribuições normais.

Considerando que os objetivos deste trabalho não contemplam a modelagem de múltiplos QTL's simultaneamente e suas interações epistáticas, apresentou-se o modelo geral do 
método de mapeamento por múltiplos intervalos; descrições detalhadas encontram-se em Kao et al. (2002).

Métodos estatísticos para o mapeamento de QTL's, via a informação de um mapa de marcadores moleculares, quando é considerado só um traço em cada análise são bem desenvolvidos na literatura e têm sido utilizados em diferentes áreas (Lander \& Botstein, 1989; Haley \& Knott ,1992; Jansen \& Stam, 1994; Zeng, 1994).

O modelo que será considerado para o mapeamento univariado é o modelo descrito em 3.3 referente ao mapeamento por intervalo composto e será abordado segundo as considerações propostas em Zeng (1994), Jansen (1992), em que os resíduos seguem uma distribuição de mistura de normais.

\subsubsection{Modelos de Mistura}

Para uma população $F 2$ os possíveis genótipos do QTL são $Q Q, Q q$ ou $q q$, cada um com sua própria probabilidade de ocorrência que neste caso segue a razão 1:2:1. Deste modo, a distribuição dos fenótipos avaliados nestes indivíduos pode depender da categorização genotípica dos indivíduos. Suponha que $y_{i}$ denote o valor do traço do $i$-ésimo indivíduo F2. Na Tabela 3.3 é apresentada esta informação mais suscintamente, a qual é utilizada para descrever uma distribuição de misturas (Balding et al. 2003).

Tabela 3.3 Genótipos com sua probabilidade de ocorrência e componentes da função de densidade de probabilidade.

\begin{tabular}{ccccc}
\hline \hline & & & $\mathrm{P}($ Genótipo $)$ & $\mathrm{P}(\mathrm{y} /$ Genótipo $)$ \\
\hline 1 & $y_{i}$ & qq & $\mathrm{P}(\mathrm{qq})$ & $\phi\left(y_{i} ; \mu_{q q}, \sigma_{q q}^{2}\right)$ \\
2 & $y_{i}$ & $\mathrm{Qq}$ & $\mathrm{P}(\mathrm{Qq})$ & $\phi\left(y_{i} ; \mu_{Q q}, \sigma_{Q q}^{2}\right)$ \\
3 & $y_{i}$ & $\mathrm{QQ}$ & $\mathrm{P}(\mathrm{QQ})$ & $\phi\left(y_{i} ; \mu_{Q Q}, \sigma_{Q Q}^{2}\right)$. \\
\hline \hline
\end{tabular}

De forma geral,

$\phi\left(y ; \mu, \sigma^{2}\right)=\frac{1}{\sqrt{2 \pi \sigma^{2}}} \exp \left(\frac{-(y-u)^{2}}{2 \sigma^{2}}\right)$ é a função densidade de probabilidade da distribuição normal com média 0 e variância $\sigma^{2}$.

Considerando $y_{i}$ o valor do traço para o $i$-ésimo indivíduo, o modelo de misturas pro- 
posto por Jansen (1992) é dado por:

$$
\begin{aligned}
f_{M i x}\left(y_{i}\right) & =f_{Q Q}\left(y_{i} ; G_{Q Q}\right)+f_{Q q}\left(y_{i} ; G_{Q q}\right)+f_{q q}\left(y_{i} ; G_{q q}\right) \\
& =P(Q Q) f_{Q Q}\left(y_{i} \mid G_{Q Q}\right)+P(Q q) f_{Q q}\left(y_{i} \mid G_{Q q}\right)+P(q q) f_{q q}\left(y_{i} \mid G_{q q}\right) \\
& =P_{Q Q} \phi\left(y_{i} ; \mu_{Q Q}, \sigma_{Q Q}^{2}\right)+P_{Q q} \phi\left(y_{i} ; \mu_{Q q}, \sigma_{Q q}^{2}\right)+P_{q q} \phi\left(y_{i} ; \mu_{q q}, \sigma_{q q}^{2}\right) .
\end{aligned}
$$

Considerando uma população $F 2$ os pesos em cada mistura são 1/4, 1/2, 1/4 para cada categoria genotípica $Q Q, Q q, q q$, respectivamente.

A função de verossimilhança das observações $y_{1}, y_{2}, \ldots, y_{n}$ é o produto das contribuições individuais de verossimilhanças dada por:

$$
L=\prod_{i=1}^{n} f_{M i x}\left(y_{i}\right)
$$

e cujo espaço dos parâmetros, comumente denotado por $\Theta$, é:

$$
\Theta=\left\{P_{q q}, \mu_{q q}, \sigma_{q q}^{2}, P_{Q q}, \mu_{Q q}, \sigma_{Q q}^{2}, P_{Q Q}, \mu_{Q Q}, \sigma_{Q Q}^{2}\right\}
$$

em geral é assumido homocedasticidade tal que $\sigma_{Q Q}^{2}=\sigma_{Q q}^{2}=\sigma_{q q}^{2}$.

Para o caso de mistura de normais, os estimadores de máxima verossimilhança não têm solução explícita e devem ser obtidos por métodos numéricos. O algoritmo EM (Esperança -Maximização) tem sido amplamente utilizado em análises de dados genômicos porque é poderoso especialmente quando a amostra possui dados incompletos ${ }^{3}$, (Liu, 1998; Jansen, 1992; Zeng, 1994). Os estimadores dos parâmetros sob o modelo de mistura também podem ser calculados através do algoritmo ECM (Esperança-Maximização condicional), que consiste em uma versão do algoritmo EM o qual converge mais rapidamente. Este último método está implementado no aplicativo Cartographer (Basten, Weir \& Zeng, 1994), uma ferramenta computacional validada na literatura de análise de QTL's em cruzamentos controlados e que será utilizada nas aplicações deste trabalho.

${ }^{3}$ No contexto genético, a informação sobre o genótipo do QTL é considerada incompleta, com três componentes possíveis $Q Q, Q q, q q$ para o caso do delineamento $F 2$. 


\subsubsection{Hipóteses estatísticas sobre os efeitos do QTL}

Para o modelo do tipo 3.2 e 3.3, as seguintes hipóteses estatísticas podem ser formuladas sobre os efeitos aditivos e de dominância do QTL quando considerada uma posição específica.

$$
\begin{aligned}
& H_{0}: a=0, d=0 \\
& H_{1}: a \neq 0, d=0 \\
& H_{2}: a=0, d \neq 0 \\
& H_{3}: a \neq 0, d \neq 0
\end{aligned}
$$

Os testes que podem ser realizados, descritos em Zeng(1994), são:

$$
\begin{aligned}
& H_{0} \times H_{3} \\
& H_{1} \times H_{3} \\
& H_{2} \times H_{3} \\
& H_{0} \times H_{1} \\
& H_{0} \times H_{2} .
\end{aligned}
$$

O teste $H_{0} \times H_{3}$, equivale a testar simultaneamente se há efeito aditivo e de dominância do QTL, já o teste $H_{0} \times H_{1}$, equivale a testar se há efeito aditivo do QTL na ausência de efeito de dominância e assim por diante. Estes testes podem ser realizados em qualquer posição no genoma flanqueada por marcadores. O teste estatístico para detectar a presença de um QTL é realizado movendo a posição do suposto QTL ao longo do cromossomo e é baseado na estatística razão de verossimilhanças a qual é dada por:

$$
\wedge=L R=-2 \ln \left[\frac{L\left(H_{0}\right)}{L\left(H_{a}\right)}\right],
$$

sendo $L\left(H_{0}\right)$ a função de verossimilhança sob a hipótese nula $\left(H_{0}: a=0, d=0\right.$, isto é, não existe um QTL na posição específica) e $L\left(H_{a}\right)$ a função de verossimilhança sob a hipótese 
alternativa (existe QTL na posição específica). A estatística da razão de verossimilhanças tem distribuição assintótica Qui-Quadrado com $d$ graus de liberdade, onde $d$ representa

a diferença entre o número de parâmetros sob as hipótese $H_{a}$ e $H_{0}, L R \sim \chi_{d}^{2}$ (Lynch \& Walsh, 1998; Bearzoti, 2000). Como são realizados múltiplos testes através do mapeamento por todo o genoma, a determinação do valor crítico do teste deve ter correção. Várias propostas são abordadas na literatura, por exemplo, a correção de Bonferroni, testes de permutação e FDR (razão de falsas descobertas), essas propostas são comentadas no Apêndice B deste trabalho.

\subsubsection{Estatística Lod Score}

No mapeamento de QTL's, bem como em Genética Quantitativa em geral, o teste da razão de verossimilhanças tem sido por conveniência expresso por meio de uma mudança de escala definindo a estatística Lod Score (do inglês, Log of the odds ratio) utilizada comumente em mapeamento para declarar se um QTL está presente ou não em determinada posição do genoma.

A estatistica Lod Score é definida como o logaritmo na base 10 da razão de verossimilhanças:

$$
\text { Lod Score }=\log _{10} \frac{L\left(H_{a}\right)}{L\left(H_{0}\right)}
$$

a mudança para a escala logarítmica na base 10 é feita para facilitar a interpretação. Dada a equivalência entre $L R$ e Lod Score ( $L R=4.6$ Lod Score) sob uma distribuição Qui Quadrado com um grau de liberdade, um Lod Score igual a 3 indica, de maneira geral, que a ocorrência de ligação entre marcador e QTL é mil vezes mais provável que a segregação independente entre eles.

Um passo importante na análise é fixar um valor crítico da estatística do teste que indique a significância do efeito. No caso de mapeamento por todo o genoma há necessidade do ajuste do valor crítico para os múltiplos testes realizados, de acordo com o número e tamanho dos intervalos, número de múltiplos QTL's ligados ou não ligados, etc (Lander \& Botstein, 1989). Contudo, como evidência exploratória de ligação genética entre o mar- 
cador e o QTL, tem sido adotado um valor crítico da estatística Lod Score de 2,5 como sugerido por Kao et al. (1999). Note que Lod Score =2, 5 em um teste com um grau de liberdade equivale a um nível descritivo $p<0,001$. Isto significa que, quando a estatística Lod Score for maior que 2,5 para uma determinada posição, tem-se indicação de que o QTL deve estar naquela região cromossômica com uma chance de um falso positivo de no máximo 0,001 .

\subsection{Mapeamento de QTL's sob modelos multivariados}

As propostas para o mapeamento de múltiplos traços encontradas na literatura são principalmente, o Modelo de Regressão Intervalar Multivariado (Jiang e Zeng, 1995), Método da Decomposição Espectral via Componentes Principais (Mangin et al. 1998) e o Método de mapeamento de QTL's para múltiplos traços utilizando a teoria de Mínimos Quadrados (Knott \& Haley, 2000).

O mapeamento de QTL's considerando um traço de cada vez não toma vantagem da estrutura de correlação dos dados e tem muitas desvantagens para o mapeamento de QTL's, assim como para o entendimento da correlação genética. A utilização de técnicas multivariadas é mais apropriada em virtude das características serem consideradas simultaneamente, obtendo interpretações que não seriam possíveis com o uso de métodos univariados aplicados separadamente a cada traço. Ressalta-se o fato de que mediante estas técnicas é possível investigar questões biológicas importantes tais como o efeito de pleiotropia e interações QTL×ambiente (Jiang \& Zeng, 1995; Mangin et al., 1998) descritos na Seção 2.7.

Levando em consideração a estrutura de correlação de múltiplos traços, a análise conjunta tem várias vantagens comparada à análise de traços individuais no mapeamento de QTL's, incluindo o aumento de poder dos testes e da precisão das estimativas dos parâmetros (Jiang \& Zeng, 1995).

Muitas estratégias de análises em mapeamento multivariado de QTL's exploram diferentes tipos de dados, como observações sobre múltiplos traços (conteúdo de gordura e 
proteína no leite de gado, (Weller et al. 1996) ou sobre um traço em múltiplas condições ambientais (rendimento de populações segregantes de grãos em diferentes métodos de semeadura). Com um conjunto de tais observações surgem perguntas como: um QTL tem efeitos pleiotrópicos sobre os traços em estudo? Um QTL interage com o ambiente, respondendo a mudanças que podem ocorrer? A correlação entre traços é devida ao efeito de pleiotropia? Ou diferentes QTL's atuam sobre as observações? Quando um fenótipo é avaliado em diferentes ambientes, por exemplo, no caso da pressão arterial medida para o mesmo conjunto de indivíduos antes e após de uma dose de sal, isto pode ser modelado por meio da análise de múltiplos traços (Falconer, 1952). Assim, com observações de muitos marcadores genéticos e muitos traços quantitativos é possível extrair informação da variância e covariância entre traços localizando e estimando QTL's responsáveis pela sua regulação. Neste trabalho será utilizado o modelo de regressão multivariado apresentado por Jiang \& Zeng (1995).

\subsubsection{Modelo de Regressão Intervalar Multivariado}

O modelo de regressão intervalar multivariado bem como o modelo de regressão intervalar composto multivariado podem ser vistos como uma extensão dos correspondentes modelos para um único traço descritos nas expressões 3.2 e 3.3 respectivamente. O modelo estatístico para o mapeamento de QTL's pleiotrópicos assim como para o mapeamento de genes com efeito de interação com o ambiente, pode ser formulado usando o método de Mapeamento Multivariado.

Para uma amostra de $n$ indivíduos F2 com observações sobre $m$ traços ou fenótipos e $t$ marcadores que são utilizados como covariáveis, o modelo intervalar composto para o 
i-ésimo indivíduo é dado a seguir:

$$
\begin{gathered}
y_{i 1}=\mu_{01}+a_{1} X_{a i}+d_{1} X_{d i}+\sum_{l}^{t}\left(a_{l 1} x_{a i l}+d_{l 1} x_{d i l}\right)+e_{i 1}, \\
y_{i 2}=\mu_{02}+a_{2} X_{a i}+d_{2} X_{d i}+\sum_{l}^{t}\left(a_{l 2} x_{a i l}+d_{l 2} x_{d i l}\right)+e_{i 2}, \\
\vdots \\
y_{i m}=\mu_{0 m}+a_{m} X_{a i}+d_{m} X_{d i}+\sum_{l}^{t}\left(a_{l m} x_{a i l}+d_{l m} x_{d i l}\right)+e_{i m} .
\end{gathered}
$$

A descrição dos parâmetros e das variáveis envolvidas segue aquela apresentada para o modelo descrito na expressão $3.3 \mathrm{com}$ a extensão para $m$ traços. Nota-se que o modelo assume que cada traço está associado ao mesmo conjunto de variáveis explicativas (QTL e marcadores).

Considera-se que os efeitos residuais $e_{i k}^{\prime} s$ são correlacionados entre traços dentro de indivíduos, mas são assumidos independentes entre indivíduos isto é:

$$
\operatorname{Cov}\left(\mathrm{e}_{i k}, e_{i^{\prime} k^{\prime}}\right)=\left\{\begin{array}{l}
0, \text { se } i \neq i^{\prime} \forall k, k^{\prime} \\
\sigma_{k k^{\prime}}=\rho_{k k^{\prime}} \sigma_{k} \sigma_{k^{\prime}}, \text { se } i=i^{\prime} \text { e } k \neq k^{\prime} \\
\sigma_{k}^{2}, \text { se } i=i^{\prime} \text { e } k=k^{\prime}
\end{array}\right.
$$

Em notação matricial a matriz de covariância para as respostas observadas no indivíduo $i$ é dada por:

$$
\boldsymbol{\Sigma}_{i_{m \times m}}=\left(\begin{array}{cccc}
\sigma_{1}^{2} & \sigma_{12} & \ldots & \sigma_{1 m} \\
\sigma_{21} & \sigma_{2}^{2} & \ldots & \sigma_{2 m} \\
\vdots & & \ddots & \vdots \\
\sigma_{m 1} & \sigma_{m 2} & \ldots & \sigma_{m}^{2}
\end{array}\right)
$$

$\forall i=1,2, \ldots, n$.

Logo a matriz de covariância $\boldsymbol{\Sigma}$ para os $n$ indivíduos avaliados nos $m$ traços é uma matriz bloco diagonal (de dimensão $n m \times n m$ ) com o $i$-ésimo bloco dado por $\boldsymbol{\Sigma}_{i}$.

O modelo 3.13, em forma matricial pode ser escrito como: 


$$
\mathbf{Y}=\mathbf{X}^{a} \mathbf{a}^{\top}+\mathbf{X}^{d} \mathbf{d}^{\top}+\mathbf{X A}+\mathbf{E}
$$

onde,

$\mathbf{Y}_{n \times m}$ : é a matriz contendo os componentes $y_{i k}$ (valor do $k$-ésimo traço no $i$-ésimo indivíduo);

$\mathbf{X}_{n \times 1}^{a}=\left(X_{a 1}, X_{a 2}, \ldots, X_{a n}\right)^{\top}$ vetor dos $X_{a i}$;

$\mathbf{X}_{n \times 1}^{d}=\left(X_{d 1}, X_{d 2}, \ldots, X_{d n}\right)^{\top}$ vetor dos $X_{d i}$;

$\mathbf{a}_{m \times 1}=\left(a_{1}, a_{2}, \ldots, a_{m}\right)^{\top}$ vetor $\operatorname{dos} a_{k} ;$

$\mathbf{d}_{m \times 1}=\left(d_{1}, d_{2}, \ldots, d_{m}\right)^{\top}$ vetor dos $d_{k}$;

$\mathbf{X}_{n \times(2 t+1)}$ : matriz das categorias genotípicas associadas aos efeitos aditivos e de dominância dos t marcadores de controle $\left(x_{a i l}^{\prime} s\right.$ e $\left.x_{d i l}^{\prime} s\right)$ às quais é adicionada uma coluna de $1^{\prime} s$ associada aos parâmetros $\mu_{0 k}$;

$\mathbf{A}_{(2 t+1) \times m}$ : matriz dos coeficientes de regressão, $a_{l k}$ e $d_{l k}$, associados aos efeitos dos marcadores de controle e $\mu_{0 k}$ a média geral associada ao traço $k$;

$\mathbf{E}_{n \times m}$ : matriz dos resíduos $e_{i k}$.

Dado o modelo 3.15 (equivalente ao modelo 3.13) pode-se definir um modelo de misturas de normais multivariadas para a distribuição do vetor de resíduos do $i$-ésimo indivíduo (Jiang \& Zeng, 1995). A função de verossimilhanças para a amostra de $n$ indivíduos $F 2$ (considerados independentes), é definida por:

$$
L=\prod_{i=1}^{n}\left[P(Q Q) f_{Q Q}\left(y_{i} \mid G_{Q Q}\right)+P(Q q) f_{Q q}\left(y_{i} \mid G_{Q q}\right)+P(q q) f_{q q}\left(y_{i} \mid G_{q q}\right)\right]
$$

onde, $P(Q Q), P(Q q)$ e $P(q q)$ denotam as probabilidades a priori sobre o genótipo do QTL, (que sob o delineamento $F 2$ são dadas por 1/4, 1/2, 1/4 respectivamente). Neste caso as funções de densidade $f$ são normais multivariadas ( $m$ dimensionais), tal que:

$f_{Q Q}\left(y_{i} \mid G_{Q Q}\right) \sim N_{m}\left(\boldsymbol{\mu}_{Q Q} ; \boldsymbol{\Sigma}_{i}\right)$,

$f_{Q q}\left(y_{i} \mid G_{Q Q}\right) \sim N_{m}\left(\boldsymbol{\mu}_{Q q} ; \boldsymbol{\Sigma}_{i}\right)$,

$f_{q q}\left(y_{i} \mid G_{Q Q}\right) \sim N_{m}\left(\boldsymbol{\mu}_{q q} ; \boldsymbol{\Sigma}_{i}\right)$,

onde $\boldsymbol{\Sigma}_{i}$ é a matriz de covariância descrita em 3.14, assumida homogênea para todos os níveis genotípicos e indivíduos. 


\subsubsection{Testes de hipóteses dos efeitos de QTL's pleiotrópicos e interação gene $\times$ ambiente}

Com algumas restrições sobre os valores dos parâmetros em um modelo multivariado como em 3.15, diferentes hipóteses podem ser construídas e testadas sobre os efeitos aditivos e de dominância dos QTL's. Sem perda de generalidade, a seguir, hipóteses de interesse ao problema de mapeamento genético multivariado considerando $m=2$ traços (ou equivalentemente, um traço sob duas condições ambientais diferentes) são descritas:

- Teste sobre a presença de algum QTL em uma posição específica

$$
\begin{aligned}
& H_{0} \quad: \quad a_{1}=0, d_{1}=0, a_{2}=0, d_{2}=0 \\
& H_{1} \quad: \quad \text { ao menos um dos parâmetros é diferente de zero. }
\end{aligned}
$$

Para uma posição de QTL específica, dado que a hipótese $H_{0}$ em 3.17 tenha sido rejeitada, as seguintes hipóteses podem ser formuladas:

- Teste de efeitos condicionais

Sob a suposição de que existe somente um QTL na região mapeada o qual tem efeito sobre um ou sobre os dois traços, as hipóteses podem ser formuladas como segue:

$$
\begin{gathered}
H_{10}: a_{1}=0, d_{1}=0, a_{2} \neq 0, d_{2} \neq 0 \\
H_{11}: a_{1} \neq 0, d_{1} \neq 0, a_{2} \neq 0, d_{2} \neq 0,
\end{gathered}
$$

e

$$
\begin{gathered}
H_{20}: a_{1} \neq 0, d_{1} \neq 0, a_{2}=0, d_{2}=0 \\
H_{21}: a_{1} \neq 0, d_{1} \neq 0, a_{2} \neq 0, d_{2} \neq 0 .
\end{gathered}
$$

Jiang \& Zeng (1995) destacam que o teste sobre QTL com efeito pleiotrópico é equivalente a testar as duas hipóteses, 3.18 e 3.19 simultaneamente. Embora cada hipótese tenha restrição somente sobre um traço, a análise não é a mesma como no 
caso univariado, pois a correlação entre os traços está sendo modelada na verossimilhança já que o teste do QTL sobre um traço está sendo feito sob a hipótese da presença de efeito sobre o outro traço.

Como será descrito com respeito aos testes da razão de verossimilhanças, este teste tem mais poder que no caso da análise univariada (Jiang \& Zeng, 1995).

- Teste de efeitos pleiotrópicos vs ligação

Embora rejeitar $H_{10}$ em 3.18 e $H_{20}$ em 3.19 seja consistente com a hipótese de efeitos pleiotrópicos de um QTL, o teste não distingue se o efeito significativo é dado por um QTL com efeitos pleiotrópicos sobre os dois traços (ou mais) ou, possivelmente o efeito significativo seja dado por QTL's diferentes mas ligados, em que cada um tenha um efeito predominante sobre um único traço mas que estão muito próximos. Assim, em mapeamento de QTL's, para algumas regiões, pode existir interesse em distinguir essas duas possibilidades.

Suponha-se dois QTL's diferentes no mesmo cromossomo, cada um com efeito sobre um único traço, e que tenham posições especificadas por $p_{1}$ para o QTL com efeito sobre o traço 1 e $p_{2}$ para o QTL com efeito sobre o traço 2, então as hipóteses podem ser formuladas como:

$$
\begin{array}{ll}
H_{30} & : p_{(1)}=p_{(2)} \\
H_{31} & : \quad p_{(1)} \neq p_{(2)} .
\end{array}
$$

Jiang \& Zeng (1995) discutem que a hipótese $H_{31}$ é um caso especial de muitas situações. Uma delas é que os dois QTL's em $p_{(1)}$ e $p_{(2)}$ tenham efeitos pleiotrópicos. Esta alternativa é, no entanto, a hipótese para o mapeamento de dois QTL's pleiotrópicos ligados. Várias situações práticas poderiam motivar tal arquitetura genética, contudo os autores apresentam um teste baseado na estatística da razão de verossimilhanças para o caso em que os dois QTL's estão ligados mas não são pleiotrópicos, neste caso as expressões 3.13 e 3.15 são reformuladas considerando os efeitos aditivos e de dominância específicos aos QTL's localizados em $p_{(1)}$ e $p_{(2)}$. Deste modo 
o modelo de mistura definido na função de verossimilhanças envolveria 9 vetores de médias considerando as possíveis combinações genotípicas dos dois QTL's envolvidos.

Vale ressaltar que o teste da hipótese 3.20 envolve um número maior de parâmetros e a precisão das inferências realizadas dependerá de um número maior de indivíduos na amostra e também de um mapa muito denso de marcadores que consiga discriminar os efeitos de QTL's ligados. Neste trabalho este teste (descrito em 3.20) não é tratado.

- Interação de genes com o ambiente

Essencialmente, o teste da hipótese de interação gene com o ambiente considera dados de um mesmo fenótipo avaliado em diferentes ambientes ou condições de avaliação. Assim, com a rejeição de $H_{0}, H_{10}$ e $H_{20}$, para testar a interação QTL×ambiente, há interesse nas seguintes hipóteses:

$$
\begin{array}{ll}
H_{40}: & a_{1}=a_{2}=a, d_{1}=d_{2}=d \\
H_{41} & : \quad a_{1} \neq a_{2}, d_{1} \neq d_{2} .
\end{array}
$$

Neste caso, rejeitar a hipótese nula $H_{40}$ implica aceitar que o gene está sendo expresso de forma diferente em cada ambiente, nos componentes aditivo e de dominância.

Os testes das hipóteses $3.17,3.18,3.19,3.21$ são realizados por meio da estatística da razão de verossimilhanças sob o modelo multivariado dado em 3.15 , o qual é um modelo de mistura de normais e a estimação dos parâmetros do modelo podem ser obtidos pelos algoritmos EM e ECM. A especificação dos testes e a iteração dos algoritmos é descrita em Jiang \& Zeng (1995). Os procedimentos 3.17, 3.18, 3.19 estão implementados no aplicativo Cartographer (Basten, Weir \& Zeng, 1994; Wang et al. 2007) e foram usados neste trabalho. 


\subsubsection{Vantagens do mapeamento multivariado}

A seguir, destacam-se algumas características importantes da análise conjunta consideradas em Jiang \& Zeng (1995) e Mangin et al. (1998) quando comparadas com a análise univariada. Sem perda de generalidade, os resultados são descritos para a situação de dois traços $(m=2)$. Considere $L R_{12}, L R_{1}$ e $L R_{2}$ as estatísticas da razão de verossimilhanças conjunta e para os dois traços independentemente.

- Se a covariância entre dois traços for nula, $\rho=0$, então $L R_{12} \cong L R_{1}+L R_{2}$. O teste estatístico conjunto é aproximadamente a soma de testes estatísticos individuais para traços independentes;

- Se o coeficiente aditivo de um dos traços for igual a zero, por exemplo $a_{2}=0, L R_{12} \cong$

$\frac{L R_{1}}{1-\rho^{2}} \geq L R_{1}$, a estatística da razão de verossimilhanças da análise conjunta será maior ou igual à estatística calculada para o outro traço isoladamente, se os traços forem correlacionados;

- $L R_{12} \geq \operatorname{Máximo}\left(L R_{1}, L R_{2}\right)$. A estatística razão de verossimilhanças da análise conjunta será sempre maior ou igual ao valor máximo encontrado para as estatísticas individualmente. Por exemplo, para dois casos extremos, tem-se:

Caso 1. ( observação anterior) $a_{2}=0, L R_{12} \cong \frac{L R_{1}}{1-\rho^{2}} \geq L R_{1}$.

Caso 2. (Efeitos aditivos iguais nos dois traços) $a_{1}=a_{2}=a, L R_{12} \cong \frac{2}{(1+\rho) a^{2}} \geq L R_{1}$ ou $L R_{2}$;

- Se a multiplicação dos efeitos aditivos ou de dominância $\left(a_{1} a_{2}\right.$ ou $\left.d_{1} d_{2}\right)$ associados aos dois traços com a correlação $(\rho)$ entre eles resultar em um sinal negativo, isto é, $\rho a_{1} a_{2}<0$ ou $\rho d_{1} d_{2}<0$ então a estatística razão de verossimilhanças da análise conjunta é maior que a soma das estatísticas calculadas separadamente, $L R_{12}>L R_{1}+L R_{2}$. Neste caso, o poder da análise conjunta para mapeamento de QTL's é maior que a de qualquer análise separada. Trata-se da situação mais favorável para a análise conjunta. 
Apesar da decisiva importância do último critério apresentado, sua interpretação não é simples. No Capítulo 6 de aplicações das diversas metodologias do mapeamento genético, serão exploradas as vantagens do mapeamento genético multivariado, levando-se em conta principalmente a última vantagem descrita, em que é apresentada a condição mais favorável para a análise conjunta, a qual será uma ferramenta fundamental nas análises deste trabalho, permitindo obter conclusões importantes no estudo da pressão arterial. 


\section{Capítulo 4}

\section{Modelos alternativos no mapeamento multivariado}

Como estabelecido anteriormente, com respeito ao efeito de pleiotropia e interações gene $\times$ ambiente, os estudos devem ser abordados do ponto de vista dos modelos multivariados. Contudo, ao analisar os traços em conjunto, muitas vezes não fica claro a contribuição de cada traço ao mapeamento de genes. Nestas análises é importante identificar, tanto quanto possível, genes com efeito sobre um único traço e aqueles com efeito pleiotrópico (sobre mais de um traço), assim como a interação gene×ambiente.

Neste capítulo são apresentadas três possíveis abordagens univariadas para esclarecer os diferentes padrões de regulação genética encontrados nas análises multivariadas:

- Mapeamento univariado da medida resumo diferença entre fenótipos avaliados em situações antes e depois de uma intervenção;

- Mapeamento genético mediante o ajuste por covariáveis;

- Mapeamento utilizando a decomposição espectral das respostas multivariadas.

\subsection{Análise da diferença entre dois fenótipos}

Quando um mesmo fenótipo é medido em duas condições ambientais diferentes é comum, nas análises estatísticas dos dados, adotar a medida resumo diferença entre os fenótipos. Vale notar que é possível obter resultados mais precisos em alguns experimentos de comparações simples se a comparação é feita sob amostras pareadas onde as análises 
são realizadas através do teste $t$ pareado e a estatística do teste é a média das diferenças entre as respostas dentro das unidades (Montgomery, 1984; Neter et al. 1996).

Seja $Y_{1}$ o fenótipo avaliado na condição ambiental 1 e $Y_{2}$ o fenótipo avaliado na condição ambiental 2. Para o caso em estudo, os fenótipos nos diferentes ambientes são avaliados no mesmo conjunto de indivíduos.

Considere os dois seguintes modelos univariados para o $i$-ésimo indivíduo:

$$
\begin{aligned}
& y_{1 i}=\mu_{01}+a_{1} X_{a i}+d_{1} X_{d i}+\sum_{l}^{t}\left(a_{l 1} x_{a i l}+d_{l 1} x_{d i l}\right)+e_{1 i} ; \\
& y_{2 i}=\mu_{02}+a_{2} X_{a i}+d_{2} X_{d i}+\sum_{l}^{t}\left(a_{l 2} x_{a i l}+d_{l 2} x_{d i l}\right)+e_{2 i},
\end{aligned}
$$

de forma que a diferença entre estes fenótipos é dada por:

$$
y_{D I F i}=y_{2 i}-y_{1 i}
$$

a qual, sob 4.1 e 4.2 também pode ser escrita como:

$\left.y_{D I F i}=\left(\mu_{02}-\mu_{01}\right)+\left(a_{2}-a_{1}\right) X_{a i}+\left(d_{2}-d_{1}\right) X_{d i}+\sum_{l}^{t}\left[\left(a_{l 2}-a_{l 1}\right) x_{a i l}+\left(d_{l 2}-d_{l 1}\right) x_{d i l}\right)\right]+\left(e_{2 i}-e_{1 i}\right)$

e, em geral, como:

$$
y_{D I F i}=\mu_{D I F}+a_{D I F} X_{a i}+d_{D I F} X_{d i}+\sum_{l}^{t}\left(a_{D I F l} x_{a i l}+d_{D I F l} x_{d i l}\right)+e_{D I F i} .
$$

É conhecido que para duas variáveis aleatórias quaisquer a variância da diferença é dada por:

$$
\operatorname{Var}\left(Y_{2}-Y_{1}\right)=\operatorname{Var}\left(Y_{1}\right)+\operatorname{Var}\left(Y_{2}\right)-2 \operatorname{Cov}\left(Y_{1}, Y_{2}\right)=\sigma_{1}^{2}+\sigma_{2}^{2}-2 \sigma_{1} \sigma_{2} \rho_{12}
$$

Assim, ao adotar a variável diferença, para que haja ganho em precisão devido à incorporação da estrutura de dependência entre $y_{1}$ e $y_{2}$ nas análises, é necessário que a correlação entre as variáveis, $\rho_{12}$, seja positiva. Também, ao comparar os parâmetros de regressão dos modelos 4.4 e 4.3 pode-se pensar na situação que mais favoreça a deteção de QTL's via o modelo 4.4 relativamente aos modelos 4.1 e 4.2. Como os novos parâmetros associados ao valor esperado da diferença $\left(\mu_{D I F}, a_{D I F}, d_{D I F}\right)$ em 4.4 são dados em função 
dos parâmetros das variáveis originais $\left(y_{1}, y_{2}\right)$, (ver expressão 4.3), a magnitude do valor destes novos parâmetros será maior se os parâmetros originais tiverem sinais opostos. Sendo assim, $\left|a_{D I F}\right| \geq a_{1}$ (ou $a_{2}$ ) e $\left|d_{D I F}\right| \geq d_{1}$ (ou $d_{2}$ ). Resumindo, conclui-se que a utilidade da variável diferença ao mapeamento genético atinge seu máximo se $\rho>0$ e $a_{1} a_{2}<0$ ou $d_{1} d_{2}<0$, ou seja, se $\rho a_{1} a_{2}<0$ ou $\rho d_{1} d_{2}<0$, alcançando uma das alternativas de ocorrência da condição mais favorável para a análise conjunta, descrita na Seção 3.2.3 (último ítem).

No caso em que a correlação entre os dois fenótips seja negativa, $\rho_{12}<0$, tem-se que:

$$
\operatorname{Var}\left(Y_{2}-Y_{1}\right)=\sigma_{1}^{2}+\sigma_{2}^{2}+2 \sigma_{1} \sigma_{2} \rho_{12}
$$

nota-se que a variância da diferença entre as variáveis é inflacionada pelo termo $2 \sigma_{1} \sigma_{2} \rho_{12}$ permitindo concluir que a diferença entre as variáveis de interesse neste caso pode não ser uma escolha de medida resumo vantajosa no mapeamento genético de interações gene $\times$ ambiente. Neste caso, em que a correlação entre os fenótipos é negativa, a situação mais favorável ao ajuste multivariado ocorre quando por exemplo $a_{1}$ e $a_{2}$ têm o mesmo sinal. Assim na situação mais otimista, o modelo 4.4 poderá detectar os mesmos QTL's detectados nas análises univariadas ou não detectar nenhum deles, deste modo não apresenta vantagem pois nenhum novo QTL é esperado ser identificado.

\subsection{Mapeamento usando ajuste por covariáveis}

Resultados encontrados na literatura indicam que pode-se ganhar precisão nos resultados inferenciais por meio da inclusão de covariáveis em modelos de regressão. Nesta seção o problema de pleiotropia bem como de interação gene×ambiente será considerado um problema de "natureza" bivariada, que está sendo avaliado sob uma formulação univariada ao introduzir um fenótipo como covariável no ajuste do outro fenótipo.

Sejam $Y=\left(y_{1}, y_{2}, \ldots, y_{n}\right)^{\top}$ e $X_{c}=\left(x_{c 1}, x_{c 2}, \ldots, x_{c n}\right)^{\top}$ os fenótipos tomados de uma amostra de $n$ indivíduos. Para conhecer qual é a contribuição da variável $X_{c}$ nas análises genéticas de $Y$, propõe-se o seguinte modelo univariado para o $i$-ésimo indivíduo: 


$$
y_{i}=\mu_{0}+a X_{a i}+d X_{d i}+\sum_{l}^{t}\left(a_{l} x_{a i l}+d_{l} x_{d i l}\right)+\beta \underbrace{x_{c i}}_{\text {Covariável }}+e_{i}
$$

$i=1,2, \ldots, n$

onde,

$\beta$ : parâmetro associado à covariável $x_{c i}$ incluída no modelo.

As variáveis $X_{a i}, X_{d i}, x_{a i l}, x_{d i l}$, os outros parâmetros $a, d, a_{l}, d_{l}$ e $e_{i}$, o resíduo, foram definidos como no modelo para o caso univariado dado na expressão 3.3.

Para o ajuste do modelo de regressão com covariáveis (expressão 4.6), para finalidade de mapeamento de genes com efeitos pleiotrópicos ou modelagem do efeito de interação gene $\times$ ambiente opta-se pela análise em dois estágios. Ressalta-se que esta alternativa será adotada mais por razão de conveniência do uso do aplicativo Cartographer que é usado neste trabalho. Nota-se que o modelo 4.6, o qual pode ser chamado de modelo completo, para algumas finalidades, pode ser escrito como:

$$
y_{i}-\left(\mu_{0}+\beta x_{c i}\right)=a X_{a i}+d X_{d i}+\sum_{l}^{t}\left(a_{l} x_{a i l}+d_{l} x_{d j l}\right)+e_{i} .
$$

No primeiro estágio, o termo da esquerda $y_{i}-\left(\mu_{0}+\beta x_{c i}\right)$ pode ser estimado via um modelo de regressão simples o qual pode ser escrito como: $y_{i}=\mu_{0}+\beta x_{c i}+\epsilon_{i}$ onde os erros são assumidos normais, independentes e homocedásticos. Ajustando este modelo por métodos de regressão clássicos, são encontrados os resíduos, que serão denotados por $r_{i}$ :

$$
r_{i}=\hat{y}_{i}-\hat{\mu}_{i}-\hat{\beta} x_{c i}
$$

No segundo estágio, $r_{i}$, a estimativa do resíduo do modelo no primeiro estágio, será considerado como o novo fenótipo (considerado observado) para ser analisado sob a abordagem univariada de mapeamento genético.

$$
r_{i}=\mu_{r}+a_{r} X_{a i}+d_{r} X_{d i}+\sum_{l}^{t}\left(a_{r l} x_{a i l}+d_{r l} x_{d i l}\right)+e_{r i}
$$


Nota-se que as análises via a variável $Y_{D I F}$, descritas na seção anterior, são um caso particular do ajuste por covariáveis fixando $\beta=1$.

Para este caso específico ao se ajustar um fenótipo como covariável é possível conhecer a sua contribuição na deteção de possíveis QTL's, ou ainda, pode-se encontrar novas evidências de algum QTL na região mapeada (Amos et al. 2001). A seguir, considera-se uma estratégia de análise para a inclusão ou não de um fenótipo como covariável:

- Se o efeito do QTL decresce significativamente no modelo 4.8, comparado com o modelo sem a inclusão da covariável, isto significa que $X_{c}$ deveria ser ajustado nas análises conjuntas de mapeamento multivariado de $\left(Y, X_{c}\right)$;

- Se o sinal do QTL em 4.8 aumenta relativamente à análise sem a covariável, então, $X_{c}$ deverá ser usado como covariável e o mapeamento multivariado não é necessário.

- Se o sinal continua igual nos modelos com e sem a covariável, então há necessidade do mapeamento multivariado.

A especificação do modelo em dois estágios na análise de dados genéticos tem sido bastante explorado, possivelmente devido ao grande número de variáveis a serem consideradas ou devido a limitações computacionais. Wolfinger et al. (2001) propõe uma abordagem deste tipo no contexto de normalização de dados de microarrays. Yang (2003) e Wolfinger et al. (2001) citam que os resultados do ajuste em dois estágios e do modelo completo no caso de modelos mistos são próximos, principalmente em situações onde não há perda de dados. Cui \& Churchill (2003) concluem que a alternativa de análise em dois estágios quando aplicada a modelos com efeitos fixos produz resultados similares ao modelo em um único estágio.

\subsection{Análise utilizando a decomposição espectral}

A análise de componentes principais é uma técnica estatística que transforma linearmente um conjunto de $p$ variáveis correlacionadas em um conjunto com um número $p$ de 
variáveis não correlacionadas, em que cada variável explica uma parcela das informações do conjunto original. As $p$ variáveis originais $\left(Y_{1}, \ldots, Y_{p}\right)$ são transformadas em $p$ variáveis $\left(\tilde{Y}_{1}, \ldots, \tilde{Y}_{p}\right)$, denominadas componentes principais em que $\tilde{Y}_{1}$ explica a maior porcentagem da variabilidade total dos dados, $\tilde{Y}_{2}$ explica a segunda maior variabilidade e assim por diante. O conjunto das $p$ variáveis canônicas $\tilde{Y}$ pode ser reduzido, dado que algumas variáveis podem explicar uma parcela desprezível da variabilidade total. Existem vários critérios para a seleção do número de variáveis canônicas que dependem dos objetivos do pesquisador (Hastie et al. 2001). Em geral os principais objetivos deste tipo de análise são:

- Redução da dimensionalidade dos dados;

- Obtenção de combinações interpretáveis das variáveis originais;

- Descrição e entendimento da estrutura de correlação das variáveis.

A análise de Componentes Principais depende somente da matriz de covariância $(\boldsymbol{\Sigma})$ ou da matriz de correlação $\rho\left(X_{1}, \ldots, X_{p}\right)$ entre as variáveis. Não requer qualquer suposição sobre a forma da distribuição multivariada dessas variáveis, porém, se a normalidade nos dados é verificada, os resultados podem ser mais consistentes (Johnson \& Wichern, 1998).

Com base nessa teoria, Mangin et al. (1998) propuseram um método multivariado para o mapeamento de QTL's em dois passos: no primeiro passo, uma transformação canônica de $m$ traços é feita para se obter um conjunto de variáveis canônicas não correlacionadas, que estejam associadas aos traços originais. No segundo passo, cada variável canônica é então analisada pelo método de mapeamento por intervalo univariado como apresentado na Seção 3.1 ou por algum procedimento equivalente. Os testes da razão de verossimilhanças obtidos para cada variável canônica considerando as diferentes posições do cromossomo, são combinados para gerar um teste capaz de detectar QTL's com efeitos pleiotrópicos. Para este método de mapeamento conjunto onde são utilizadas as variáveis canônicas, os autores adotam uma população Backcross, mas nas aplicações deste trabalho adota-se uma população $F 2$. 
$Y_{n \times m}$ como em 3.15 denotará a matriz cujas $m$ colunas representam os fenótipos de $n$ indivíduos $F 2$ :

$$
Y=\left(\begin{array}{llll}
Y_{1} & Y_{2} & \ldots & Y_{m}
\end{array}\right)
$$

$\operatorname{com} \operatorname{Cov}(Y)=\boldsymbol{\Sigma}_{m \times m}$ definida como em 3.14

Pela decomposição espectral, a matriz $\boldsymbol{\Sigma}$ pode ser escrita como: $\boldsymbol{\Sigma}=P \wedge P^{\prime}$ onde

$$
P=\left(\begin{array}{llll}
V_{1} & V_{2} & \ldots & V_{m}
\end{array}\right)
$$

representa o conjunto dos $m$ autovetores e,

$$
\wedge_{n \times m}=\left(\begin{array}{cccc}
\lambda_{1} & 0 & \ldots & 0 \\
0 & \lambda_{2} & \ldots & 0 \\
\vdots & & \ddots & \vdots \\
0 & 0 & \ldots & \lambda_{m}
\end{array}\right)
$$

a matriz dos autovalores contidos na diagonal principal.

Seja $\tilde{Y}_{n \times m}$ a matriz cujas $m$ colunas representam as $m$ variáveis canônicas obtidas mediante a decomposição espectral da matriz $\boldsymbol{\Sigma}$, isto é,

$$
\tilde{Y}_{n \times m}=\left(\begin{array}{llll}
\tilde{Y}_{1} & \tilde{Y}_{2} & \ldots & \tilde{Y}_{m}
\end{array}\right)
$$

onde,

$$
\begin{gathered}
\tilde{Y}_{1}=V_{1}^{T} Y=v_{11} Y_{1}+v_{12} Y_{2}+\ldots v_{1 m} Y_{m}, \\
\tilde{Y}_{2}=V_{2}^{T} Y=v_{21} Y_{1}+v_{22} Y_{2}+\ldots v_{2 m} Y_{m}, \\
\vdots \\
\\
\tilde{Y}_{m}=V_{m}^{T} Y=v_{m 1} Y_{1}+v_{m 2} Y_{2}+\ldots v_{m m} Y_{m},
\end{gathered}
$$

tal que, $\operatorname{Var}\left(\tilde{Y}_{j}\right)=\lambda_{j}, \operatorname{Cov}\left(\tilde{Y}_{j}, \tilde{Y}_{k}\right)=0$ e $\operatorname{Cov}\left(\tilde{Y}_{j}, Y_{i}\right)=\rho_{\tilde{Y}_{j}, Y_{i}} \sqrt{\lambda_{j}} \sigma_{Y_{i}}$

O segundo passo é mapear os QTL's através de cada variável canônica $\tilde{Y}_{j}$, utilizando a 
metodologia de mapeamento por intervalo ou por algum procedimento equivalente. Para o estudo realizado no presente trabalho, procura-se variáveis canônicas com o intuito de encontrar QTL's que estejam associados às medidas de pressão arterial antes e após uma dose de sal. Cada variável canônica é considerada como um fenótipo e será analisada sob o modelo dado em 3.3 descrito para o mapeamento univariado.

A hipótese de interesse é a mesma do caso multivariado como descrito na Seção 3.2.2, hipóteses $H_{01}, H_{02}$ e $H_{03}$. Contudo a estatística do teste é construída a partir da análise univariada das variáveis canônicas.

\subsubsection{Teste para mapear QTL's com efeitos pleiotrópicos ou de interação gene $\times$ ambiente na análise canônica}

Como proposto em Mangin et al. (1998), o teste para mapear genes (QTL's) com efeitos pleiotrópicos (bem como a interação gene×ambiente) será descrito considerando um cromossomo para depois ser estendido ao genoma completo. Cada posição no cromossomo será denotada por $\pi$ e o mapeamento será realizado em cada posição $\pi_{1}, \pi_{2}, \ldots, \pi_{s}$, onde chama-se $\pi_{s}$ à última posição mapeada do cromossomo.

Considerando as variáveis canônicas representadas em 4.13, para cada uma delas é encontrado o teste da razão de verossimilhanças sob a hipótese nula. Seja $\tilde{L} R_{j}(\pi)$ denotar a estatística da razão de verossimilhanças da $j$-ésima variável canônica na posição $\pi$. Por exemplo, para o conjunto das $m$ variáveis canônicas e o cromossomo com $s$ posições são realizados $m \times s$ testes cuja formulação é representada na Tabela 4.1.

Percebe-se que cada coluna da Tabela 4.1 contém os testes da razão de verossimilhanças de todos os $m$ traços encontrados para uma posição específica $\pi_{i}$. O objetivo da aplicação do teste é encontrar a posição desse cromossomo cuja soma dos testes seja a maior possível (análise da última linha da Tabela 4.1).

Neste caso, a combinação da informação das várias posições (teste combinado) para encontrar um QTL com efeitos pleiotrópicos é definido em Mangin et al. (1998) como:

$$
\tilde{L R}=\operatorname{Sup}_{\left(\pi_{1} \leq \pi \leq \pi_{s}\right)} \sum_{j=1}^{m} L \tilde{R}_{j}(\pi) .
$$


Tabela 4.1 Testes estatísticos em cada posição de um determinado cromossomo

\begin{tabular}{ccccc}
\hline \hline \multirow{2}{*}{ Variáveis Canônicas } & \multicolumn{4}{c}{ Posições $\left(\pi_{1}, \pi_{2}, \ldots, \pi_{s}\right)$} \\
\cline { 2 - 5 } & $\pi_{1}$ & $\pi_{2}$ & $\ldots$ & $\pi_{s}$ \\
\hline$\tilde{Y}_{1}$ & $L \tilde{R}_{1}\left(\pi_{1}\right)$ & $L \tilde{R}_{1}\left(\pi_{2}\right)$ & $\ldots$ & $L \tilde{R}_{1}\left(\pi_{s}\right)$ \\
$\tilde{Y}_{2}$ & $L \tilde{R}_{2}\left(\pi_{1}\right)$ & $L \tilde{R}_{2}\left(\pi_{2}\right)$ & $\ldots$ & $L \tilde{R}_{2}\left(\pi_{s}\right)$ \\
$\vdots$ & $\vdots$ & & & $\vdots$ \\
$\tilde{Y}_{m}$ & $L \tilde{R}_{m}\left(\pi_{1}\right)$ & $L \tilde{R}_{m}\left(\pi_{2}\right)$ & $\ldots$ & $L \tilde{R}_{m}\left(\pi_{s}\right)$ \\
\hline \hline & $\sum_{j=1}^{m} L \tilde{R}_{j}\left(\pi_{1}\right)$ & $\sum_{j=1}^{m} L \tilde{R}_{j}\left(\pi_{2}\right)$ & $\ldots$ & $\sum_{j=1}^{m} L \tilde{R}_{j}\left(\pi_{s}\right)$ \\
\hline
\end{tabular}

Sob $H_{0}, \tilde{L R}$ é assintoticamente equivalente á estatística da razão de verossimilhanças no caso multivariado descrito em $3.16(\tilde{L R} \cong L R)$, a diferença entre os dois testes é uma variável aleatória que converge assintoticamente em probabilidade a zero (Mangin et al. 1998). A vantagem do teste via a análise canônica está na facilidade para encontrar as verossimilhanças para cada variável canônica utilizando análises univariadas. A aplicação deste método também traz vantagens porque a informação genotípica é separada através da informação que cada variável canônica contém permitindo uma interpretação melhor dos QTL's associados com os traços analisados.

Em Mangin et al. (1998) é mostrado que $\tilde{L R}$ é assintoticamente distribuído como o supremo de um processo $\chi^{2}$ sob $H_{0}$ e o supremo de um processo $\chi^{2}$ não central sob a hipótese alternativa.

Nota-se que o teste descrito em 4.14 é uma forma alternativa em que os autores abordam o problema de múltiplos testes apresentado no mapeamento genético. Mediante esta metodologia, onde para cada variável canônica é realizada uma varredura através de todo a genoma (cromossomo por cromossomo), múltiplos testes estão sendo realizados através de todas as posições em cada cromossomo, assim, ao tomar o Sup de todas as somas sobre todas as variáveis canônicas para as posições fixas, um problema multidimensional é transformado em um problema unidimensional.

Os autores discutem também que um loco com efeitos pleiotrópicos (ou efeitos de interação gene $\times$ ambiente) "pequenos" para ser detectado mediante a análise univarada pode ser detectado com a ajuda das análises multivariadas no caso de satisfazer a condição 
mais favorável para a análise conjunta $\left(\rho a_{1} a_{2}<0\right)$ ou $\left(\rho d_{1} d_{2}<0\right)$. O problema mais sério encontrado na análise combinada com variáveis canônicas surge quando são observados dados faltantes; se este número é desprezível, opta-se por fazer as análises eliminando os indivíduos com dados faltantes; caso contrário, os dados faltantes podem ser substituídos pela média empírica do correspondente traço, no entanto isto pode causar um viés na estimação do efeito do QTL. 


\section{Capítulo 5}

\section{Ferramentas gráficas no mapeamento genético}

\begin{tabular}{r}
\hline \\
"Um gráfico pode valer mais \\
que mil palavras, mas pode tomar \\
muitas palavras para fazê-lo" \\
(Tukey)
\end{tabular}

Os métodos gráficos têm encontrado um uso cada vez maior em estatística devido ao seu forte apelo visual. Normalmente, é mais fácil para qualquer pessoa entender a mensagem de um gráfico que aquela apresentada na forma de tabelas ou resumos numéricos (Tukey, 1977).

Os gráficos são usados para diversos fins (Chambers et al. 1983):

- Buscar padrões e relações;

- Confirmar (ou não) certas expectativas que se tenha sobre os dados;

- Descobrir novos fenômenos;

- Confirmar (ou não) suposições feitas sobre os procedimentos estatísticos usados;

- Apresentar resultados de forma mais rápida e fácil.

Neste capítulo, apresentam-se algumas ferramentas gráficas úteis na procura por algumas evidências de genes que regulam um traço ou vários traços simultaneamente. Em primeiro lugar, são apresentados os gráficos comumente utilizados no caso univariado tais como boxplots, histogramas, gráficos de perfis de médias e gráficos para estudar as interações entre dois possíveis locos genéticos. Com respeito ao caso multivariado, não há na 
literatura ferramentas gráficas que possam ajudar na compreensão da regulação genética de vários fenótipos simultaneamente, contudo, neste capítulo são sugeridos alguns gráficos de perfis de médias para o estudo da interação gene×ambiente que podem ser estendidos para o estudo do efeito de pleiotropia.

\subsection{Análise Univariada}

Em relação à análise de dados genéticos, um dos objetivos principais é verificar se há evidência da participação de um gene na variação fenotípica. Para esse fim os gráficos podem ser úteis para descrever os possíveis padrões de regulação de genes oferecendo argumentos de como conduzir uma pesquisa.

Fenótipos qualitativos (como sexo, cor da pele, cor dos olhos, rugosidade das ervilhas, entre outros), bem como fenótipos quantitativos do tipo discreto que assumem poucos valores (como número de dedos, número de costelas, número de grãos na vagem) são, de maneira geral, considerados como monogênicos (Mendelianos), isto é, controlados por um único gene. Por outro lado, fenótipos quantitativos (como altura, peso, glicemia, triglicérides, área foliar, entre outros) são, em geral, considerados como controlados por muitos genes, por fatores ambientais e possíveis interações. Contudo, mesmo nestes casos, há interesse em identificar a participação de um gene com efeito maior sobre o fenótipo (denominado oligogene), e entender como se dá seu efeito sobre a variação fenotípica.

\subsubsection{Visualização da variação quantitativa. Histogramas e boxplots}

Um primeiro passo, uma vez coletados dados fenotípicos, é a construção de gráficos do tipo histogramas e boxplots para visualização do padrão de variação do fenótipo sob estudo. O interesse é a visualização da variação do traço em função de categorias genéticas observadas nos indivíduos da população. Este é um importante passo, pois as indicações resultantes desta análise, freqüentemente, têm um impacto na escolha da metodologia de inferência estatística a ser adotada. 
Quando um fenótipo está classificado de acordo com as categorias genotípicas $(m m, M m$, ou $M M)$ para um loco específico, é útil considerar os boxplots para conhecer a variabilidade do fenótipo nas três classes genotípicas, também, com o intuito de identificar indivíduos com respostas fenotípicas aberrantes e estudar cuidadosamente o comportamento deles, pois é possível que estas respostas "caudais" forneçam alguma informação genética relevante.

Os boxplots na Figura 5.1 estão representando os valores fenotípicos da variável $Y$ classificados segundo os genótipos $(m m, M m, M M)$ de um certo loco cromossômico. O padrão de variação das medianas dão a idéia de efeito de dominância positivo do gene sobre o fenótipo. Observa-se que para o genótipo $M m$, os dados apresentam mediana mais próxima de $m m$ do que o grupo $M M$. Os valores dos dados para os indivíduos com genótipo $M M$ são mais altos que os valores para os indivíduos com genótipos $M m$ e $m m$. Deste modo há indicação de efeito aditivo do gene já que o valor mediano do fenótipo nas categorías $m m$ e $M m$ são bem diferentes. Ainda, há indicação da presença de valores discrepantes para as categorias $M m$ e $M M$. Omitindo estes valores, o padrão de homocedasticidade parece ser apropriado para estes dados.

Figura 5.1 Variabilidade fenotípica segundo as categorias genotipicas (mm, Mm e $M M$ ).

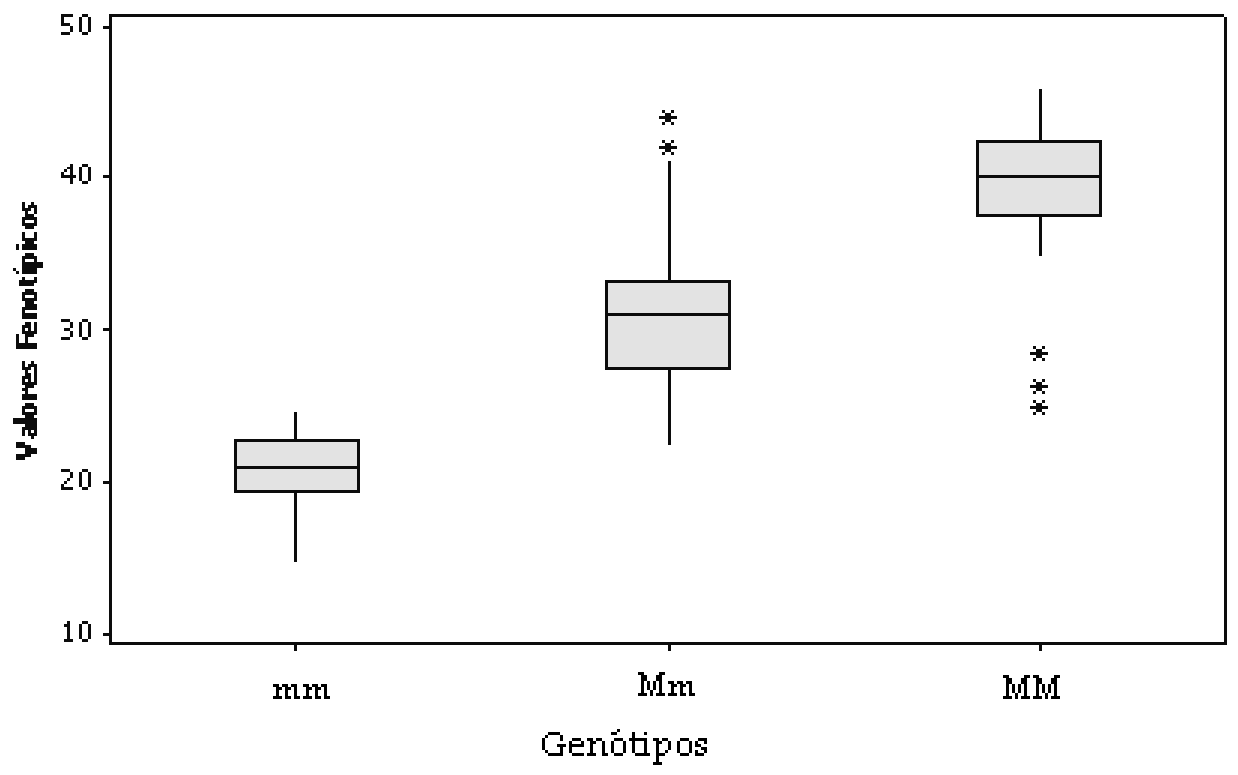


Gráficos deste tipo podem ser usados para ilustrar outros cenários, em que o gene apresenta efeito exclusivamente aditivo, exclusivamente de dominância ou mesmo não tem nenhum efeito sobre o fenótipo. Na próxima seção retoma-se este tema.

Com respeito ao fenótipo quantitativo, o qual tem uma distribuição contínua (por exemplo, nível de colesterol no sangue, o peso ou índice de massa corpórea), havendo interesse na identificação de um oligogene ou um único gene de maior efeito controlando o traço, em adição aos boxplots outros métodos gráficos como histogramas podem ser adotados para caracterizar simetria, curtose e identificar valores aberrantes.

A distribuição de traços quantitativos, em geral, é assumida como seguindo uma única distribuição Normal. No entanto, na população, a distribuição do traço condicional ao genótipo do indivíduo em algum loco de interesse é esperada seguir o modelo de mistura de distribuições normais (dois componentes no caso de locos que segregam de forma dominante ou recessiva e três componentes no caso de locos codominantes). A mistura pode ser bimodal, unimodal ou assimétrica como apresentado na Figura 5.2 (Balding et al. 2003).

A Figura 5.2(a) claramente indica uma distribuição bimodal para uma população duplohaplóide, pois a mistura de genótipos cai dentro de 2 diferentes grupos homozigotos, os quais podem ser nomeados $m m$ e $M M$, respectivamente.

A Figura 5.2(b) indica um histograma com uma distribuição unimodal para uma população F2. Esta distribuição representa o caso de um gene codominante explicando a metade da variação total, em que a população segregante consiste de uma mistura de genótipos $M M, M m, m m$ na razão 1:2:1, respectivamente. Fenótipos que seguem um padrão de regulação genética deste tipo podem satisfatoriamente serem modelados por meio da suposição de uma única distribuição normal.

A Figura 5.2(c) indica outro histograma com uma distribuição unimodal para uma população $F 2$, mas, neste caso, a distribuição é assimétrica e sugere a ação de um gene recessivo, isto é, o valor esperado do traço é o mesmo para os genótipos $m m$ e $M m$ e aumenta na presença de duas cópias do alelo $M$. 
Figura 5.2 Modelos de mistura.

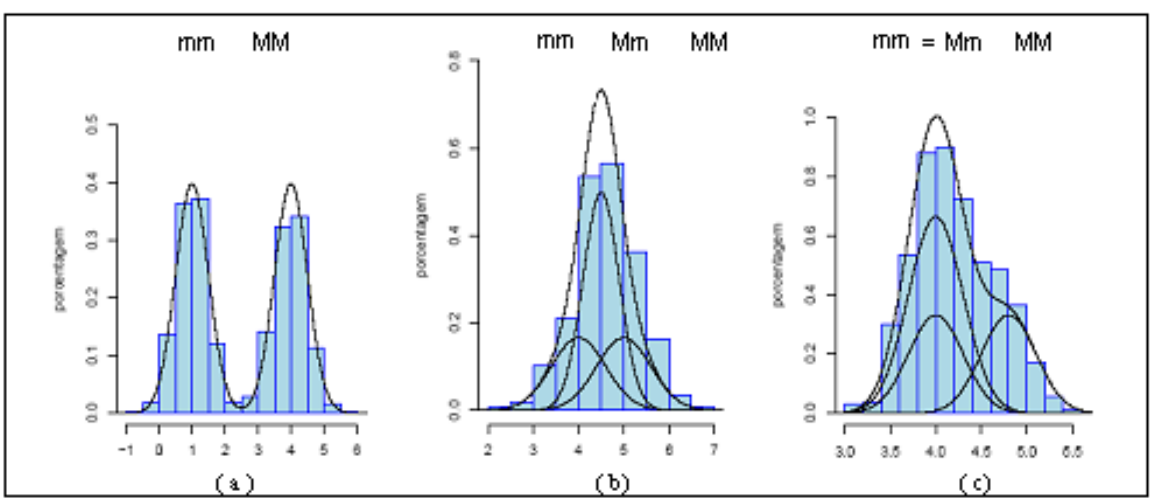

\subsubsection{Gráfico de colunas ou de perfis de médias}

Como descrito na Seção 2.5, os efeitos de um gene (codominante) são medidos por meio de dois componentes: efeito aditivo $(a)$ e de dominância $(d)$. Antes de ajustar um modelo genético aos dados, é importante entender os efeitos de um gene, em um loco cromossômico específico, sobre o fenótipo. Para esta finalidade, um gráfico útil é o gráfico de perfis de médias no qual é apresentado o perfil da variação da média fenotípica em cada classe genética, como ilustrado na Figura 5.3. (Em cada gráfico, da esquerda para a direita, as colunas representam as médias amostrais para as classes $m m, M m$ e $M M$, respectivamente.)

Na Figura 5.3(a) percebe-se linearidade no padrão de variação das médias o que indica que o efeito de dominância é nulo e, neste caso, o efeito aditivo é positivo, $(d=0, a>0$, pois $\left.\mu_{M M}>\mu_{m m}\right)$.

Na Figura 5.3(b) percebe-se uma fuga da linearidade devido ao genótipo do heterozigoto fazer com que a média fenotípica seja maior do que o esperado sob linearidade. Neste caso, os dois efeitos são positivos $(d>0, a>0)$.

Na Figura 5.3(c) também é observada fuga da linearidade por causa do genótipo do heterozigoto fazer com que a média fenotípica, neste caso, seja menor do que esperado sob linearidade, o efeito aditivo continua positivo e o efeito de dominância é negativo $(d<0, a>0)$. 
Figura 5.3 Perfis de médias para um loco cromossômico codominante, com genótipos $(m m, M m, M M)$.

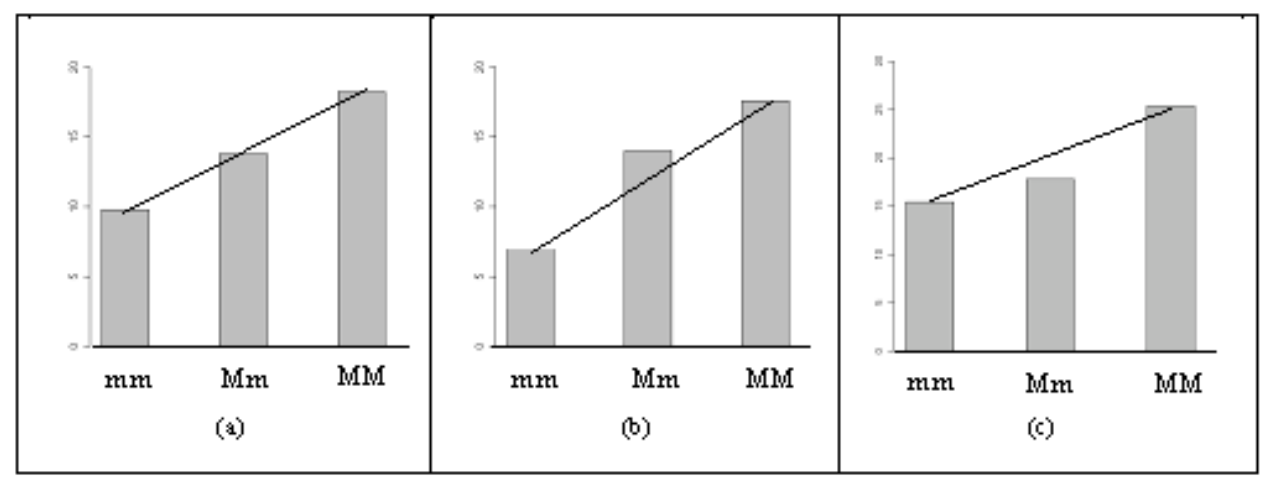

Nas três situações observa-se que o efeito aditivo é positivo, já que $\mu_{M M}>\mu_{m m}$ mas se fossem trocados os genótipos dos homozigotos o efeito aditivo seria negativo nas três situações.

\subsubsection{Gráficos para detectar interações entre genes}

Acredita-se que traços quantitativos são controlados por muitos genes que interagem entre si e com o ambiente. Modelos genéticos em geral estudam a participação de componentes oligogênicas (poucos locos de grande efeito agindo sobre o traço) e de componentes poligênicos (muitos locos de pequeno efeito), possíveis interações entre componentes genéticos, além de componentes ambientais, na regulação de traços quantitativos. A interação entre genes é conhecida como "epistasia", sendo o termo "epistasia" usado em genética para definir "dependência" entre genes em um contexto bem mais geral. Cordell (2002) e Moore (2005) abordam a polêmica envolvida na formulação desta definição por meio do uso de uma linguagem biológica, genética e estatística. Apesar de sua importância, não é objetivo deste trabalho dar ênfase a este tema e adota-se a formalização estatística de epistasia, em particular, sob modelos de regressão de efeitos fixos.

Muitos experimentos em genética, são realizados para estudar os efeitos produzidos por dois ou mais genes sobre um mesmo fenótipo quantitativo e a resposta fenotípica é investigada sob combinações dos níveis dos fatores genéticos. Por exemplo, se dois locos 
genéticos estão sendo estudados, loco $A$ e loco $B$, cada um em três níveis genotípicos ( $a a, A a, A A$ e $b b, B b, B B$, respectivamente), então a resposta fenotípica será avaliada em indivíduos pertencentes às 9 possíveis combinações dos níveis dos dois locos (ver Tabela 5.1). Assim, um delineamento balanceado com $r=10$ réplicas em cada grupo genotípico, deverá ter um total amostral de 90 indivíduos.

Figura 5.4 Interações epistáticas entre dois locos cromossômicos.

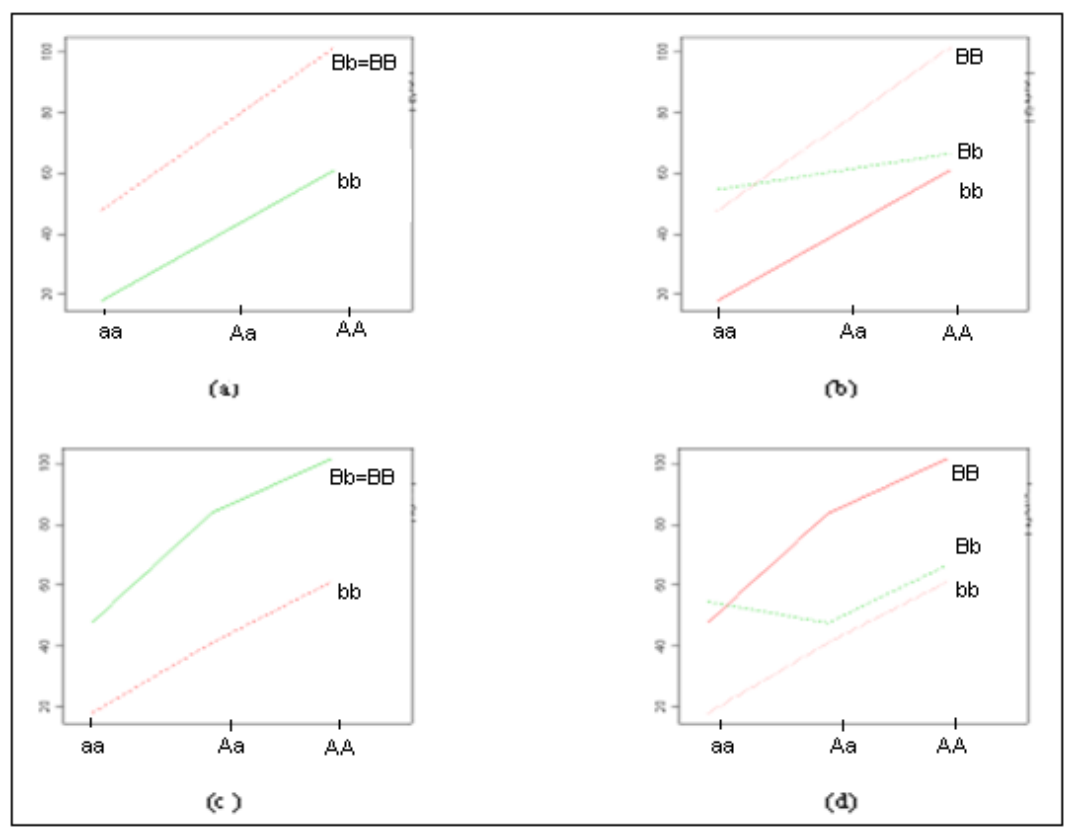

No contexto de delineamentos fatoriais, os genes interagem quando o "efeito" de um gene depende do genótipo do outro ou outros locos genéticos. Na Figura 5.4 são apresentados os tipos de interações epistáticas entre dois locos cromossômicos. Estes gráficos de perfis de médias fornecem ao pesquisador uma idéia geral do tipo de interação entre genes (Shimomura et al. 2001). Entre dois locos, ao se considerar a interação entre os possíveis efeitos aditivos e de dominância em cada loco, são encontradas 4 possíveis interações que podem ser analisadas: (a) aditivo/aditivo, $(b)$ aditivo/dominância, $(c)$ dominância/aditivo e (d) dominância/dominância (Kao \& Zeng, 2002) como apresentado na expressão 3.4. 
Tabela 5.1 Classes genotípicas para dois locos cromossômicos, loco A e loco B.

\begin{tabular}{llll}
\hline \hline & \multicolumn{3}{c}{ Loco A } \\
\cline { 2 - 4 } Loco B & $\mathbf{a a}$ & $\mathbf{A a}$ & $\mathbf{A A}$ \\
\hline $\mathbf{b b}$ & $a a b b$ & $A a b b$ & $A A b b$ \\
$\mathbf{B b}$ & $a a B b$ & $A a B b$ & $A A B b$ \\
$\mathbf{B B}$ & $a a B B$ & $A a B B$ & $A A B B$ \\
\hline \hline
\end{tabular}

\subsection{Análises bivariadas- Efeito de interação gene $\times$ ambiente}

Uma etapa importante na análise de um ajuste de regressão, é a verificação de possíveis afastamentos das suposições feitas para o modelo, bem como a existência de observações extremas com alguma interferência desproporcional nos resultados do ajuste. Esta etapa é conhecida como análise de diagnóstico e existem vários métodos para abordar este problema de valores discrepantes (por exemplo em Paula, 2004). No caso de análise de variáveis fenotípicas ainda não existem critérios claros sobre como tratar observações extremas, apesar de haver indicação de que estas contêm informações genéticas relevantes.

Como visto, um gene pode ter efeitos pleiotrópicos e isto gerar correlação. Além disso a correlação entre fenótipos pode se dar quando um perfil longitudinal de resposta é avaliado (um mesmo fenótipo avaliado em diferentes ambientes) ou também pode existir o fenômeno de ligação entre genes, o qual pode ser a causa de correlações (genéticas) entre os fenótipos. Há grande interesse no estudo e conhecimento da ação de genes nestas situações, muitas vezes utilizados como marcadores ou auxiliares na seleção e ou identificação de fenótipos mais complexos ou de difícil medição. Para abordar este problema no contexto de análise descritiva de dados, considera-se a situação de um mesmo fenótipo avaliado sob diferentes condições ambientais, por exemplo, a pressão sistólica avaliada antes e depois da intervenção de um medicamento. O objetivo é encontrar genes que são diferencialmente expressos em cada situação. Se esses genes têm uma manifestação diferente em cada condição avaliada (interação gene×ambiente) então sua caracterização, posição e efeitos 


\subsection{Análises bivariadas- Efeito de interação gene $\times$ ambiente}

serão conhecidos com maior facilidade. É útil então conhecer a variabilidade genética através das ferramentas estatísticas, em particular, ferramentas gráficas.

Para o estudo de interação gene×ambiente foi apresentado o modelo multivariado na Seção 3.2 e alguns modelos alternativos no Capítulo 4. O objetivo desta seção é explorar por meio de diagramas de perfis quais tendências e quais indivíduos, em geral, são os que favorecem o estudo do efeito da interação gene×ambiente no caso bivariado. Para isso, parte-se dos resultados já apresentados sobre a condição mais favorável para o ajuste multivariado na Seção 3.2.3, a saber $\rho a_{1} a_{2}<0$ onde, $a_{1}$ e $a_{2}$ representam o efeito aditivo do gene no ambiente 1 e no ambiente 2 , respectivamente.

Sejam os fenótipos $Y_{1}$ e $Y_{2}$ avaliados na condição 1 e na condição 2, considera-se em primeiro lugar o caso em que a correlação é positiva e depois o caso em que a correlação entre os traços é negativa.

\section{Correlação positiva entre os fenótipos $(\rho>0)$}

A Figura 5.5 corresponde ao diagrama de dispersão e ao diagrama de perfis no caso em que a correlação entre os dois traços hipotéticos é positiva $\rho\left(Y_{1}, Y_{2}\right)>0$.

No diagrama de dispersão, Figura 5.5(a), observa-se só alguns pontos que fogem do padrão de correlação linear positiva entre as respostas na condição 1 e 2. Na Figura 5.5(b), para o mesmo conjunto de dados é apresentado o gráfico de perfis para os indivíduos avaliados na condição 1 e na condição 2. Nota-se que a tendência dos perfis individuais é de aumentar na condição 2, percebe-se que os dois pontos discrepantes no diagrama de dispersão são capturados no diagrama de perfis.

Para a visualização gráfica, com o intuito de conhecer o sinal de $\rho a_{1} a_{2}$, assume-se uma possível categorização dos indivíduos em classes genotípicas $(m m, M m$ e $M M)$, de tal forma que os efeitos $a_{1}$ e $a_{2}$ estejam definidos e, como a correlação é assumida positiva, o critério é atingido quando os sinais dos efeitos aditivos tenham sinais opostos.

Suponha-se que os indivíduos avaliados nas duas condições estejam classificados segundo 


\subsection{Análises bivariadas- Efeito de interação gene $\times$ ambiente}

estas classes genotípicas e que as respectivas médias em cada classe sejam $\mu_{m m}, \mu_{M m} \mathrm{e}$ $\mu_{M M}$; também pode ser assumido que na condição 1 a média para a classe genotípica $M M$ seja maior que a média da classe genotípica $m m, \mu_{M M}>\mu_{m m}$, implicando que o efeito aditivo nesta condição é positivo $a_{1}>0$. De acordo com o diagrama de perfis na Figura 5.5(b) nota-se que como, em geral, a tendência dos valores fenotípicos é de aumentar no ambiente 2 , as médias em cada classe genotípica vão continuar obedecendo à mesma ordenação e, portanto, na condição 2 também o efeito aditivo é esperado ser positivo, isto é, $\mu_{M M}>\mu_{m m}$ implicando que $a_{2}>0$. Assim, onde todos os indivíduos têm a mesma tendência não há informação favorável para a análise conjunta já que $\rho a_{1} a_{2}>0$. Deste modo, no caso da correlação positiva, para encontrar-se sinais opostos dos efeitos aditivos para as análises bivariadas, questiona-se, como devem ser as tendências mostradas nos gráficos de perfis para atingir-se a situação mais favorável para a deteção de efeitos de interação gene×ambiente.

Figura 5.5 Diagramas de dispersão e gráfico de perfis indicando correlação positiva entre fenótipos

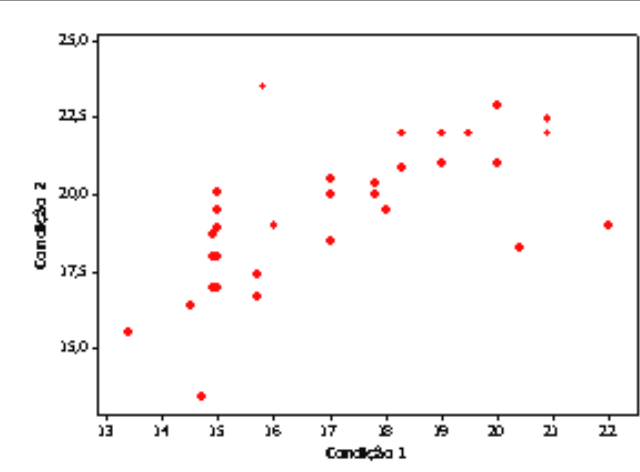

(a)

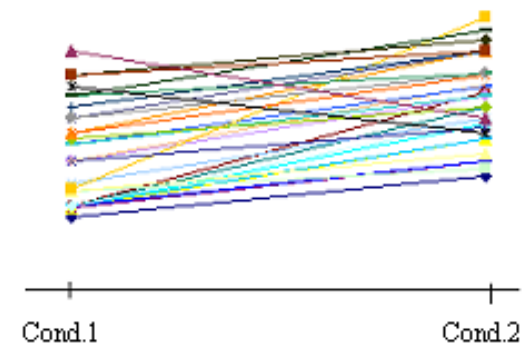

(b)

Na Figura 5.6 são apresentados dois diagramas de perfis para a amostra de indivíduos apresentados na Figura 5.5 mas, com a ressalva de que são incluídos alguns indivíduos que fogem do padrão de variação de correlação positiva, chama-se $Y_{1}^{\prime}$ e $Y_{2}^{\prime}$ a estes novos fenótipos.

Na Figura 5.6(a) observa-se que indivíduos com os valores mais altos na condição 1 apre- 


\subsection{Análises bivariadas- Efeito de interação gene $\times$ ambiente}

sentam uma queda drástica da resposta na condição 2. Suponha-se que esses indivíduos fazem parte da classe genotípica $M M$ tal que, $\mu_{M M}>\mu_{m m}$ na condição 1 , levando a que o efeito aditivo seja positivo $a_{1}>0$; já no ambiente 2, esse grupo de indivíduos classificados com genótipo $M M$ apresentam os valores mais baixos fazendo com que nesta condição $\mu_{M M}<\mu_{m m}$ e, então, o efeito aditivo é negativo, $a_{2}<0$, atingindo-se assim a condição procurada, efeitos aditivos com sinais opostos, tal que $\rho a_{1} a_{2}<0$.

Nota-se que para o caso apresentado na Figura 5.6(b), em que indivíduos com os valores mais baixos na condição 1 apresentam os valores mais altos na condição 2, sob as mesmas considerações que no caso anterior, no ambiente 1 tem-se $\mu_{M M}<\mu_{m m}$, o qual implica que $a_{1}<0$ e no ambiente 2 tem-se $\mu_{M M}>\mu_{m m}$, obtendo-se $a_{2}>0$. Também nesta situação o critério $\rho a_{1} a_{2}<0$ é atingido.

Ressalta-se que o conjunto de indivíduos que fogem da tendência geral de correlação positiva é um conjunto pouco numeroso de observações influentes. Estas observações permitem encontrar informação genética relevante para se atingir a condição mais favorável para explorar descritivamente o efeito de interação gene×ambiente. Com respeito às amostras, nota-se que ao incluir aqueles indivíduos que fogem do padrão de variação geral, a correlação entre os traços continua sendo positiva, $\rho\left(Y_{1}^{\prime}, Y_{2}^{\prime}\right)>0$, mas um pouco mais baixa que $\rho\left(Y_{1}, Y_{2}\right)$, ou seja, $\rho\left(Y_{1}^{\prime}, Y_{2}^{\prime}\right)<\rho\left(Y_{1}, Y_{2}\right)$.

Figura 5.6 Perfis individuais de resposta para fenótipos com correlação positiva.

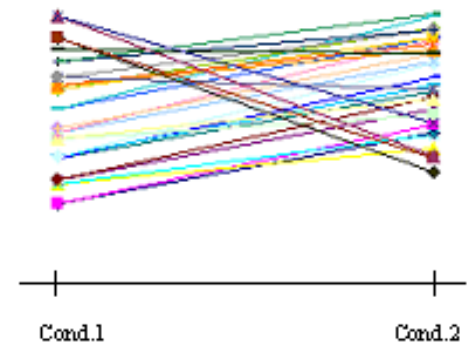

(a)

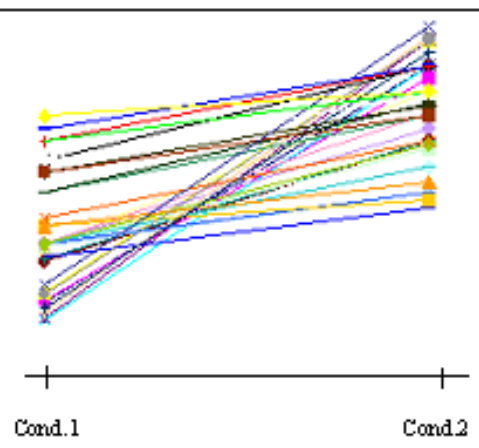

(b) 


\subsection{Análises bivariadas- Efeito de interação gene $\times$ ambiente}

Correlação negativa entre os fenótipos, $\rho\left(Y_{1}, Y_{2}\right)<0$

Quando a correlação entre fenótipos é negativa, para se atingir a condição mais favorável para a análise conjunta $\left(\rho a_{1} a_{2}<0\right)$ é necessário que os efeitos aditivos tenham sinais iguais nos dois ambientes.

Na Figura 5.7 é apresentado o diagrama de dispersão e o gráfico de perfis individuais para o caso em que a correlação entre os fenótipos na condição 1 e na condição 2 é negativa. Nota-se que, como esperado, a tendência geral no diagrama de perfis é de que indivíduos com valores altos no ambiente 1 apresentam valores baixos no ambiente 2 e vice-versa. Novamente, para introduzir informação genética à análise, é necessário que os indivíduos estejam categorizados segundo as classes genotípicas para algum loco sob estudo.

Suponha-se que na condição 1 os indivíduos com valores mais altos sejam da categoria $M M$. Claramente, $\mu_{M M}>\mu_{m m}$ o que implica que o efeito aditivo é positivo $a_{1}>0$ e, como na condição 2, estes indivíduos apresentam os valores mais baixos em geral, então $\mu_{M M}<\mu_{m m}$, e deste modo o efeito aditivo na condição 2 é negativo, $a_{2}<0$. Assim, neste caso em que a correlação entre os fenótipos é negativa, os sinais dos efeitos aditivos têm sinais opostos e nessa situação o critério $\rho a_{1} a_{2}<0$ não é atingido.

Figura 5.7 Diagramas de dispersão e gráfico de perfis indicando correlação negativa entre fenótipos.

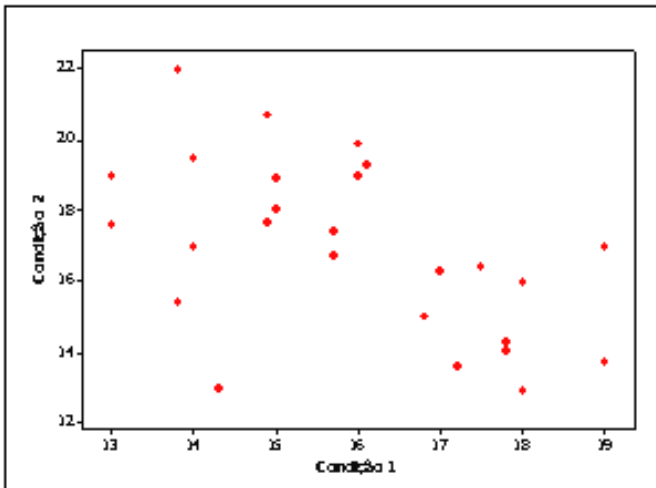

(a)

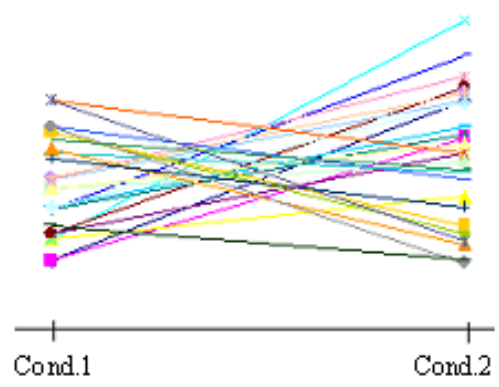

(b) 


\subsection{Análises bivariadas- Efeito de interação gene $\times$ ambiente}

Na Figura 5.8 são apresentados dois diagramas de perfis com alguns perfis que fogem do padrão dos demais, que mostram correlação negativa entre os fenótipos nas duas condições.

Na Figura 5.8(a) observa-se alguns indivíduos com os valores mais altos na condição 1 e também com os valores mais altos na condição 2. Na Figura 5.8(b) observa-se que alguns indivíduos com os valores mais baixos na condição 1 mantém também os valores mais baixos na condição 2 .

Para fazer as análises do ponto de vista genético, considera-se a Figura 5.8(a), supondo que os indivíduos estejam classificados segundo as categorias $(m m, M m$ e $M M)$ e que os indivíduos que fogem do padrão geral (de correlação negativa) fazem parte do grupo classificado como $M M$. Como estes indivíduos estão com os valores mais altos na condição 1, tem-se que $\mu_{M M}>\mu_{m m}$, e, portanto $a_{1}>0$. Na condição 2 , os valores destes indivíduos têm que ser suficientemente altos para que as médias fenotípicas dos homozigotos continuem com o mesmo padrão de ordenação e o sinal do efeito aditivo seja preservado, ou seja, $a_{2}>0$. Análises análogas para o gráfico de perfis na Figura 5.8(b) podem ser feitas, pois o sinal do efeito aditivo é negativo na condição 1 e na condição 2 (isto se é assumido que a amostra com os valores mais baixos façam parte da classe genotípica $M M$ ) e assim $\mu_{M M}<\mu_{m m}$ nas duas condições. Portanto, os indivíduos que fogem do padrão de correlação negativa geral permitem que os sinais sejam iguais para os efeitos aditivos nas duas condições, obtendo-se o critério desejado, $\rho a_{1} a_{2}<0$.

Figura 5.8 Perfis individuais de resposta para fenótipos com correlação negativa.

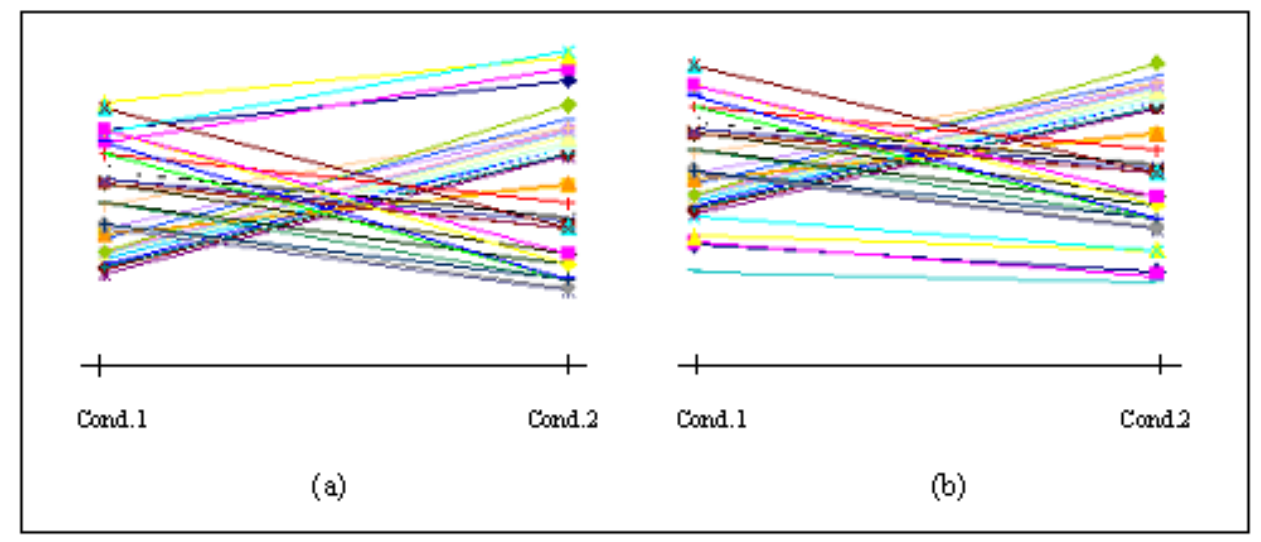




\subsection{Análises bivariadas- Efeito de interação gene $\times$ ambiente}

Nas análises anteriores, os indivíduos que fogem do padrão de correlação geral em cada caso podem ser classificados como discrepantes cujo perfil afeta, principalmente, o resíduo do modelo e em estatística vários métodos são encontrados para abordar as análises com este tipo de interferência (Osorio, 2006). Como estudado, do ponto de vista genético esses indivíduos discrepantes são os que permitem obter informações relevantes para as análises multivariadas sobre o efeito de interação gene $\times$ ambiente e é importante ter-se métodos de análise descritiva que permitam o diagnóstico deste tipo de situação amostral favorável ao ajuste de modelos para o estudo da interação gene×ambiente.

Com respeito à influência da correlação entre traços quando o objetivo é detectar genes com efeito de interação gene×ambiente, ou mesmo efeitos pleiotrópicos, resultados encontrados na literatura de modelos de componentes de variância genéticos indicam que a análise multivariada pode conduzir a ganho no poder quando a covariância genética devida a um QTL é negativa e a covariância (residual) entre os traços é positiva (Curtis \& de Andrade, 2003). Em Evans (2002) é demonstrado pela primeira vez, como o poder de uma análise de ligação bivariada depende não somente da magnitude da correlação entre as variáveis, mas também da origem desta correlação. Amos et al. (2001) e Evans, (2002) mostram que o enfoque multivariado é mais poderoso que a análise univariada, exceto para traços com correlação positiva excessivamente alta. Nota-se que essa foi a situação nas análises realizadas mediante os diagrams de perfis, pois se a correlação entre traços é muito alta não devem existir aqueles indivíduos discrepantes que fornecem informação à condição mais favorável para a análise multivariada.

Apesar desta seção ter sido desenvolvida para a interação gene×ambiente, os mesmos resultados podem ser aplicados ao problema de pleiotropia considerando que neste caso os gráficos de perfis devem ser construídos utilizando-se eixos verticais com escalas apropriadas a cada um dos fenótipos. Outra adaptação refere-se à interpretação dos parâmetros $a_{1}$ e $a_{2}$, que no caso de pleiotropia correspondem aos efeitos aditivos do QTL sobre cada traço. 


\section{Capítulo 6}

\section{Aplicações}

Nos Capítulos 3, 4 e 5 foram descritas algumas metodologias estatísticas, as quais são utilizadas no mapeamento de QTL's com efeitos pleiotrópicos e interação gene×ambiente. No presente capítulo são apresentados os resultados obtidos mediante a aplicação destas metodologias aos dados das medidas de pressão arterial de ratos da população $F 2$, descritos no Capítulo 1.

Os fenótipos que são utilizados nas análises são os seguintes:

$Y_{S B P}:$ medidas da pressão arterial sistólica dos ratos na condição basal;

$Y_{S B P S}:$ medidas da pressão arterial sistólica dos ratos após a intervenção com sal;

$Y_{\text {Captopril }}$ : medidas da pressão arterial sistólica após administrado o medicamento antihipertensivo chamado Captopril;

$Y_{D I F}=Y_{S B P S}-Y_{S B P}$ : diferença entre as medidas de pressão arterial sistólica antes e após a dose de sal;

$Y_{\text {DIFCapt }}=Y_{\text {Captopril }}-Y_{S B P S}$ : diferença entre as medidas de pressão arterial sistólica pós-sal e pós-medicamento.

Além destes fenótipos tomados do banco de dados são analisados outros fenótipos obtidos a partir do ajuste por covariáveis e do método da decomposição espectral como apresentado nas Seções 4.2 e 4.3, respectivamente.

Inicialmente são apresentadas as análises sob o modelo univariado das medidas de pressão $\left(Y_{S B P}, Y_{S B P S}, Y_{\text {Captopril }}\right)$, com o intuito de encontrar QTL's que são reguladores da pressão arterial. Na sequência será apresentado o diagrama de perfis e as análises sob o modelo multivariado das medidas de pressão antes e após a dose de sal, $\left(Y_{S B P}, Y_{S B P S}\right)$ 
junto com as abordagens alternativas, análise da diferença $Y_{D I F}$ entre as medidas de pressão, ajuste por covariáveis e o método da decomposição espectral.

Finalmente será apresentado o diagrama de perfis individuais com respostas em três etapas: antes do sal $\left(Y_{S B P}\right)$, pós-sal $\left(Y_{S B P S}\right)$ e pós-remédio $\left(Y_{\text {Captopril }}\right)$, como uma ferramenta informativa da tendência das medidas de pressão avaliadas nos três diferentes ambientes. Resultados da análise bivariada entre $Y_{S B P S}$ e $Y_{\text {Captopril }}$, assim como as análises das três variáveis sob modelos multivariados, também são apresentados.

Os coeficientes de correlação empírica das medidas de pressão sistólica são mostrados na Tabela 6.1. Observa-se que as correlações entre os fenótipos são positivos e , em geral, assumem valores de moderado a baixos.

Tabela 6.1 Correlação entre os fenótipos da pressão sistólica.

\begin{tabular}{ccc}
\hline \hline & $Y_{S B P S}$ & $Y_{\text {Captopril }}$ \\
\hline$Y_{S B P}$ & 0,423 & 0,382 \\
$Y_{S B P S}$ & & 0,573 \\
\hline \hline
\end{tabular}

A matriz de covariância amostral, $\hat{\Sigma}$, entre as medidas de pressão $Y_{S B P}, Y_{S B P S}$ e $Y_{\text {Captopril }}$ é dada por:

$$
\hat{\boldsymbol{\Sigma}}=\left(\begin{array}{ccc}
\sigma_{S B P}^{2} & \sigma_{(S B P, S B P S)} & \sigma_{(\text {SBP,Capt })} \\
\sigma_{(S B P, S B P S)} & \sigma_{S B P S}^{2} & \sigma_{(\text {SBPS,Capt })} \\
\sigma_{(\text {SBP,Capt })} & \sigma_{(\text {SBPS,Capt })} & \sigma_{(\text {Capt })}^{2}
\end{array}\right)=\left(\begin{array}{ccc}
234,786 & 101,898 & 110,883 \\
101,898 & 237,250 & 70,449 \\
110,883 & 70,449 & 153,313
\end{array}\right)
$$

\subsection{Resultados da análise univariada}

As medidas de pressão arterial sistólica dos ratos são analisadas em primeiro lugar sob 
o modelo univariado, dado na expresão 3.3 , tal que:

$$
\begin{aligned}
y_{S B P i} & =\mu_{S B P}+a_{S B P} X_{a i}+d_{S B P} X_{d i}+\sum_{l}^{t}\left(a_{S B P l} x_{a i l}+d_{S B P l} x_{d i l}\right)+e_{S B P i} ; \\
y_{S B P S i} & =\mu_{S B P S}+a_{S B P S} X_{a i}+d_{S B P S} X_{d i}+\sum_{l}^{t}\left(a_{S B P S l} x_{a i l}+d_{S B P S l} x_{d i l}\right)+e_{S B P S i} ; \\
y_{\text {Capti }} & =\mu_{\text {Capt }}+a_{\text {Capt }} X_{a i}+d_{\text {Capt }} X_{d i}+\sum_{l}^{t}\left(a_{\text {Captl }} x_{a i l}+d_{\text {Captl }} x_{d i l}\right)+e_{\text {Capti }} .
\end{aligned}
$$

A seguir, nas Figuras 6.1, 6.2 e 6.3 são apresentados os perfis da estatística Lod score da análise de mapeamento genético para os fenótipos descritos anteriormente. Nos gráficos, o valor representado pela linha horizontal corresponde à estatística Lod score igual a 2,5 o qual foi sugerido por Kao et al.(1999) como um critério empírico de identificação de locos genéticos candidatos. (O problema de múltiplos testes e algumas alternativas de abordagem encontradas na literatura são apresentados no Apêndice B). Quando a estatística Lod score apresentar um valor maior que 2,5, para uma determinada posição, tem-se uma indicação de que o QTL deve estar naquela região cromossômica, com uma chance de um falso positivo menor que 0,001. A estatística Lod score presente na ordenada do gráfico corresponde ao teste $H_{0} \times H_{3}$ (ver a expressão 3.6) que equivale a testar simultaneamente se existe efeito aditivo ou de dominância do QTL. Na abscissa estão representados locos genéticos (marcadores) nos 21 cromossomos do genoma dos ratos.

Mediante as considerações feitas, observando a Figura 6.1, correspondente a $Y_{S B P}$ (pressão sistólica antes da dose de sal), nota-se que não existe sinal significativo de presença de QTL's, já que em todas as posições fixadas ao longo dos cromossomos, ao longo de todos os marcadores, a estatística Lod score é menor que 2,5. A Figura 6.2 corresponde a $Y_{S B P S}$ (pressão sistólica pós-sal) e, neste caso, há evidência para a presença de QTL's nos cromossomos 2, 4, 8 e 16 (e um efeito não muito acentuado no cromossomo 1), indicando que no teste $H_{0} \times H_{3}$ a hipótese $H_{0}$ tem sido rejeitada. Portanto, pelo menos um dos efeitos aditivos ou de dominância são significativos nessas posições. A Figura 6.3 corresponde ao fenótipo $Y_{\text {Captopril }}$, a qual indica a presença de sinal significativo de um QTL no cromossomo 4. 
Figura 6.1 Perfis da estatística Lod score sob o modelo univariado para $Y_{S B P}$.

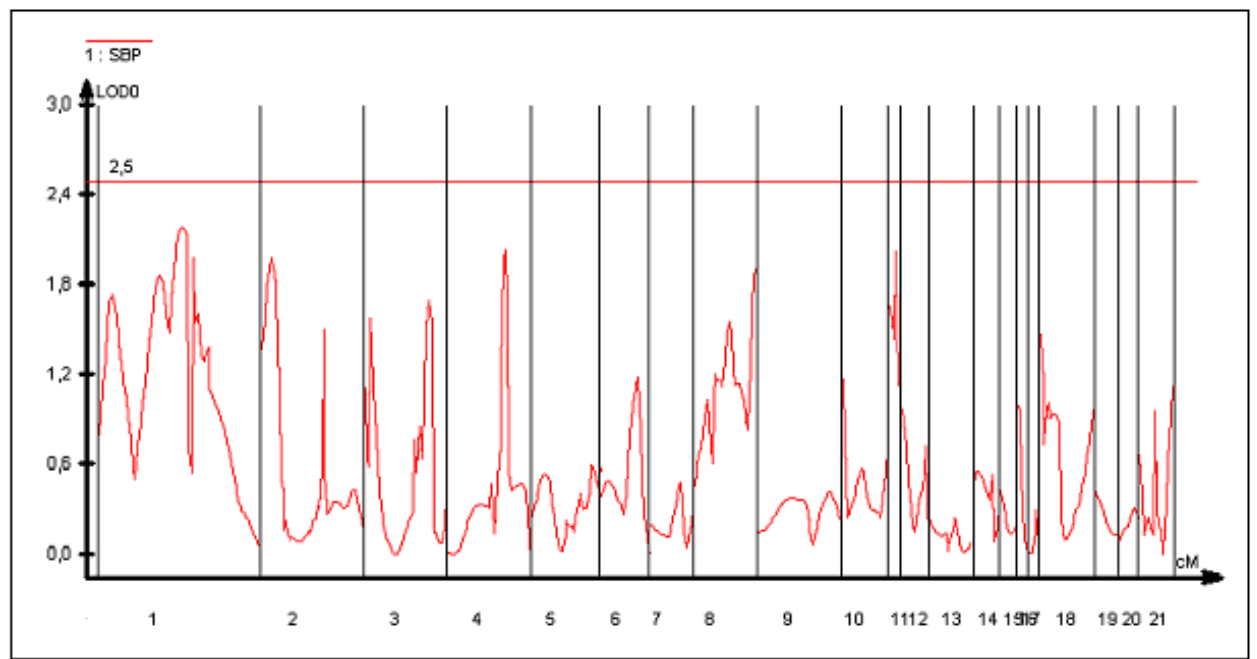

Figura 6.2 Perfis da estatística Lod score sob o modelo univariado para $Y_{S B P S}$.

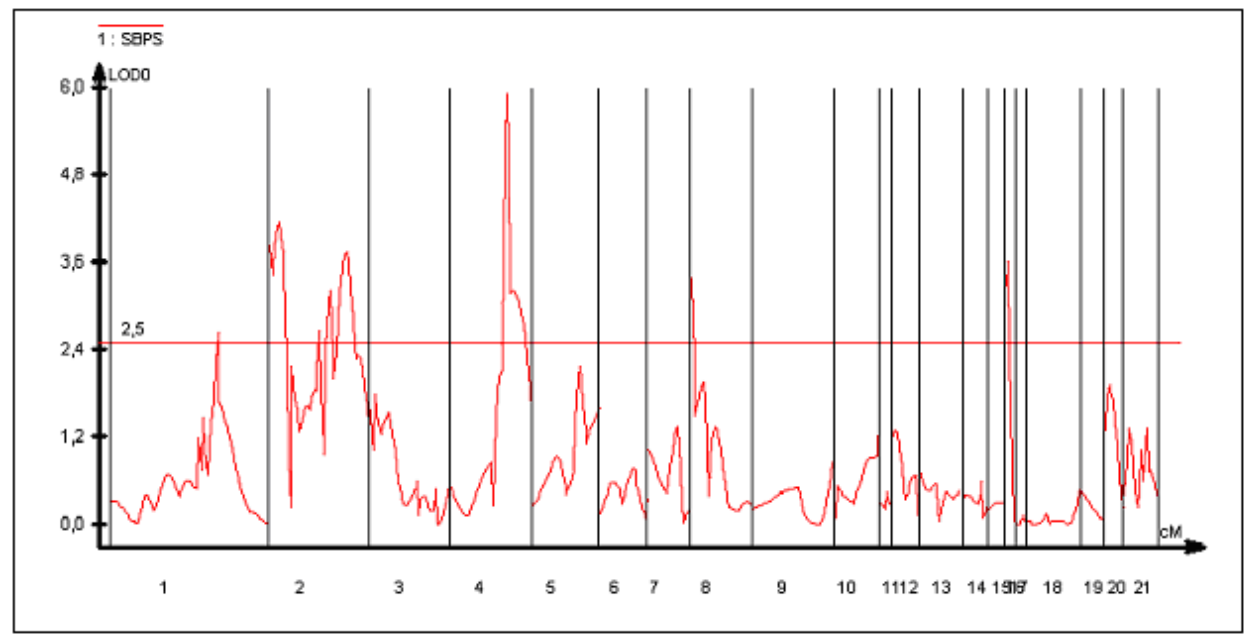

\subsection{Resultados da análise multivariada}

Inicialmente será aplicada a análise conjunta às medidas de pressão sistólica antes e após o efeito do sal, sob o modelo dado na expressão 3.13 para dois traços, $m=2$. $\mathrm{O}$ objetivo da análise é a identificação dos QTL's responsáveis pela resposta à sensibilidade ao sal, ou seja, interação gene×ambiente, assim como identificar QTL's reguladores da pressão arterial.

A Figura 6.4 apresenta os perfis individuais de resposta para os traços $Y_{S B P}$ e $Y_{S B P S}$. 
Figura 6.3 Perfis da estatística Lod score sob o modelo univariado para $Y_{\text {Captopril }}$.

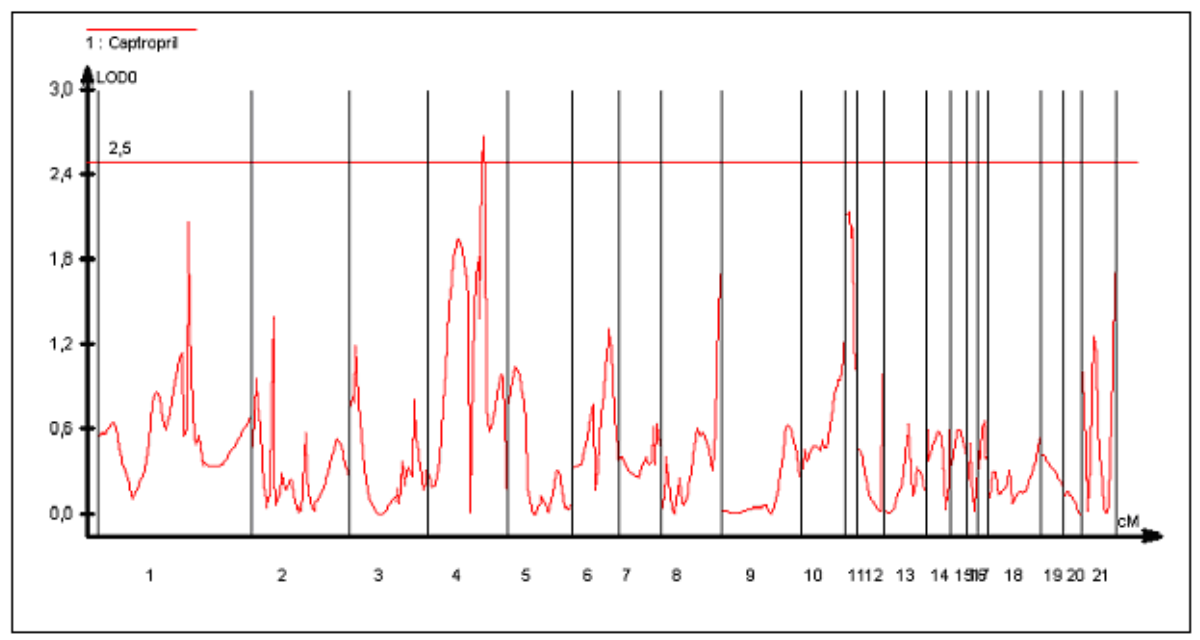

Nota-se que a tendência geral é de que a pressão aumenta com a exposição ao sal, mas, verifica-se que para alguns indivíduos cujos valores da pressão basal é muito alta houve uma diminuição marcante para os valores da pressão pós-sal, o que pode ser explicado pela presença de algum gene protetor, isto é, que regula aumentos muito elevados da pressão. Na Seção 6.4 será analisada, com mais detalhe, a influência destes indivíduos sobre os resultados, pois as medidas de pressão fogem da tendência geral de um padrão de correlação positiva e como sugerido na Seção 5.2, onde foram propostos alguns diagramas de perfis; este é um caso que favorece o estudo da interação gene×ambiente.

A resposta ao efeito do sal é vista por meio dos perfis individuais e esse comportamento conjunto das respostas $Y_{S B P}$ e $Y_{S B P S}$ é o que se pretende modelar por meio do mapeamento bivariado. As análises univariadas de cada traço (Figuras 6.1, 6.2 e 6.3) não consideram qualquer informação da mudança de comportamento da pressão do animal sob a exposição ao sal.

Na Figura 6.5 apresentam-se os gráficos de perfis da estatística Lod score da análise marginal de cada variável e da análise conjunta, para as variáveis $Y_{S B P}$ e $Y_{S B P S}$, respectivamente. Percebe-se que as análises marginais não são iguais às análises dos mesmos fenótipos no caso univariado apresentadas na Figuras 6.1 e 6.2, pois no caso da análise bivariada no teste dos efeitos genéticos leva-se em consideração a correlação existente en- 
Figura 6.4 Perfis individuais de resposta para a pressão sistólica antes e depois da exposição ao sal.

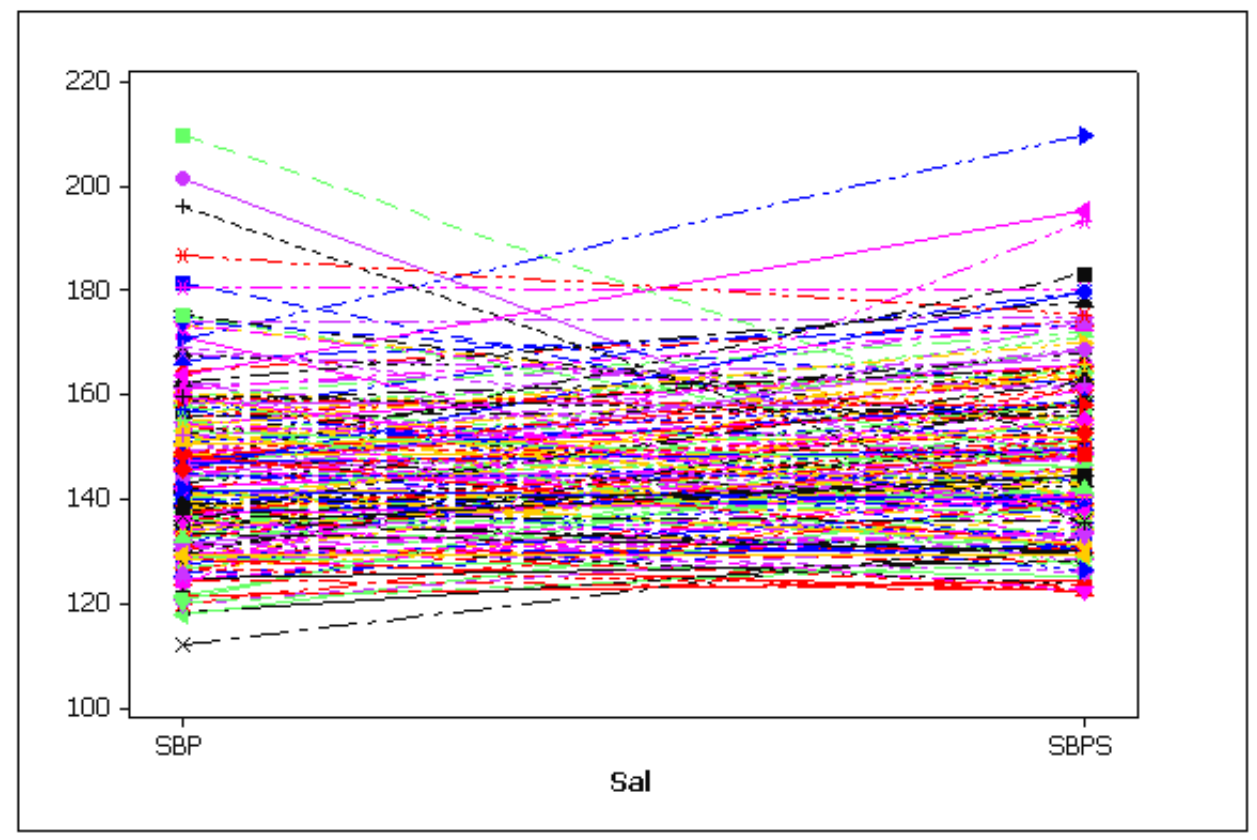

tre os fenótipos. Observa-se que para $Y_{S B P}$ no caso marginal o sinal de ligação aumentou nos cromossomos 1 e 2 (apesar de ser não significativo) e no cromossomo 4 o sinal de ligação diminuiu (ver Figuras 6.1 e 6.5(a)). Já com respeito ao fenótipo $Y_{S B P S}$ observa-se uma pequena diminuição no sinal de ligação no cromossomo 4 para o caso marginal (ver Figuras 6.2 e $6.5(\mathrm{~b}))$.

A Figura 6.5(c) apresenta os perfis da estatística Lod score da análise bivariada junto com os resultados das análises marginais já apresentados na mesma figura. Observa-se que a estatística da razão de verossimilhanças conjunta é maior ou igual à estatística da razão de verossimilhanças de cada traço individualmente, isto é, $L R_{12} \geq \operatorname{Máximo}\left(L R_{1}, L R_{2}\right)$ como visto na Seção 3.2.3. Percebe-se sinal de ligação significativo nos cromossomos 1, 2, $4,5,8,16$ e 21 .

Com respeito aos sinais detectados nos cromossomos 2, 4, 8 e 16, outros estudos já têm feito referência a essas regiões (Schork et al. 1995). Ressalta-se o fato de que o sinal no cromossomo 5 não é identificado nas análises univariadas (ver Figuras 6.1 e 6.2). A identificação deste novo QTL associado à sensibilidade ao sal das respostas de pressão 
Figura 6.5 Perfis da estatística Lod score para efeitos marginais e conjuntos sob o modelo multivariado
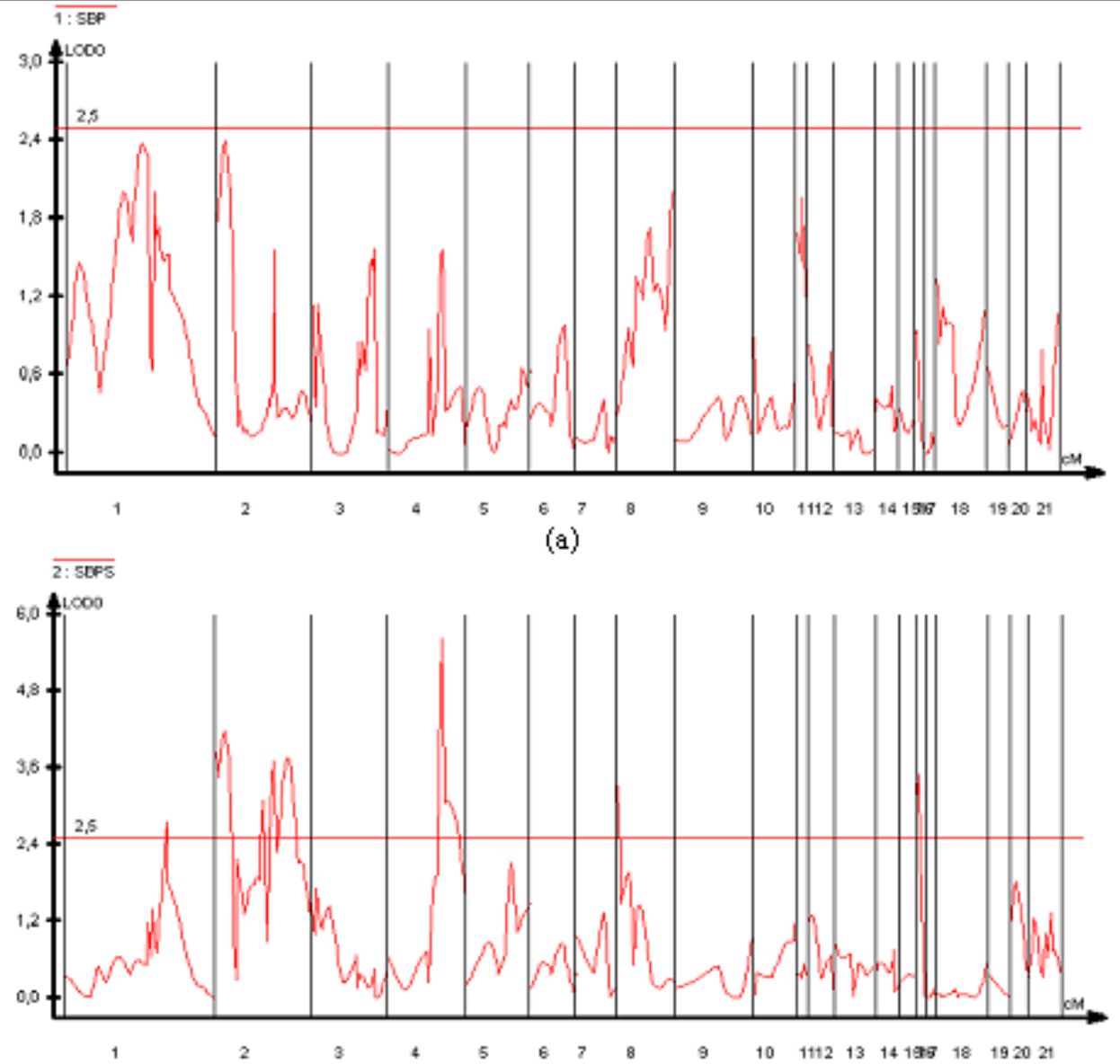

(b)

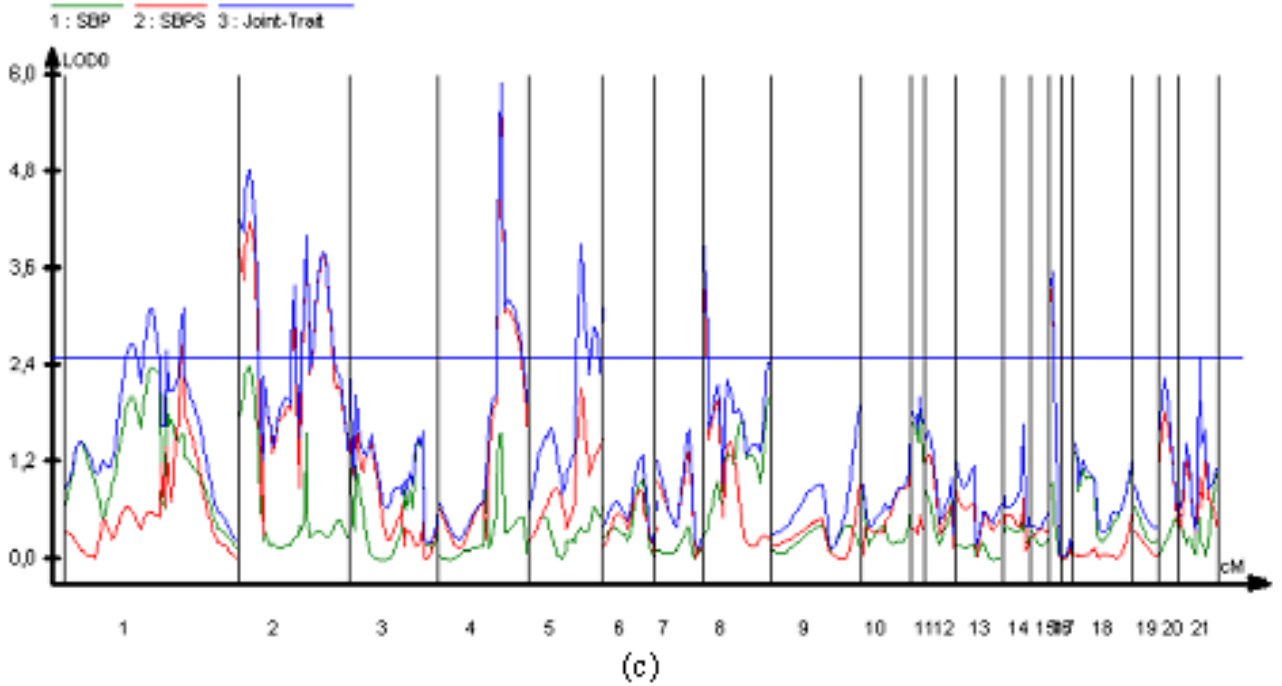


dos ratos é considerada em Soler et al. (2005). Quanto ao sinal detectado no cromossomo 21, precisa-se de estudos mais aprofundados por tratar-se do mapeamento do cromossomo sexual. Até agora, não é conhecido nenhum estudo que faça referência ao sinal detectado no cromossomo 1 para a pressão arterial.

Vários sinais de ligação entre o QTL e fenótipo foram encontrados significativos através do critério da estatística Lod score, o qual indica que pelo menos um dos efeitos aditivos ou de dominância dos QTL's são significativos naquelas regiões. Nas Tabelas 6.2 e 6.3 são apresentados os testes da razão de verossimilhanças, estimativas dos parâmetros dos efeitos aditivo e de dominância, no caso univariado e multivariado respectivamente, (em cada tabela, a coluna $M$ refere-se ao nome do marcador em que cada sub-índice representa o número do marcador no cromossomo em questão).

De acordo com a Tabela 6.2, nota-se que existem algumas posições que satifazem a condição mais favorável para a análise conjunta, ou seja, $\rho a_{1} a_{2}<0$ ou $\rho d_{1} d_{2}<0$ e, como conseqüência, o teste da razão de verossimilhanças conjunta é maior que a soma dos testes calculados para cada fenótipo no caso univariado $\left(L R_{12}>L R_{1}+L R_{2}\right)$. Para estes cromossomos e marcadores específicos os valores dados na Tabela 6.2 estão destacados em negrito. Por exemplo, para o cromossomo 5, marcador 8 (R589), $\hat{a_{1}}=-1,48, \hat{a_{2}}=6,041$, assim como $\hat{d}_{1}=3,16, \hat{d}_{2}=-5,07, L R_{1}=1,84 L R_{2}=10,11$ e na Tabela $6.3 L R_{12}=$ 18, 03 concordando com o exposto nas vantagens de mapeamento multivariado na Seção 3.2.3.

Continuando com os resultados apresentados na Tabela 6.2 (colunas $L R_{1}$ e $L R_{2}$ ), ressalta-se que os testes da razão de verossimilhanças são muito mais altos para as medidas da pressão arterial pós-sal $\left(Y_{S B P S}\right)$ em todas as posições, exceto na posição do cromossomo 1 marcador 5 (R1301).

Considerando a Tabela 6.3 (resultados obtidos mediante a análise conjunta e testes das hipóteses indicadas na Seção 3.2.2), ao comparar os efeitos de dominância na condição basal e pós-sal $\left(\hat{d}_{1}\right.$ e $\left.\hat{d}_{2}\right)$ percebe-se que a maior diminuição ao passar da condição basal à condição pós-sal, é no cromossomo 5. Nota-se também que para algumas posições ainda é 
Tabela 6.2 Testes da razão de verossimilhanças, estimativas dos efeitos aditivo e de dominância para $Y_{S B P}$ e $Y_{S B P S}$ no caso univariado.

\begin{tabular}{|c|c|c|c|c|c|c|c|c|}
\hline \multirow[b]{2}{*}{$\mathrm{Cr}$} & \multirow[b]{2}{*}{ M } & \multirow[b]{2}{*}{ Posição } & \multicolumn{3}{|c|}{ SBP } & \multicolumn{3}{|c|}{ SBPS } \\
\hline & & & $\mathrm{LR}_{1}$ & $\hat{a_{1}}$ & $\hat{d}_{1}$ & $\mathrm{LR}_{2}$ & $\hat{a_{2}}$ & $\hat{d_{2}}$ \\
\hline \multirow{3}{*}{1} & $\mathrm{R} 1301_{M 5}$ & 0,72 & 9,78 & 6,52 & $-0,54$ & 2,80 & $-0,22$ & 4,50 \\
\hline & $\mathrm{IGF} 2_{M 12}$ & 1,00 & 6,38 & 1,28 & 3,65 & 12,16 & 1,35 & 5,21 \\
\hline & $\mathrm{R} 155_{M 3}$ & 0,13 & 7,96 & 5,58 & $-0,77$ & 16,28 & 6,91 & $-0,04$ \\
\hline 2 & FIBG $2_{M 21}$ & 0,71 & 1,51 & 2,77 & 0,29 & 17,24 & 10,01 & $-0,78$ \\
\hline 4 & $\mathrm{R} 514 \mathrm{a}_{M 6}$ & 0,53 & 9,36 & 6,31 & $-2,59$ & 27,30 & 10,44 & $-3,40$ \\
\hline 5 & $\mathrm{R} 589_{M 8}$ & 0,43 & 1,84 & $-1,48$ & 3,16 & 10,11 & 6,041 & $-5,07$ \\
\hline 8 & $\mathrm{R} 19 \mathrm{a}_{M 1}$ & 0,0001 & 2,13 & 1,03 & 1,85 & 15,54 & 7,68 & $-3,93$ \\
\hline 16 & $\mathrm{R} 762_{M 1}$ & 0,0001 & 4,56 & 3,88 & $-0,76$ & 15,07 & 7,06 & $-4,37$ \\
\hline
\end{tabular}

Tabela 6.3 Testes da razão de verossimilhanças, estimativas dos efeitos aditivo e de dominância para $Y_{S B P}$ e $Y_{S B P S}$, sob o modelo multivariado.

\begin{tabular}{|c|c|c|c|c|c|c|c|c|c|}
\hline \multirow[b]{2}{*}{$\mathrm{Cr}$} & \multirow[b]{2}{*}{ M } & \multirow[b]{2}{*}{ Posição } & \multicolumn{3}{|c|}{ SBP } & \multicolumn{3}{|c|}{ SBPS } & \multirow[b]{2}{*}{$\mathrm{LR}_{12}$} \\
\hline & & & $\mathrm{LR}_{1}$ & $\hat{a_{1}}$ & $\hat{d_{1}}$ & $\mathrm{LR}_{2}$ & $\hat{a_{2}}$ & $\hat{d_{2}}$ & \\
\hline \multirow{3}{*}{1} & $\mathrm{R} 1301_{M 5}$ & 0,72 & 10,76 & 6,80 & $-1,40$ & 2,67 & 1,66 & 4,12 & 14,27 \\
\hline & $\mathrm{IGF} 2_{M 12}$ & 1,00 & 7,01 & 3,67 & 3,87 & 12,68 & 4,29 & 5,63 & 14.32 \\
\hline & $\mathrm{R} 155_{M 3}$ & 0,13 & 8,62 & 4,72 & $-2,45$ & 16,35 & 6,27 & $-1,21$ & 18,24 \\
\hline 2 & FIBG $2_{M 21}$ & 0,71 & 1,31 & 2,90 & $-2,76$ & 17,16 & 8,24 & $-4,47$ & 17,35 \\
\hline 4 & $\mathrm{R} 514 \mathrm{a}_{M 6}$ & 0,53 & 7,16 & 4,58 & $-3,71$ & 25,92 & 9,30 & $-2,12$ & 27,18 \\
\hline 5 & $\mathrm{R} 589_{M 8}$ & 0,43 & 1,87 & 0,004 & 3,75 & 9,73 & 3,60 & $-4,41$ & 18,03 \\
\hline 8 & $\mathrm{R} 19 \mathrm{a}_{M 1}$ & 0,0001 & 1,31 & 1,53 & 1,82 & 15,29 & 5,69 & $-3,23$ & 17,83 \\
\hline 16 & $\mathrm{R} 762_{M 1}$ & 0,0001 & 4,25 & 3,11 & $-0,33$ & 14,73 & 4,95 & $-4,24$ & 15,60 \\
\hline
\end{tabular}

encontrado que os parâmetros apresentam sinais opostos (destacados em negrito), para o caso do cromossomo 5 marcador 8 (R589), no qual os efeitos de dominância do QTL sobre $Y_{S B P}$ e sobre $Y_{S B P S}$ apresentam sinais opostos $\left(\hat{d}_{1}=3,75, \hat{d}_{2}=-4,41\right)$. Considerando a definição do parâmetro de dominância (ver expressão 2.7) pode-se dizer que o efeito do sal afeta principalmente os indivíduos com genótipo heterozigoto relativamente àqueles com genótipo homozigoto no sentido de aumentar a média da pressão dos homozigotos.

Mediante as análises univariadas (Figuras 6.1, 6.2 e 6.3) não foi identificado sinal de 
ligação no cromossomo 5. Este loco cromossômico, sob as análises univariadas de $Y_{S B P} \mathrm{e}$ $Y_{S B P S}$, pode ser interpretado como um falso negativo (erro tipo II), já que somente nas análises bivariadas há poder para evidenciar um QTL nesse cromossomo. Em Turner et al. (2004) é descrito que a análise de ligação multivariada provê um enfoque para identificar genes influenciando dois ou mais traços correlacionados e que a maior vantagem sobre a análise univariada é o poder estatístico para identificar locos cujos efeitos são muito pequenos para serem detectados pelas análises univariadas.

\subsection{Análise da medida resumo diferença}

A análise do fenótipo diferença $Y_{D I F}$ entre as respostas de pressão, é feita com o intuito de acomodar a estrutura de dependência entre as medidas de pressão basal e pós-sal, por meio da análise univariada de uma medida resumo relevante à situação de respostas pareadas. A diferença entre as variáveis é dada por:

$$
Y_{D I F}=\left(y_{S B P S 1}-y_{S B P 1}, y_{S B P S 2}-y_{S B P 2}, \ldots, y_{S B P S n}-y_{S B P n}\right),
$$

e será analisada mediante o modelo univariado dado em 3.3 que pode ser escrito como:

$$
y_{D I F i}=\mu_{D I F}+a_{D I F} X_{a i}+d_{D I F} X_{d i}+\sum_{l}^{t}\left(a_{D I F l} x_{a i l}+d_{D I F l} x_{d i l}\right)+e_{D I F i} .
$$

Neste caso, pode-se considerar $\mu_{D I F}=\left(\mu_{S B P S}-\mu_{S B P}\right), a_{D I F}=\left(a_{S B P S}-a_{S B P}\right), d_{D I F}=$ $\left(d_{S B P S}-d_{S B P}\right)$ e $e_{D I F}=\left(e_{S B P S}-e_{S B P}\right)$.

Na Figura 6.6 apresenta-se o perfil da estatística Lod score para o mapeamento de genes envolvidos com a medida da pressão $Y_{D I F}$. O gráfico indica que um único QTL no cromossomo 5 na posição do marcador 8 (R589), é significativo. É interessante notar que o sinal encontrado mediante este novo fenótipo não é detectado nas análises univariadas dos correspondentes fenótipos $Y_{S B P}$ e $Y_{S B P S}$ (Figura 6.1 e 6.2), mas é detectado mediante o mapeamento conjunto das respectivas variáveis, já apresentado na Figura 6.5(c).

Na Tabela 6.4 apresenta-se a estatística do teste da razão de verossimilhanças, estimativas dos efeitos aditivo e de dominância para cada fenótipo nessa posição específica 
Figura 6.6 Perfis da estatística Lod score sob o modelo univariado para $Y_{D I F}$.

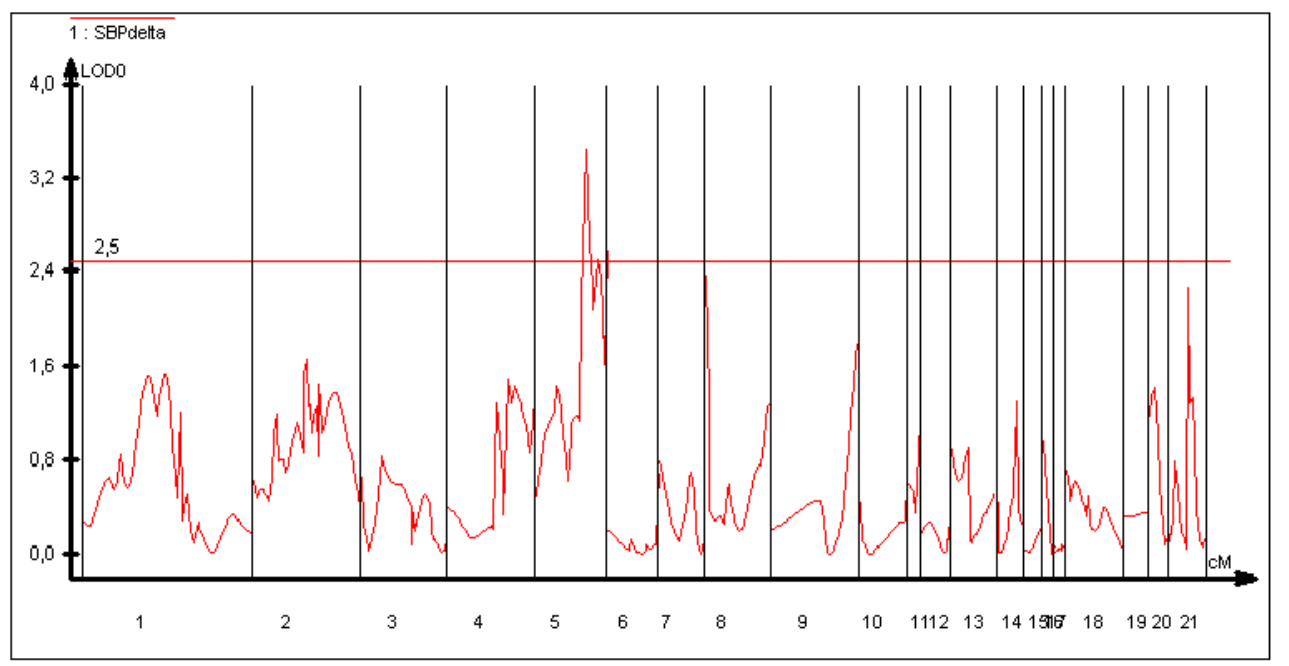

(cromossomo 5 marcador 8, R589). Comparando os resultados obtidos do ajuste univarado para $Y_{D I F}$ com os resultados obtidos para $Y_{S B P}$ e $Y_{S B P S}$ percebe-se que a estatística do teste da razão de verossimilhanças é mais alta para a variável $Y_{D I F}(15,87)$, o efeito aditivo é mais alto $(7,87)$ e o efeito de dominância é também muito mais alto em valor absoluto $(-8,27)$.

Tabela 6.4 Estatística da razão de verossimilhanças, estimativas dos efeitos aditivo e de dominância para o QTL sob o modelo univariado com alto sinal de ligação no cromossomo 5.

\begin{tabular}{cccc}
\hline \hline Variável & LR & Efeito Aditivo & Efeito de dominância \\
\hline $\mathrm{Y}_{S B P}$ & 1,84 & $-1,48$ & 3,16 \\
$\mathrm{Y}_{S B P S}$ & 10,11 & 6,04 & $-5,07$ \\
$\mathrm{Y}_{D I F}$ & $\mathbf{1 5 , 8 7}$ & $\mathbf{7 , 8 7}$ & $\mathbf{- 8 , 2 7}$ \\
\hline \hline
\end{tabular}

Como as estimativas dos parâmetros dos efeitos aditivos e de dominância dos fenótipos $Y_{S B P}$ e $Y_{S B P S}$ têm sinais opostos e sua magnitude é relativamente alta, então, era esperado que as magnitudes das estimativas dos parâmetros correspondentes para a diferença $Y_{D I F}$ fossem aumentados (destacado em negrito na Tabela 6.4). Tal aumento na magnitude das estimativas (e possível ganho em precisão envolvido na análise) permitiu que se atingisse significância na deteção deste QTL nas análises da interação gene×ambiente. Assim, o 
mapeamento genético da diferença entre as duas variáveis foi informativo para a identificação do QTL no cromossomo 5 na região próxima do marcador 8 (R589), pois como estabelecido na Seção 4.1, a diferença entre dois fenótipos (positivamente correlacionados) pode conduzir a um ganho em poder se os parâmetros das variáveis envolvidas têm sinais opostos.

\subsection{Influência de pontos atípicos sobre a pressão arte- rial}

Como observado no diagrama de perfis apresentado na Figura 6.4, o padrão geral é de correlação positiva entre os traços, mas existe um grupo de indivíduos que foge da tendência geral, isto é, indivíduos com pressão basal muito alta e que ao ingerir sal a pressão teve uma queda drástica, comportamento este diferente do padrão observado nas respostas da maioria dos indivíduos. Nesta seção essa amostra de indivíduos será analisada com o intuito de explorar com mais detalhe a existência de gene comprometido com a diminuição da pressão sob a exposição ao sal (interação gene×ambiente).

Analisando os dados das medidas de pressão arterial antes e após a dose de sal destes indivíduos discrepantes, tem-se que, para a amostra de 221 ratos há 21 observações faltantes, das 200 observações restantes, para 118 a pressão teve um aumento pós-sal e para 82 a pressão diminuiu. Ressalta-se que, dentre os 82 indivíduos em que a pressão diminuiu, encontra-se um grupo de 21 indivíduos os quais são os que apresentam a maior queda na pressão(entre 17 e 65 unidades).

Considerando o conjunto dos 21 indivíduos que apresentam a maior queda, a seguir, são feitas algumas análises com o intuito de conhecer especificamente sua influência nos padrões de regulação genética encontrados nas análises univariadas e bivariadas. Para isso, considera-se a variável $Y_{D I F}$ (diferença entre as medidas de pressão basal e póssal) e, desta variável, em primeiro lugar são retirados os 7 indivíduos com a maior queda, ficando com uma amostra de 193 indivíduos. Chama-se a esta nova variável $Y_{D I F 7}$. A seguir são retirados mais 7 indivíduos com respostas caudais, totalizando 14 indivíduos com a 
maior queda na pressão. A amostra a ser analisada é agora constituída de 186 indivíduos e denota-se esta variável por $Y_{D I F 14}$. Finalmente será retirado o conjunto completo dos 21 indivíduos, analisando-se uma amostra de 179 indivíduos, cuja notação neste caso será $Y_{D I F 21}$. Portanto, tem-se três variáveis $Y_{D I F 7}, Y_{D I F 14}$ e $Y_{D I F 21}$ que serão analisadas como a variável $Y_{D I F}$ através do modelo de regressão univariado descrito em 3.3.

Na Figura 6.7 são apresentados os perfis da estatística Lod score do mapeamento das variáveis descritas $\left(Y_{D I F}, Y_{D I F 7}, Y_{D I F 14}, Y_{D I F 21}\right)$. Observam-se mudanças no sinal de ligação no cromossomo 5 . Na Tabela 6.5 são apresentados, a estatística da razão de verossimilhanças, os efeitos aditivo e de dominância para as variáveis envolvidas nestas análises, para a posição fixa no cromossomo 5 marcador 8 (R589). Percebe-se que à medida em que é retirado cada grupo de indivíduos, o valor da estatística do teste da razão de verossimilhanças diminui nesta posição específica, considerando as duas primeiras figuras $\left(Y_{D I F}\right.$ e $\left.Y_{D I F 7}\right)$, tem-se que quando é retirado o primeiro conjunto de indivíduos ocorre uma pequena diminuição no sinal de ligação no cromossomo 5 , este valor muda de 15,87 para 15,09; o efeito aditivo diminui indicando que a diferença entre as médias dos homozigotos é cada vez menor e o valor do efeito de dominância aumenta. Retirando os outros conjuntos de indivíduos, $\left(Y_{D I F 14}\right.$ e $\left.Y_{D I F 21}\right)$, o sinal de ligação no cromossomo 5 diminui até não ser significativo $(L R<11,50$, equivalente a Lod score $<2,5)$. Estes resultados indicam a influência da presença de tais observações caudais na deteç̧ão de QTL sensível ao sal na situação experimental sob estudo.

Ressalta-se que foi realizado um exercício omitindo-se outros conjuntos de indivíduos típicos da amostra, mantendo-se na análise os 21 indivíduos atípicos já descritos e, neste caso, o sinal do QTL no cromossomo 5 manteve-se significativo (resultados não apresentados).

\subsection{Mapeamento usando ajuste por covariáveis}

De acordo com as análises feitas até agora, nota-se que a informação obtida pela análise conjunta captura mais os sinais de QTL's obtidos da análise com a variável $Y_{S B P S}$, do que 
Figura 6.7 Perfis da estatística Lod score sob o modelo univariado para $Y_{D I F}, Y_{D I F 7}, Y_{D I F 14} e$ $Y_{D I F 21}$.
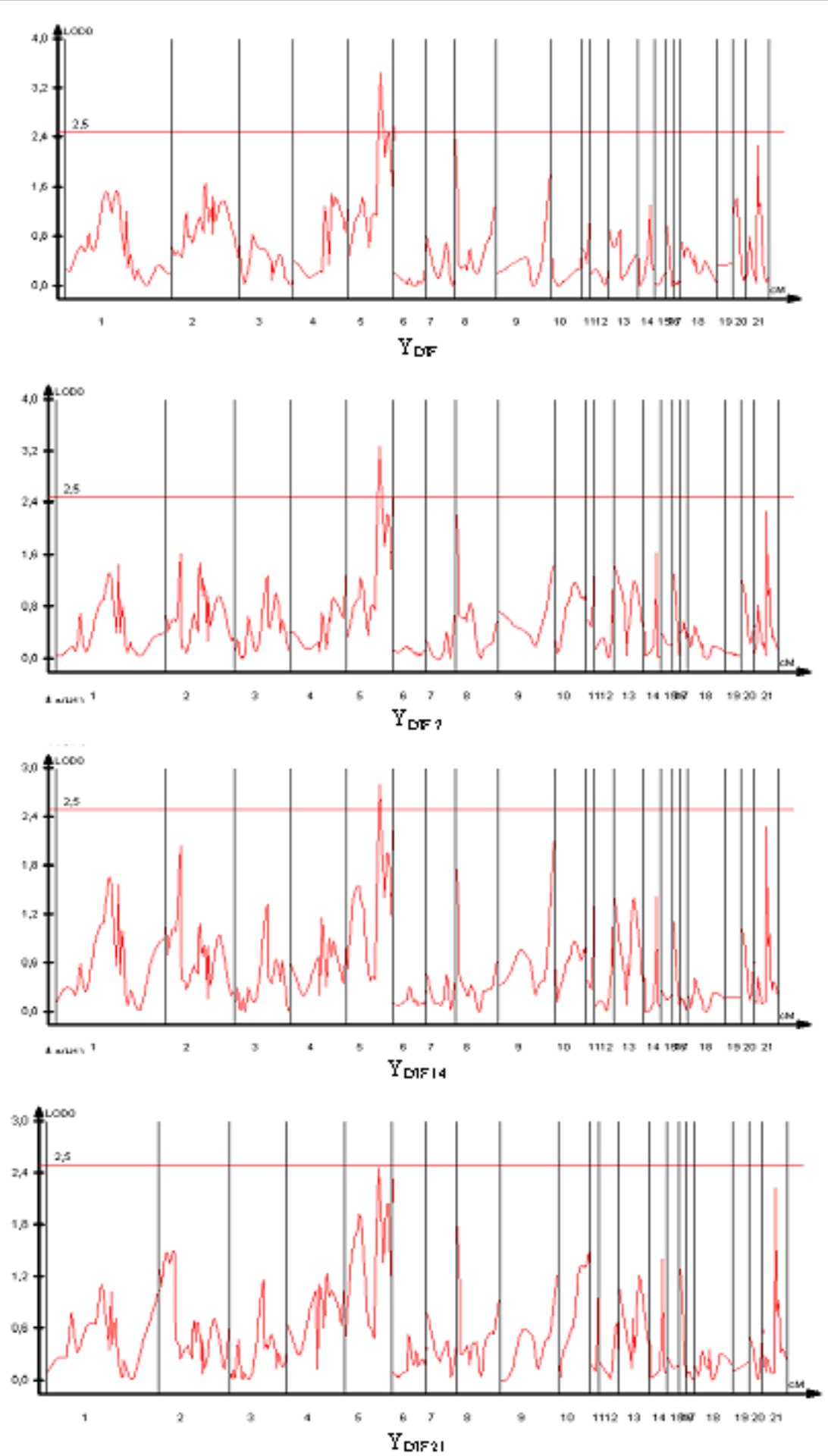
Tabela 6.5 Teste da razão de verossimilhanças, estimativas dos efeitos aditivo e de dominância para as variáveis $Y_{D I F}, Y_{D I F 7}, Y_{D I F 14}$ e $Y_{D I F 21}$.

\begin{tabular}{ccccc}
\hline \hline Variáveis & $\hat{a}$ & $\hat{d}$ & Lod score & LR \\
\hline$Y_{D I F}$ & 7,87 & $-8,27$ & 3,45 & 15,87 \\
$Y_{D I F 7}$ & 6,56 & $-7,53$ & 3,29 & 15,09 \\
$Y_{D I F 14}$ & 5,46 & $-6,21$ & 2,80 & 12,90 \\
$Y_{D I F 21}$ & 5,031 & $-5,057$ & 2,49 & 11,32 \\
\hline \hline
\end{tabular}

com aquela da variável $Y_{S B P}$ (ver Figura 6.5). Considerando as Tabelas 6.2 e 6.3, nota-se que os valores da estatística do teste da razão de verossimilhanças para $Y_{S B P S}\left(L R_{2}\right.$ na Tabela 6.2) são próximos dos valores para a análise conjunta entre $Y_{S B P}$ e $Y_{S B P S}\left(L R_{12}\right.$ na Tabela 6.3).

Para medir o efeito do sal na expresssão de possíveis QTL's associados com a regulação da pressão sistólica (efeito de interação gene×ambiente) inclui-se a variável $Y_{S B P}$ como covariável para o ajuste de $Y_{S B P S}$, ou seja, ajusta-se $Y_{S B P S}$ por $Y_{S B P}$ mediante o modelo de regressão dado em 4.6 denominado modelo completo e para este caso pode ser escrito como:

$$
y_{S B P S i}=\mu_{S B P S}+a_{S B P S} X_{a i}+d_{S B P S} X_{d i}+\sum_{l}^{t}\left(a_{l S B P S} x_{a i l}+d_{l S B P S} x_{d i l}\right)+\beta \underbrace{y_{S B P i}}_{\text {Covariável }}+e_{S B P S i},
$$

como descrito na Seção 4.3, as análises são realizadas em dois estágios:

- Primeiro estágio. Ajuste do modelo de regressão:

$$
Y_{S B P S}=\mu+\beta Y_{S B P}+\epsilon
$$

tal que obtém-se $r=Y_{S B P S}-\hat{\beta} Y_{S B P}$, em que $r$ representa os resíduos corrigidos pela constante $\hat{\mu}$. Ajustando este modelo aos dados, encontrou-se que:

$$
r=Y_{S B P S}-0,423 Y_{S B P}
$$

- Segundo estágio. Os resíduos estimados $r$, são considerados como o novo fenótipo 
o qual é analisado sob as considerações do modelo univariado cuja especificação é dada na expresão 4.8 .

A Figura 6.8 apresenta o perfil da estatística Lod score para a variável $r$. O gráfico sugere sinais de ligação nos cromossomos $2,4,5,8$ e 16 . Vale a pena lembrar, que o objetivo da análise que inclui $Y_{S B P}$ como covariável é olhar a contribuição das medidas da pressão basal na análise das medidas de pressão pós-sal e entender a utilidade deste modelo para a deteção de QTL que responde ao efeito do ambiente (interação gene×ambiente) Comparando o gráfico da Figura 6.8 do modelo do ajuste com a covariável com o gráfico da análise da variável $Y_{S B P S}$ (Figura 6.5(b)), percebe-se uma pequena diminuição nos sinais de ligação nos cromossomos 2, 4 e 16 e o sinal no cromossomo 1 desapareceu, possivelmente este seja um "QTL fantasma" ou que mereça um entendimento diferenciado.

Figura 6.8 Perfis da estatística Lod score sob o modelo univariado para $r$

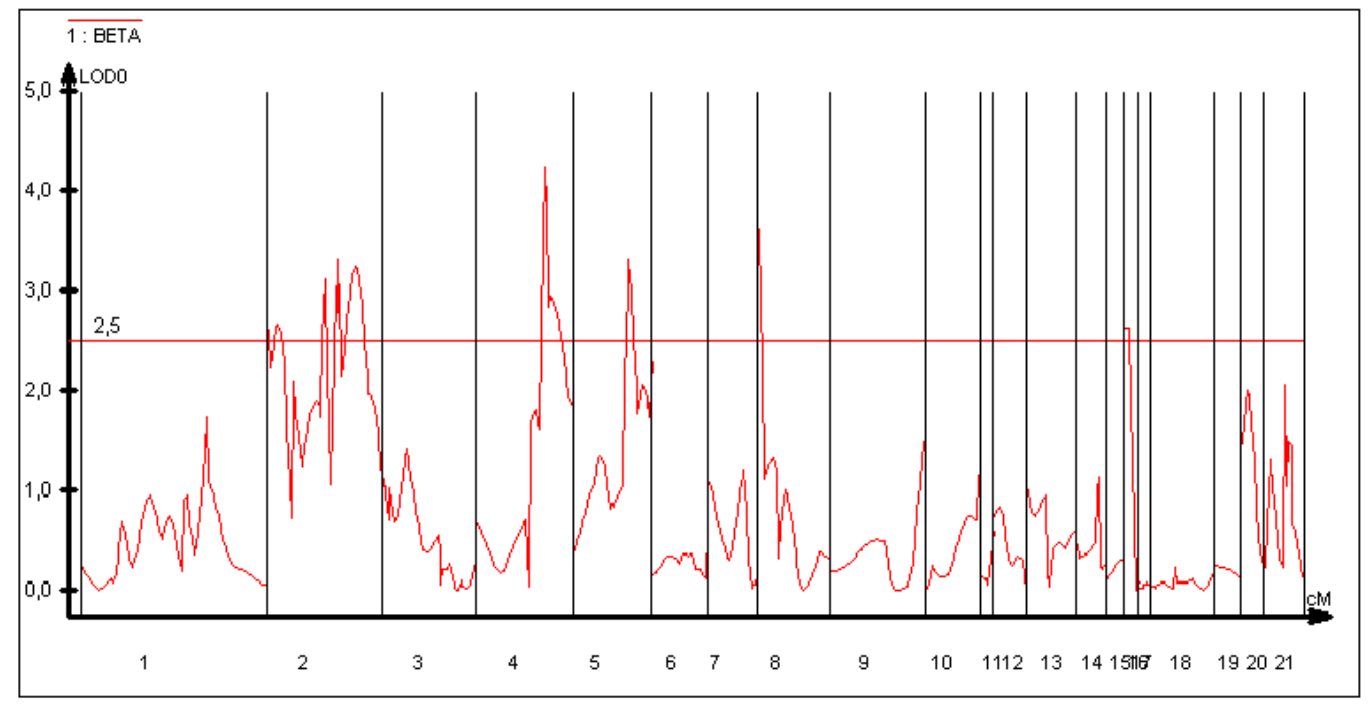

Na Tabela 6.6 apresentam-se a estatística do teste da razão de verossimilhanças, estimativas dos efeitos aditivo e de dominância para $r$ nas mesmas posições que para a análise de $Y_{S B P S}$. Olhando as Tabelas 6.2 e 6.6 nas colunas $L R_{2}$ para $Y_{S B P S}$ e $L R_{r}$ para $r$ respectivamente (nas posições onde o sinal de ligação foi significativo $L R>11,51$, ou seja, Lod score $>2,5)$ percebe-se uma pequena diminuição na $L R_{r}$ nos cromossomos 2, 4 e 16 e um aumento na $L R_{r}$ para o sinal no cromossomo 5 e 8 , sendo que o incremento 
mais alto é no cromossomo $5\left(L R_{2}=10,11, L R_{r}=15,30\right)$, alcançando significância como observado na Figura 6.8 .

Tabela 6.6 Testes da razão de verossimilhanças, estimativas dos efeitos aditivo e de dominância para $r$.

\begin{tabular}{|c|c|c|c|c|c|}
\hline \multirow[b]{2}{*}{$\mathrm{Cr}$} & \multirow[b]{2}{*}{ M } & \multirow[b]{2}{*}{ Posição } & \multicolumn{3}{|c|}{$r$} \\
\hline & & & $L R_{r}$ & $\hat{\hat{a}}$ & $\hat{d}$ \\
\hline \multirow{3}{*}{1} & $\mathrm{R} 1301_{M 5}$ & 0,72 & 3,05 & $-2,62$ & 4,40 \\
\hline & IGF $2_{M 12}$ & 1,00 & 8,11 & 0,64 & 4,08 \\
\hline & $\mathrm{R} 155_{M 3}$ & 0,08 & 12,56 & 5,48 & 1,072 \\
\hline 2 & FIBG $2_{M 21}$ & 0,71 & 15,32 & 7,88 & $-1,13$ \\
\hline 4 & $\mathrm{R} 14 \mathrm{a}_{M 6}$ & 0,53 & 18,78 & 7,34 & $-2,22$ \\
\hline 5 & $\mathrm{R} 589_{M 8}$ & 0,43 & 15,30 & 6,68 & $-6,12$ \\
\hline 8 & $\mathrm{R} 19 \mathrm{a}_{M 1}$ & 0,0001 & 17,09 & 7,27 & $-4,28$ \\
\hline 16 & $\mathrm{R} 762_{M 1}$ & 0,0001 & 12,08 & 5,63 & $-3,95$ \\
\hline
\end{tabular}

É conhecido que o valor de $\hat{\beta}=0,43$ maximiza os resultados quando $Y_{S B P}$ é ajustada como covariável para $Y_{S B P S}$. Nota-se que a variável $Y_{D I F}$, já analisada anteriormente, deu sinal de ligação significativo só no cromossomo 5. Observa-se que esta variável é um caso particular da análise do modelo com a covariável quando $\beta=1$, (expressão 6.3) pois $Y_{D I F}=Y_{S B P S}-1 Y_{S B P}$. Em resumo, temos a seguinte situação, quando $\hat{\beta}=0,43$ tem-se informação sobre os cromossomos 2, 4, 5, 8 e 16 (esta é a informação ao se incluir a $Y_{S B P}$ como covariável). Com $\beta=1$ os resultados são informativos só para o cromossomo 5 , então, questiona-se que informação pode ser obtida mediante o mapeamento de outros resíduos $r$ tomando diferentes valores para $\beta$.

Para responder a esta questão, são realizadas algumas análises com o intuito de conhecer como a detecção de QTL's varia com os resíduos ao se utilizar outros valores para $\beta$. Os valores de $\beta$ analisados são dados a seguir: 0,05, 0,10, 0,15, 0,20, 0,25, 0,30, 0,40, 0,50, 0,55, 0,60, 0,65, 0,75, 0,80,0,85,0,90, 0,95. Seguindo a metodologia da análise com a covariável $Y_{S B P}$ em cada caso, os "resíduos" obtidos no primeiro estágio são descritos por: 


$$
\begin{aligned}
r_{1} & =Y_{S B P S}-0,05 Y_{S B P}, \\
r_{2} & =Y_{S B P S}-0,10 Y_{S B P}, \\
r_{3} & =Y_{S B P S}-0,15 Y_{S B P}, \\
\vdots & \\
r & =Y_{S B P S}-\mathbf{0 , 4 2 3} Y_{S B P}, \\
\vdots & \\
Y_{D I F} & =Y_{S B P S}-1 Y_{S B P} .
\end{aligned}
$$

No segundo estágio, cada fenótipo encontrado em 6.4 é analisado sob o modelo descrito em 4.8. A Figura 6.9 apresenta os perfis da estatística Lod Score para todos os fenótipos descritos em função de $\beta$. Os gráficos sugerem um comportamento bem diferente entre os sinais de ligação apresentados nos cromossomos 2, 4, 8 e 16 quando comparados com o sinal apresentado no cromossomo 5. Percebe-se que à medida que o valor de $\beta$ aumenta para a unidade, os sinais nos cromossomos 2, 4, 8 e 16 são cada vez menos significativos enquanto o sinal no cromossomo 5 começa a ser significativo a partir do $\beta=0,15$. Nota-se que a partir de $\beta=0,80$ todos os sinais nos cromossomos 2, 4, 8 e 16 desaparecem, ficando só um sinal significativo no cromosomo 5 até o fenótipo da diferença $\left(Y_{D I F}\right)$.

Na Tabela 6.7 encontram-se os valores dados para $\beta$, a estatística do teste da razão de verossimilhanças junto com as estimativas dos efeitos aditivos e de dominância avaliados no cromossomo 5 marcador 8 (R589) e, na Figura 6.10, apresenta-se a tendência destes valores encontrados. Na Figura 6.10(a) apresenta-se valores de $\beta$ vs efeitos aditivos, notase que enquanto os valores de $\beta$ aumentam, os efeitos aditivos aumentam indicando que a diferença entre as médias dos homozigotos é cada vez maior. A Figura 6.10(b) apresenta valores de $\beta$ vs efeitos de dominância, observa-se uma relação inversa que indica que para este loco a média do heterozigoto é sempre menor que a média dos homozigotos. Identifica-se assim os indivíduos heterozigotos como os mais protegidos de ter sua pressão aumentada devido ao efeito do sal. A Figura 6.10(c) apresenta valores de $\beta$ vs $L R$, nota-se 
Figura 6.9 Perfis da estatística Lod score para todos os fenótipos obtidos mediante variações nos valores de $\beta$

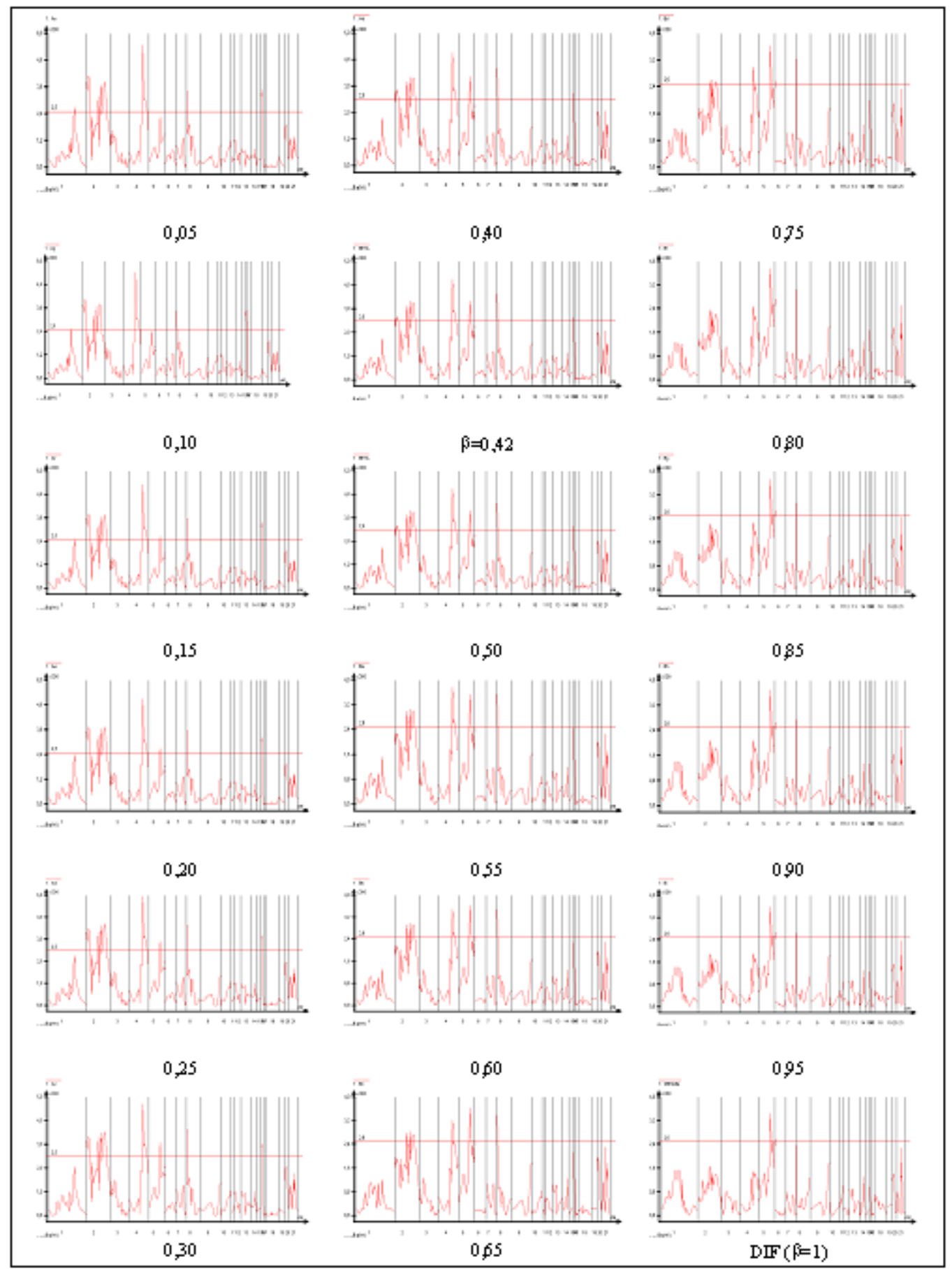


que o máximo é alcançado para o valor de $\beta=0,75$. A linha horizontal representa o valor de $L R=11,51$ que é equivalente 2, 5 na escala da estatística Lod score.

Pelos resultados obtidos, percebe-se que o QTL identificado no cromossomo 5 segue um comportamento bem diferenciado dos demais QTL's encontrados nos outros cromossomos, isto porque somente esse QTL responde ao efeito do sal (interação QTL×ambiente).

Tabela 6.7 Testes da razão de verossimilhanças, estimativas dos efeitos aditivo e de dominância para os fenótipos formados por meio dos diferentes valores de $\beta$.

\begin{tabular}{cccc}
\hline \hline Valores de $\beta$ & $\hat{a}$ & $\hat{d}$ & $\mathrm{LR}$ \\
\hline$(0,05)$ & 5,99 & $-5,01$ & 10,36 \\
$(0,10)$ & 6,08 & $-5,16$ & 11,14 \\
$(0,15)$ & 6,24 & $-5,44$ & 12,21 \\
$(0,20)$ & 6,20 & $-5,44$ & 12,48 \\
$(0,25)$ & 6,36 & $-5,66$ & 13,42 \\
$(0,30)$ & 6,47 & $-5,80$ & 14,11 \\
$(0,40)$ & 6,67 & $-6,15$ & 15,40 \\
$(\mathbf{0 , 4 2})$ & $\mathbf{6 , 6 8}$ & $\mathbf{- 6 , 1 2}$ & $\mathbf{1 5 , 2 8}$ \\
$(0,50)$ & 6,91 & $-6,47$ & 16,28 \\
$(0,55)$ & 7,02 & $-6,75$ & 16,71 \\
$(0,60)$ & 7,11 & $-6,90$ & 16,70 \\
$(0,65)$ & 7,18 & $-7,04$ & 16,72 \\
$(0,75)$ & 7,50 & $-7,56$ & 17,34 \\
$(0,80)$ & 7,59 & $-7,76$ & 17,11 \\
$(0,85)$ & 7,66 & $-7,89$ & 16,96 \\
$(0,90)$ & 7,73 & $-8,00$ & 16,53 \\
$(0,95)$ & 7,81 & $-8,14$ & 16,23 \\
$(\mathbf{1 , 0 0 )}$ & $\mathbf{7 , 8 7}$ & $\mathbf{- 8 , 2 7}$ & $\mathbf{1 5 , 8 7}$ \\
\hline \hline
\end{tabular}

Figura 6.10 Representação gráfica da tendência dos efeitos aditivos, de dominância e da estatística do teste da razão de verossimilhanças de acordo com $\beta$.

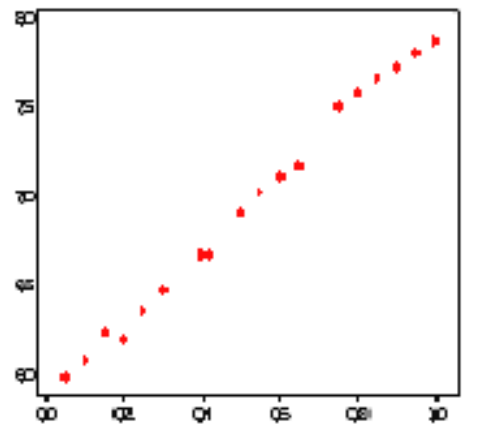

(a)

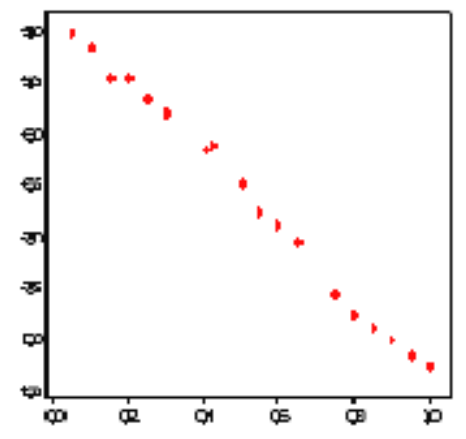

(b)

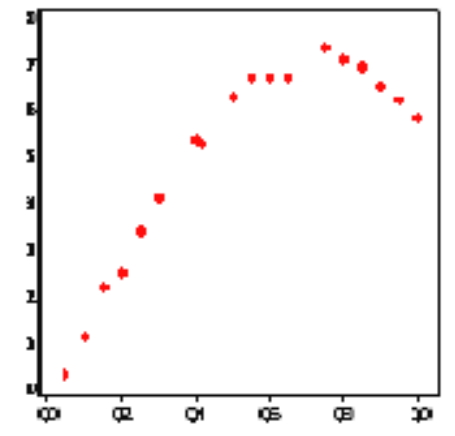

(c) 


\subsection{Aplicação do método de decomposição espectral}

A seguir a aplicação do método de componentes principais será apresentado, o intuito é obter combinações interpretáveis das variáveis $Y_{S B P}$ e $Y_{S B P S}$ que, possivelmente, auxiliam no entendimento da natureza dos QTL's identificados.

A matriz de covariância amostral, $\hat{\Sigma}$, entre as medidas de pressão $Y_{S B P}$ e $Y_{S B P S}$ é dada por:

$$
\hat{\Sigma}=\left(\begin{array}{cc}
\hat{\sigma}_{S B P}^{2} & \hat{\sigma}_{(S B P, S B P S)} \\
\hat{\sigma}_{(S B P, S B P S)} & \hat{\sigma}_{S B P S}^{2}
\end{array}\right)=\left(\begin{array}{cc}
234,786 & 101,898 \\
101,898 & 237,250
\end{array}\right) .
$$

Mediante a decomposição espectral da matriz $\hat{\Sigma}$ dada em 6.5 obteve-se os seguintes autovetores e autovalores, representados por $P$ e $\lambda$ respectivamente,

$$
\mathbf{P}=\left(\begin{array}{cc}
0,702 & 0,711 \\
0,711 & -0,702
\end{array}\right), \boldsymbol{\lambda}=\left(\begin{array}{cc}
337,923 & 0 \\
0 & 134,112
\end{array}\right) .
$$

As variáveis canônicas são obtidas pelas combinações lineares:

$$
\begin{aligned}
& \tilde{Y}_{1}=0,702 Y_{S B P}+0,711 Y_{S B P S}, \\
& \tilde{Y}_{2}=0,711 Y_{S B P}-0,702 Y_{S B P S} .
\end{aligned}
$$

Note que: $\tilde{Y}_{1}$ é uma média ponderada entre as medidas da pressão basal e pós-sal e $\tilde{Y}_{2}$ é um contraste entre estas medidas de pressão. Com respeito aos autovalores, $\lambda_{1}=337,923$ indica que a variável canônica $\tilde{Y}_{1}$ explica $71,58 \%$ da variância total e $\lambda_{2}=134,112$ indica que a segunda variável canônica $\tilde{Y}_{2}$ explica $28,41 \%$ da variância total.

Na Tabela 6.8 apresenta-se a correlação entre as variáveis canônicas e os fenótipos originais. Nota-se que a variável canônica $\tilde{Y}_{1}$ é altamente correlacionada (positivamente) com as variáveis originais, enquanto que a variável canônica 2 se correlaciona moderadamente (positivamente com $Y_{S B P}$ e negativamente com $Y_{S B P S}$ ).

Na Figura 6.11(a) encontra-se o perfil da estística Lod score da variável canônica $\tilde{Y}_{1}$ o qual apresenta sinais de ligação nos cromossomos 1, 2, 4 e 16. A Figura 6.11(b) considera o 
Tabela 6.8 Correlação entre as variáveis canônicas e as originais.

\begin{tabular}{ccc}
\hline \hline & $Y_{S B P}$ & $Y_{S B P S}$ \\
\hline$\tilde{Y}_{1}$ & 0,845 & 0,842 \\
$\tilde{Y}_{2}$ & 0,557 & $-0,516$ \\
\hline \hline
\end{tabular}

perfil da estística Lod score para a variável canônica $\tilde{Y}_{2}$ a qual apresenta sinais de ligação somente no cromossomo 5 .

Novamente por meio desta análise, percebe-se que o gene encontrado no cromossomo 5 apresenta um comportamento bem diferenciado dos genes encontrados nos demais cromossomos. Especificamente para finalidade de mapeamento genético a informação da variável canônica $\tilde{Y}_{2}$ é equivalente à informação obtida mediante a análise da variável $Y_{D I F}$, sobre o QTL no cromossomo 5 (Figura 6.6) pois as duas variáveis são definidas em termos de contrastes entre $Y_{S B P}$ e $Y_{S B P S}$ e dão informação de ligação significativa no cromossomo 5.

A Tabela 6.9 apresenta os resultados do teste para mapeamento multivariado via a teoria espectral (ver Seção 4.3.1). Os resultados foram obtidos através do método de mapeamento por intervalo mediante um refinamento das posições dos cromossomos, isto é, o teste, além de ser realizado na posição de cada marcador é realizado em posições adjacentes. São apresentadas as maiores somatórias encontradas nas diferentes posições dos cromosssomos. Por exemplo, no cromossomo 2 marcador 2 (R5129) a 0.04 cM o sup é 21,58, dando evidências da existência de um QTL neste loco. Concluí-se que mediante este teste foi encontrada evidência de possíveis QTL's nos cromossomos 2, 4 ,5, 8 e 16, confirmando os resultados da análise multivariada realizada na Seção 6.2. A maior contribuição da análise via a teoria espectral é obter uma decomposicão dos fenótipos originais em componentes ortogonais $\left(\tilde{Y}_{1}\right.$ e $\left.\tilde{Y}_{2}\right)$ e conseguir uma correspondente decomposição também dos QTL's identificados, confirmando que o QTL no cromossomo 5 é de natureza diferente dos demais. 
Figura 6.11 Perfis da estatística Lod score sob o modelo univariado para as variáveis canônicas

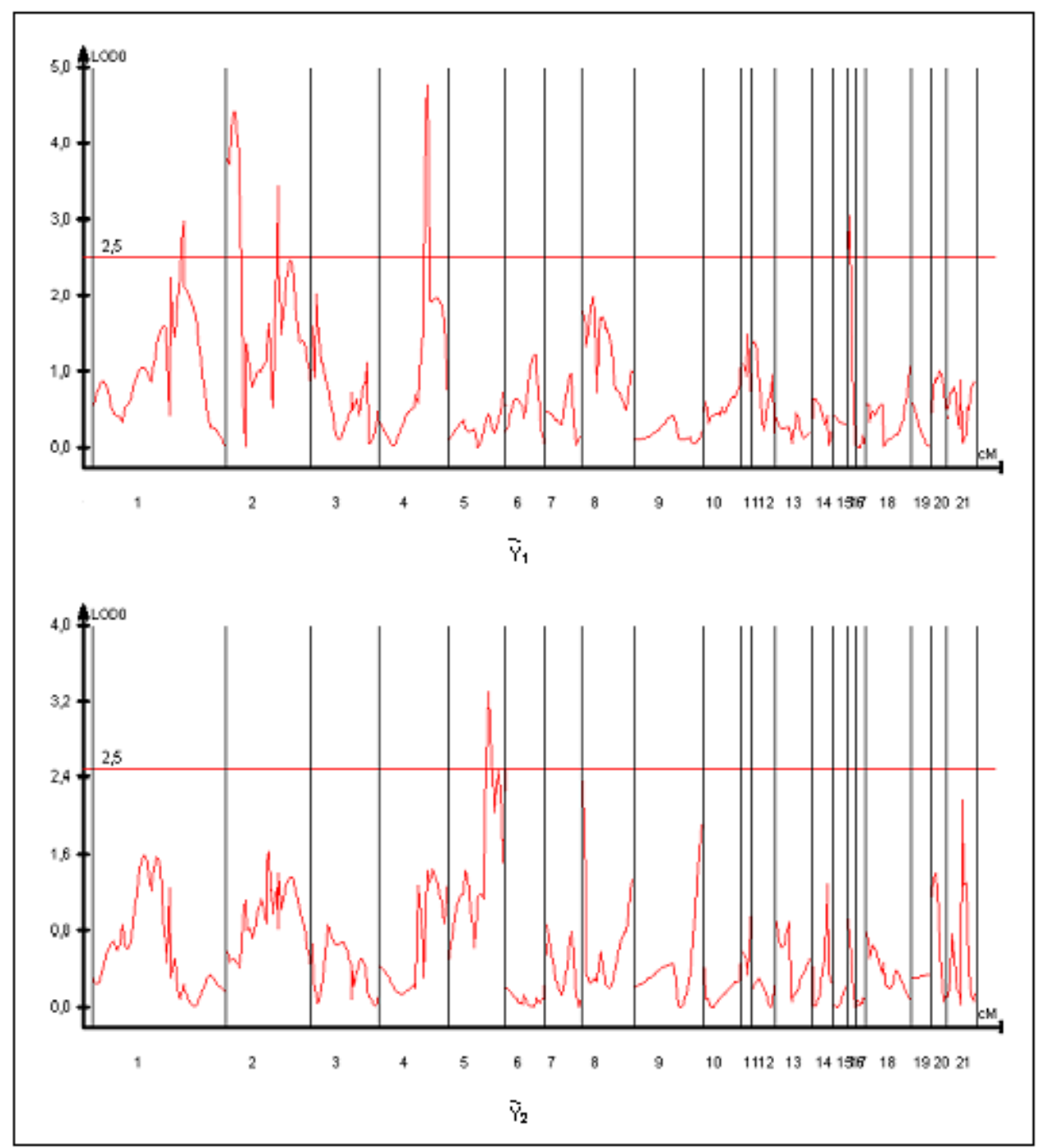

\subsection{Análise da resposta ao medicamento}

Segundo o delineamento experimental realizado, uma vez medida a pressão sistólica após administrar sal, os mesmos ratos receberam o medicamento Captopril para controle da hipertensão e após este tratamento foi medida novamente a pressão sistólica. Na Figura 6.12 apresenta-se o diagrama de perfis individuais de resposta para as três variáveis $Y_{S B P}, Y_{S B P S}$ e $Y_{\text {Captopril }}$, no qual pode-se observar a variação na pressão sistólica devido à sensibilidade ao sal e sensibilidade ao medicamento. 
Tabela 6.9 Resultados dos testes estatísticos (mapeamento por intervalo).

\begin{tabular}{|c|c|c|c|}
\hline Cromossomo & Marcador (M) & $\operatorname{Posição}(\pi)$ & $\sum_{i=1}^{2} L \tilde{R_{i}}(\pi)$ \\
\hline \multirow[t]{9}{*}{2} & $\mathrm{MT}_{1 \mathrm{~PB}}{ }_{M 1}$ & 0,00 & 20,19 \\
\hline & $\mathrm{R} 5129_{M 2}$ & 0,02 & 20,19 \\
\hline & $\mathrm{R} 5129_{M 2}$ & 0,04 & 21,58 \\
\hline & $\mathrm{R} 5129_{M 2}$ & 0,06 & 18,610 \\
\hline & $\mathrm{R} 5129_{M 2}$ & 0,08 & 22,69 \\
\hline & $\mathrm{R} 155_{M 3}$ & 0,13 & 18,79 \\
\hline & $\mathrm{R} 5159_{M 15}$ & 0,55 & 17,05 \\
\hline & $\mathrm{R} 360_{M 18}$ & 0,58 & 17,74 \\
\hline & FIBG $2_{M 21}$ & 0,73 & 17,38 \\
\hline \multirow[t]{3}{*}{4} & $\mathrm{R} 514 \mathrm{a}_{M 6}$ & 0,53 & 25,03 \\
\hline & TGFAA $_{M 7}$ & 0,54 & 28,53 \\
\hline & $\mathrm{R} 995_{M 8}$ & 0,56 & 24,30 \\
\hline \multirow[t]{2}{*}{5} & $\mathrm{R} 589_{M 8}$ & 0,43 & 17,35 \\
\hline & $\mathrm{R} 371_{M 9}$ & 0,50 & 17,35 \\
\hline 8 & $\mathrm{R} 850_{M 2}$ & 0,07 & 19,26 \\
\hline \multirow[t]{2}{*}{16} & $\mathrm{R} 762_{M 1}$ & 0,02 & 17,25 \\
\hline & $\mathrm{R} 193_{M 4}$ & 0,10 & 17,25 \\
\hline
\end{tabular}

Figura 6.12 Perfis individuais de resposta para a pressão arterial medida em três etapas

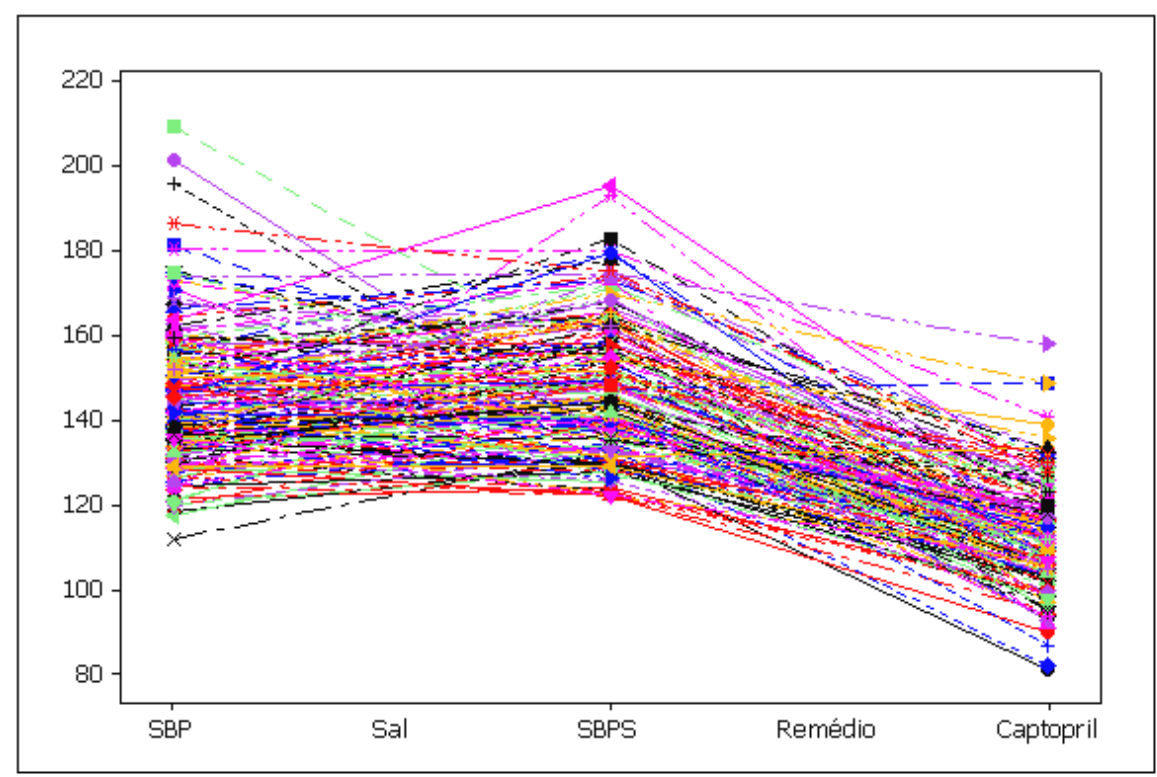

Como estabelecido na seção anterior, ao receber sal, alguns indivíduos tiveram uma queda drástica na pressão e estes indivíduos carregam, possivelmente, informação genotípica 
importante; ao receber o tratamento com Captopril a pressão de quase todos os indivíduos diminuiu, $\left(Y_{\text {Captopril }}-Y_{S B P S}<0\right)$, sendo essa diminuição homogênea para o grupo, só para dois deles a pressão aumentou. Ressalta-se que para as medidas da variável $Y_{\text {Captopril }}$ do conjunto de 221 indivíduos tem-se um grupo considerável de valores faltantes ("missings") e as análises foram realizadas omitindo aquele conjunto de indivíduos (' $n$ ' $=29)$.

Na Figura 6.3, o gráfico de perfil da estatística Lod score para o mapeamento univariado de $Y_{\text {Captopril }}$ detectou um QTL no cromossomo 4, um loco próximo ao identificado na análise de $Y_{S B P S}$. Na Tabela 6.10 são apresentados os testes da razão de verossimilhanças, estimativas dos efeitos aditivo e de dominância para as variáveis $Y_{S B P}, Y_{S B P S}$ e $Y_{\text {Captopril }}$ obtidos sob o modelo univariado.

A seguir são realizadas as análises conjuntas das variáveis $Y_{S B P S}$ e $Y_{\text {Captopril }}$ com o intuito de encontrar algum sinal de ligação de algum QTL como consequência da aplicação do medicamento antihipertensivo.

A Figura 6.13 apresenta os perfis da estatística Lod score da análise bivariada. Percebese sinal significativo nos cromossomos 2, 4, 5, 8 e 16. Chama-se a atenção ao sinal de ligação encontrado no cromossomo 5, já que este sinal não é detectado mediante as análises univariadas das variáveis $Y_{S B P S}$ e $Y_{\text {Captopril }}$ (Figuras 6.2 e 6.3, respectivamente). Deste modo, da mesma forma que foi discutido na análise dos fenótipos $Y_{S B P}$ e $Y_{S B P S}$, para o cromossomo 5 marcador 8 (R589), nesta posição, é encontrada a condição mais favorável para a análise conjunta. Como visto $\rho_{\left(Y_{S B P S}, Y_{\text {Captopril }}\right)}>0$ (Tabela 6.1) e os efeitos aditivos têm sinais opostos, $\hat{a}_{2}=6,041$ e $\hat{a}_{3}=-0,09$ (Tabela 6.10) com a ressalva de que a magnitude de $\hat{a}_{3}$ para $Y_{\text {Captopril }}$ é muito baixa, levando ao questionamento se realmente esta foi a justificativa para a significância obtida no modelo multivariado. Assim, percebe-se que as magnitudes dos efeitos de dominância para $Y_{S B P S}$ e $Y_{\text {Captopril }}$ são altas apesar de não significativas no modelo univariado e isto também pode ter sido responsável pela obtenção de significância na análise conjunta e obtenção de sinal de ligação significativo neste cromossomo. Qualquer que seja a razão, conclui-se que como resposta ao medicamento 
antihipertensivo o QTL do cromossomo 5 também apresenta sinal significativo de ligação, restando ainda entender como se dá seu efeito na pressão arterial pós-medicamento.

Na Tabela 6.11 apresenta-se a estatística do teste da razão de verossimilhanças, as estimativas dos parâmetros dos efeitos aditivo e de dominância quando analisadas conjuntamente as variáves $Y_{S B P S}$ e $Y_{\text {Captopril }}$. Nota-se que para a variável $Y_{\text {Captopril }}$, em geral, os valores de $L R_{3}$. e dos parâmetros são mais baixos (quando comparados com os valores obtidos para a variável $\left.Y_{S B P S}\right)$ dando a idéia de que a contribuição deste fenótipo é pequena na deteç̧ão de QTL's como resposta ao medicamento. Destacam-se em negrito os valores dos parâmetros que apresentam sinais opostos.

Figura 6.13 Perfis da estatística Lod score sob o modelo multivariado para $Y_{S B P S}$ e $Y_{\text {Captopril }}$.

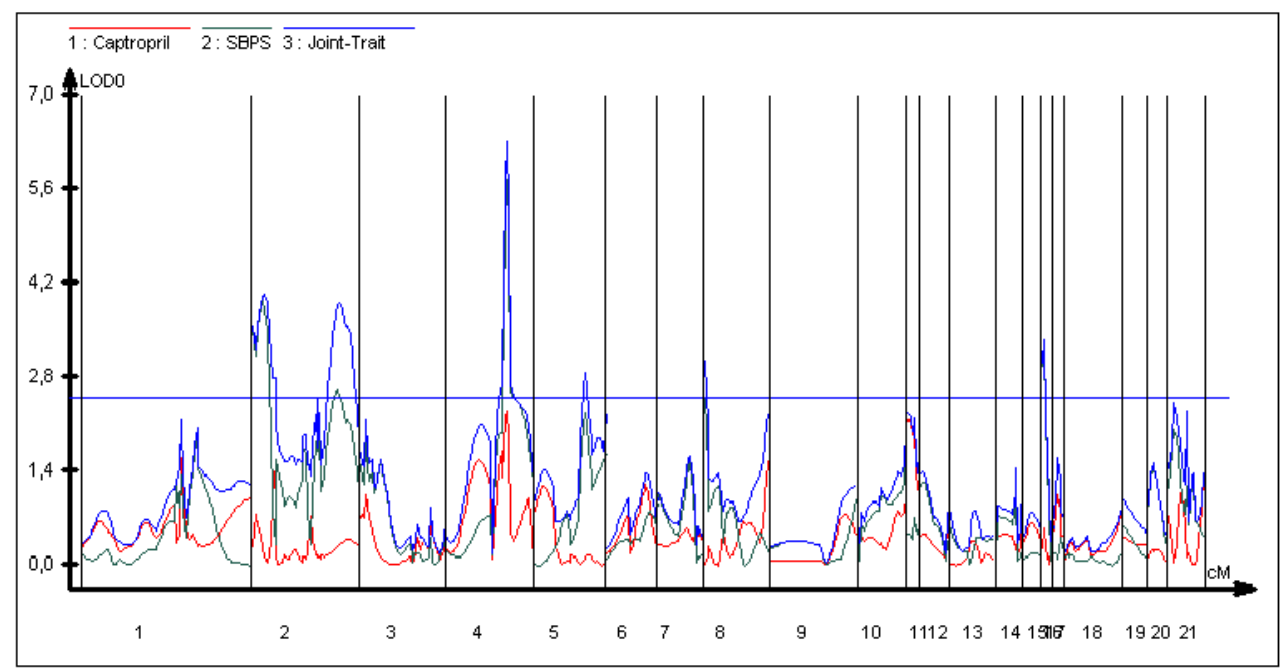

Com o intuito de conhecer a dependência das medidas da pressão pré e pós-remédio e a possibilidade de deteção de novos QTL's, considera-se a seguir o fenótipo da diferença entre estas medidas, $Y_{D I F c a p t}=Y_{\text {Captopril }}-Y_{S B P S}$. Na Figura 6.14 apresenta-se o perfil da estatística Lod score. Percebe-se sinal de ligação em dois locos do cromossomo 2, sendo que estes sinais já foram detectados sob o ajuste do modelo univariado do fenótipo da pressão arterial pós-sal $Y_{S B P S}$ (Figura 6.5(b)).

Lembra-se que a diferença entre duas variáveis fenotípicas é informativa para o mapeamento de genes, quando a correlação entre os traços é positiva e os efeitos aditivos ou os efeitos de dominância apresentam sinais opostos; nota-se que este é o caso para 
Figura 6.14 Perfis da estatística Lod score sob o modelo univariado para $Y_{D I F c a p t}$

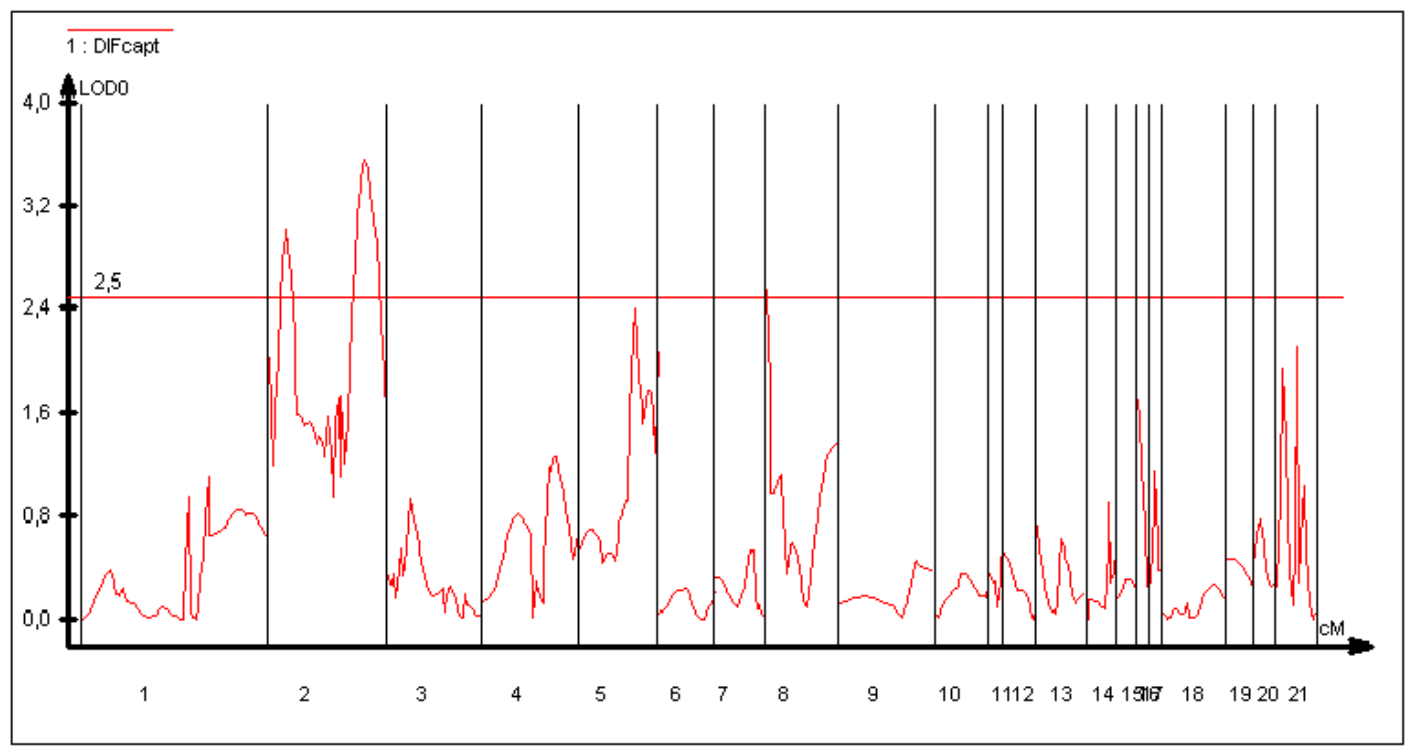

Tabela 6.10 Teste da razão de verossimilhanças, estimativas dos efeitos aditivo e de dominância para $Y_{S B P}, Y_{S B P S}$ e $Y_{\text {Captopril }}$ no caso univariado.

\begin{tabular}{|c|c|c|c|c|c|c|c|c|c|c|c|}
\hline \multirow[b]{2}{*}{$\mathrm{Cr}$} & \multirow[b]{2}{*}{ M } & \multirow[b]{2}{*}{ Posição } & \multicolumn{3}{|c|}{ SBP } & \multicolumn{3}{|c|}{ SBPS } & \multicolumn{3}{|c|}{ Captopril } \\
\hline & & & $\mathrm{LR}_{1}$ & $\hat{a_{1}}$ & $\hat{d_{1}}$ & $\mathrm{LR}_{2}$ & $\hat{a_{2}}$ & $\hat{d_{2}}$ & $\mathrm{LR}_{3}$ & $\hat{a_{3}}$ & $\hat{d_{3}}$ \\
\hline \multirow{3}{*}{1} & $\mathrm{R} 1301_{M 5}$ & 0,72 & 9,78 & 6,52 & $-0,54$ & 2,80 & $-0,22$ & 4,50 & 4,05 & $-1,18$ & 4,50 \\
\hline & $\mathrm{IGF} 2_{M 12}$ & 1,00 & 6,38 & 1,28 & 3,65 & 12,156 & 1,35 & 5,21 & 1,61 & $-1,23$ & 2,43 \\
\hline & $\mathrm{R} 155_{M 3}$ & 0,13 & 7,96 & 5,58 & $-0,77$ & 16,28 & 6,91 & $-0,04$ & 0,23 & 0,71 & 0,18 \\
\hline 2 & FIBG $2_{M 21}$ & 0,71 & 1,51 & 2,77 & 0,29 & 17,24 & 10,01 & $-0,78$ & 1,35 & $-2,074$ & 2,29 \\
\hline 4 & $\mathrm{R}^{2} 14 \mathrm{a}_{M 6}$ & 0,53 & 9,36 & 6,31 & $-2,59$ & 27,30 & 10,44 & $-3,40$ & 12,31 & 5,81 & $-1,75$ \\
\hline \multirow[t]{2}{*}{5} & $\mathrm{R} 589_{M 8}$ & 0,43 & 1,84 & $-1,48$ & 3,16 & 10,11 & 6,041 & $-5,07$ & 0,93 & $-0,09$ & $-1,40$ \\
\hline & $\mathrm{R} 19 \mathrm{a}_{M 1}$ & 0,0001 & 2,13 & 1,03 & 1,85 & 15,54 & 7,68 & $-3,93$ & 0,23 & $-0,16$ & 0,83 \\
\hline 8 & $\mathrm{ACPH}_{M 9}$ & 0,48 & 3,85 & 1,55 & 4,57 & 1,28 & $-1,09$ & $-0,92$ & 1,42 & 2,05 & $-1,08$ \\
\hline 16 & $\mathrm{R} 762_{M 1}$ & 0,0001 & 4,56 & 3,88 & $-0,76$ & 15,07 & 7,06 & $-4,37$ & 1,11 & 1,64 & $-0,64$ \\
\hline
\end{tabular}

$Y_{\text {DIF capt }}$ em posições específicas do cromossomo 2 nos marcadores 3 (R155) e 21 (FIBG2) (Tabela 6.10). Também dois pontos que sobressaem, sem serem significativos, estão nos cromossomos 5 marcador 8 (R589) e no cromossomo 8 marcador 1 (R19a), nota-se que os efeitos aditivos têm sinais opostos obtendo-se a condição mais favorável para a análise da diferença entre fenótipos, mas as magnitudes dos valores dos parâmetros na variável 
$Y_{\text {Captopril }}$ são muito baixos, não alcançando a significância mediante as análises da diferença entre os fenótipos (somente mediante a análise bivariada dos respectivos fenótipos).

Tabela 6.11 Testes da razão de verossimilhanças, estimativas dos efeitos aditivo e de dominância para $Y_{S B P S}$ e $Y_{\text {Captopril, }}$, sob o modelo multivariado.

\begin{tabular}{|c|c|c|c|c|c|c|c|c|c|}
\hline \multirow[b]{2}{*}{$\mathrm{Cr}$} & \multirow[b]{2}{*}{ M } & \multirow[b]{2}{*}{ Posição } & \multicolumn{3}{|c|}{ SBPS } & \multicolumn{3}{|c|}{ Captopril } & \multirow[b]{2}{*}{$\mathrm{LR}_{23}$} \\
\hline & & & $\mathrm{LR}_{2}$ & $\hat{a_{2}}$ & $\hat{d_{2}}$ & $\mathrm{LR}_{3}$. & $\hat{a_{3}}$ & $\hat{d_{3}}$ & \\
\hline \multirow{3}{*}{1} & $\mathrm{R} 1301_{M 5}$ & 0,72 & 2,60 & 2,05 & 3,42 & 2,95 & 1,48 & 3,72 & 4,09 \\
\hline & $\mathrm{IGF} 2_{M 12}$ & 1,00 & 8,99 & 3,74 & 4,64 & 1,32 & 0,49 & 2,09 & 9,39 \\
\hline & $\mathrm{R} 155_{M 3}$ & 0,13 & 15,31 & 6,32 & $-1,50$ & 0,13 & 0,35 & $-0,62$ & 17,72 \\
\hline 2 & FIBG $2_{M 21}$ & 0,71 & 11,81 & 6,78 & $-2,36$ & 1,10 & $-1,38$ & 2,33 & 17,03 \\
\hline 4 & $\mathrm{R} 514 \mathrm{a}_{M 6}$ & 0,53 & 26,43 & 9,38 & $-1,50$ & 10,55 & 5,16 & $-1,48$ & 28,97 \\
\hline 5 & $\mathrm{R} 589_{M 8}$ & 0,43 & 10,37 & 3,53 & $-4,73$ & 0,46 & $-0,97$ & $-0,87$ & 13,21 \\
\hline 8 & $\mathrm{R} 19 \mathrm{a}_{M 1}$ & 0,0001 & 11,53 & 4,81 & $-3,53$ & 0.01 & $-0,05$ & 0,56 & 13,90 \\
\hline 16 & $\mathrm{R} 762_{M 1}$ & 0,0001 & 13,66 & 4,85 & $-3,77$ & 1,20 & 1,21 & $-0,69$ & 13,83 \\
\hline
\end{tabular}

A seguir são consideradas conjuntamente as variáveis $Y_{S B P}, Y_{S B P S}$ e $Y_{\text {Captopril }}$ com o intuito de procurar informações quando analisadas conjuntamente a influência do sal e do remédio na pressão sistólica. A Figura 6.15 apresenta os perfis da estatística Lod score para a análise marginal e conjunta das variáveis $Y_{S B P}, Y_{S B P S}$ e $Y_{\text {Captopril }}$. Percebe-se sinal de ligação nos cromossomos 1, 2, 4, 5, 8, 16 e 21. Nota-se que a informação desta análise é praticamente a mesma que aquela obtida da análise conjunta entre $Y_{S B P}$ e $Y_{S B P S}$. Uma informação adicional é o sinal de ligação encontrado no cromossomo 8 marcador 9 (ACPH) (indicado pela flecha) e aumento no sinal de ligação já detectado no cromossomo 1.

Na Tabela 6.12 são apresentados os testes da razão de verossimilhanças marginais e conjuntos, estimativas dos efeitos aditivos e de dominância para as variáveis $Y_{S B P}, Y_{S B P S}$ e $Y_{\text {Captopril }}$, sob o modelo multivariado. Como previsto, observando os valores das estimativas obtidos para os parâmetros dos efeitos aditivos e de dominância da variável $Y_{\text {Captopril }}$, quase todos os valores são mais baixos quando comparados com os valores obtidos para as outras variáveis, $\left(Y_{S B P}\right.$ e $\left.Y_{S B P S}\right)$ concluindo que a contribuição desta variável é relativamente pequena nas análises conjuntas para a detecção de novos QTL's. 
Figura 6.15 Perfis da estatística Lod score sob o modelo multivariado para $Y_{S B P}, Y_{S B P S}$ e $Y_{\text {Captopril }}$

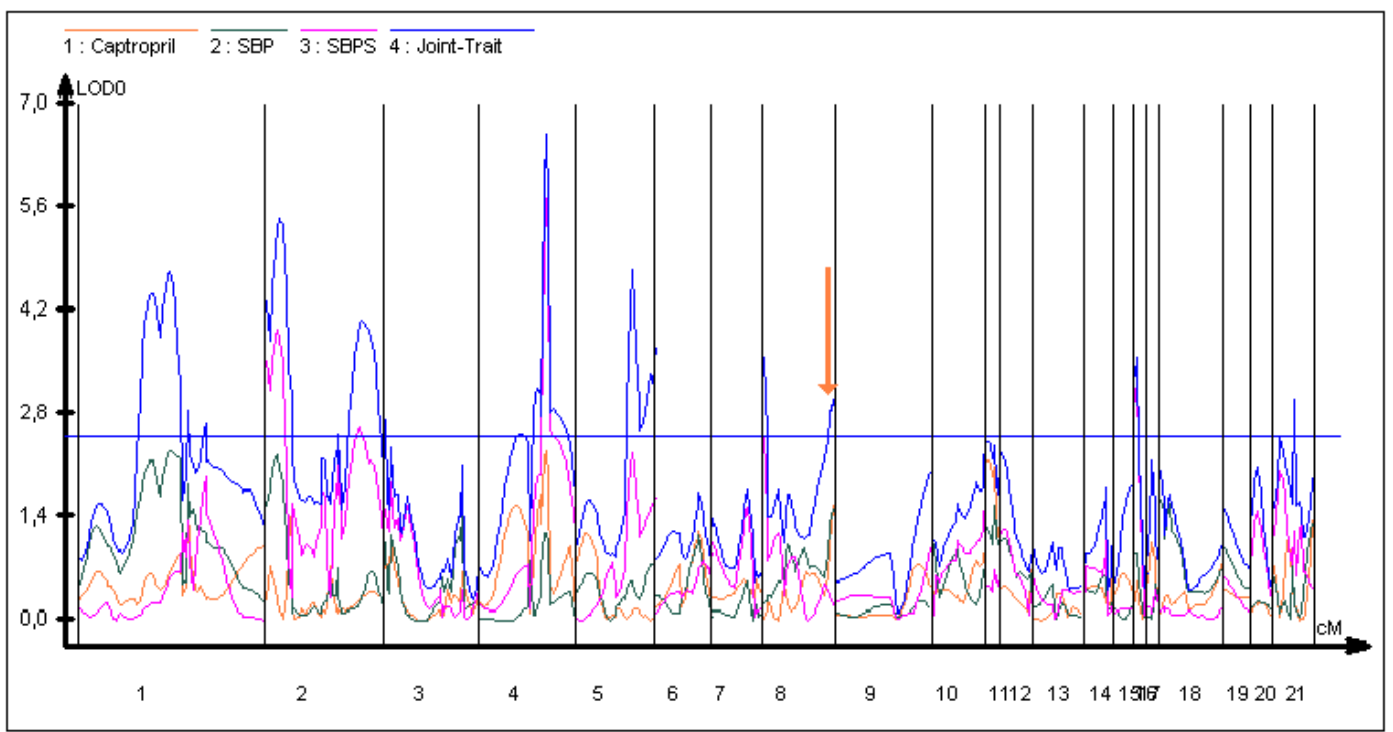

Tabela 6.12 Teste da razão de verossimilhanças, estimativas dos efeitos aditivo e de dominância para os fenótipos $Y_{S B P}, Y_{S B P S}$ e $Y_{\text {Captopril }}$ sob o modelo multivariado.

\begin{tabular}{|c|c|c|c|c|c|c|c|c|c|c|c|c|}
\hline \multirow[b]{2}{*}{$\mathrm{Cr}$} & \multirow[b]{2}{*}{$\mathrm{M}$} & \multirow[b]{2}{*}{ Posição } & \multicolumn{3}{|c|}{ SBP } & \multicolumn{3}{|c|}{ SBPS } & \multicolumn{3}{|c|}{ Captropril } & \multirow[b]{2}{*}{$\mathrm{LR}_{123}$} \\
\hline & & & $\mathrm{LR}_{1}$ & $\hat{a_{1}}$ & $\hat{d_{1}}$ & $\mathrm{LR}_{2}$ & $\hat{a_{2}}$ & $\hat{d_{2}}$ & $\mathrm{LR}_{3}$ & $\hat{a_{3}}$ & $\hat{d_{3}}$ & \\
\hline & $\mathrm{R} 1301_{M 5}$ & 0,72 & 10,47 & 7,44 & $-2,40$ & 2,60 & 2,13 & 3,47 & 2,91 & 1,26 & 4,08 & 21,70 \\
\hline \multirow[t]{2}{*}{1} & $\operatorname{IGF} 2_{M 12}$ & 1,00 & 5,35 & 3,63 & 3,55 & 8,98 & 3,79 & 4,65 & 1,32 & 0,47 & 2,08 & 12,18 \\
\hline & $\mathrm{R} 155_{M 3}$ & 0,13 & 7,93 & 5,54 & $-3,18$ & 15,30 & 6,41 & $-1,59$ & 0,01 & $-0,03$ & $-0,53$ & 24,57 \\
\hline 2 & FIBG $2_{M 21}$ & 0,71 & 0,78 & 2,38 & $-0,01$ & 11,83 & 6,91 & $-2,68$ & 1,1 & $-1,37$ & 2,32 & 17,73 \\
\hline 4 & $\mathrm{R} 514 \mathrm{a}_{M 6}$ & 0,53 & 5,47 & 3,34 & $-4,92$ & 26,38 & 9,16 & $-1,96$ & 10,48 & 5,02 & $-1,73$ & 30,33 \\
\hline 5 & $\mathrm{R} 589_{M 8}$ & 0,43 & 2,43 & 0,33 & 4,50 & 10,37 & 3,56 & $-4,56$ & 0,47 & $-0,93$ & $-0,92$ & 21,87 \\
\hline \multirow[t]{2}{*}{8} & $\mathrm{R} 19 \mathrm{a}_{M 1}$ & 0,0001 & 1,025 & 0,80 & 2,88 & 11,53 & 4,83 & $-3,45$ & 0,02 & $-0,02$ & 0,50 & 16,35 \\
\hline & $\mathrm{ACPH}_{M 9}$ & 0,54 & 6,68 & 1,22 & $-7,51$ & 1,18 & $-1,84$ & $-1,11$ & 6,16 & 2,46 & $-4,57$ & 13,46 \\
\hline 16 & $\mathrm{R} 762_{M 1}$ & 0,0001 & 4,21 & 3,44 & $-0,21$ & 13,66 & 4,88 & $-3,74$ & 1,19 & 1,19 & $-0,69$ & 15,28 \\
\hline
\end{tabular}

Na Tabela 6.13 encontram-se os testes da razão de verossimilhanças para as respectivas análises conjuntas, considerando o teste da hipótese indicada em 3.17. Nota-se que a variável $Y_{\text {Captopril }}$ (correlacionada moderadamente com as variáveis $Y_{S B P}$ e $Y_{S B P S}$ ) quando incluída na análise conjunta faz com que as estatísticas do teste da razão de verossimil- 
hanças tenham valores aumentados, exceto nas posições do cromossomo 1, marcador 12; cromossomo 8 marcador 1 e cromossomo 16 marcador 1 que no caso são mais altas para as análises entre a pressão basal e pós-sal.

É conhecido que o valor da estatística do teste da razão de verossimilhanças para a análise conjunta é sempre mais alto que o máximo das verossimilhanças individuais (Seção 3.2.3), porém, não necessariamente implica em um maior número de locos significativos porque um maior número de parâmetros a serem testados serão incluídos no modelo e o valor da estatística pode não ser compensado pela correspondente mudança no número de graus de liberdade, não atingindo-se assim a significância.

Tabela 6.13 Comparação dos testes da razão de verossimilhanças para as análises conjuntas

\begin{tabular}{|c|c|c|c|c|c|}
\hline $\mathrm{Cr}$ & M & Posição & $\operatorname{LR}_{12}(S B P, S B P S)$ & $\mathrm{LR}_{23}($ SBPS, Captopril $)$ & $\operatorname{LR}_{123}(S B P, S B P S$, Captopril $)$ \\
\hline & $\mathrm{R} 1301_{M 5}$ & 0,72 & 14,27 & 4,09 & 21,70 \\
\hline \multirow[t]{2}{*}{1} & $\operatorname{IGF} 2_{M 12}$ & 1,00 & 14,32 & 9,39 & 12,18 \\
\hline & $\mathrm{R} 155_{M 3}$ & 0,13 & 18,24 & 17,72 & 24,57 \\
\hline 2 & FIBG $_{21}$ & 0,71 & 17,35 & 17,03 & 17,73 \\
\hline 4 & $\mathrm{R} 514 \mathrm{a}_{M 6}$ & 0,53 & 27,18 & 28,97 & 30,33 \\
\hline 5 & $\mathrm{R} 589_{M 8}$ & 0,43 & 18,03 & 13,21 & 21,87 \\
\hline \multirow[t]{2}{*}{8} & $\mathrm{R} 19 \mathrm{a}_{M 1}$ & 0,0001 & 17,83 & 13,90 & 16,35 \\
\hline & $\mathrm{ACPH}_{M 9}$ & 0,54 & 11,17 & 9,73 & 13,46 \\
\hline 16 & $\mathrm{R} 762_{M 1}$ & 0,0001 & 15,60 & 13,83 & 15,28 \\
\hline
\end{tabular}

Com o objetivo de caracterizar com mais detalhe o efeito do QTL no loco do cromossomo 5 (na região do marcador R589) sobre a pressão sistólica, optou-se por explorar por meio de uma análise multivariada (MANOVA, ver Johnson \& Wichern, 1998, por exemplo). Para isso, utiliza-se a informação do loco do marcador R589 que tem seu genótipo conhecido (mensurado) no conjunto de ratos F2 sob análise, já que o específico genótipo do QTL de interesse não é conhecido.

Em primerio lugar consideram-se algumas análises descritivas e seguidamente as análises sob o modelo MANOVA das variáveis $\left(Y_{S B P}, Y_{S B P S}\right.$ e $\left.Y_{\text {Captopril }}\right)$ considerando as suas categorias genotípicas $(m m, M m$ e $M M)$ no marcador R589. 
As médias são apresentadas no diagrama de colunas na Figura 6.16. Este gráfico apresenta as médias da pressão sistólica de cada grupo genotípico $(m m, M m$ e $M M)$ dentro de cada variável $\left(Y_{S B P}, Y_{S B P S}\right.$ e $\left.Y_{\text {Captopril }}\right)$. Os valores das médias e o erro padrão estão apresentados na Tabela 6.14. Nota-se maior variabilidade entre os grupos genotípicos para as medidas da pressão pós-sal $\left(\mathrm{Y}_{S B P S}\right)$.

Ressalta-se que as médias de pressão sistólica após aplicado o medicamento Captopril são muito mais baixas que as médias de pressão basal e pós-sal indicando que o Captopril teve um efeito na diminuição da pressão em todos os grupos genotípicos e isto se deve, possivelmente, ao efeito do gene na região do loco R589 do cromossomo 5.

Figura 6.16 Perfis de médias para as classes genotípicas mm,Mm, MM dentro de cada fenótipo para a posição específica do cromossomo 5 marcador $R 589$.

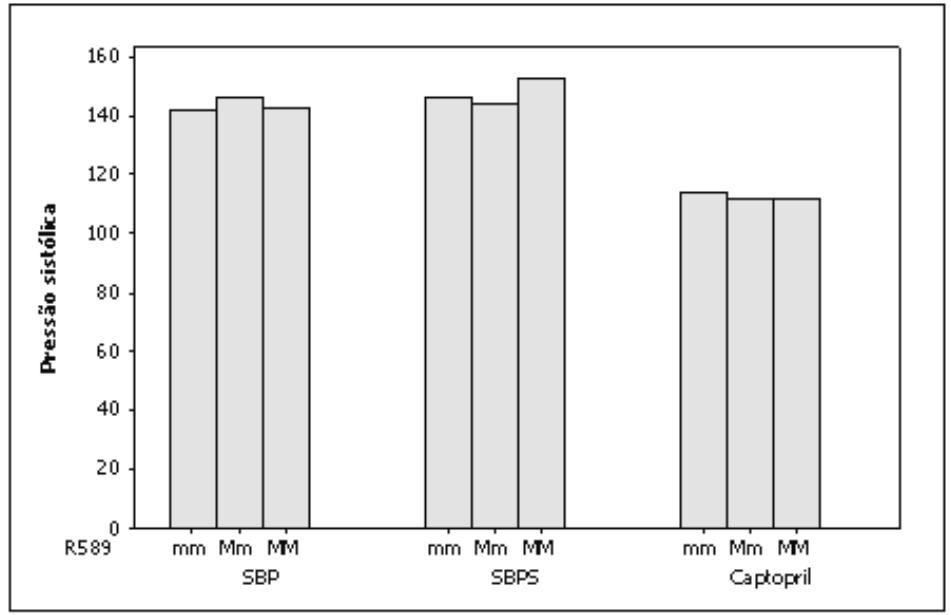

Tabela 6.14 Estatísticas descritivas para as variáveis $Y_{S B P}, Y_{S B P S}$ e $Y_{\text {Captopril }}$ em função dos genótipos.

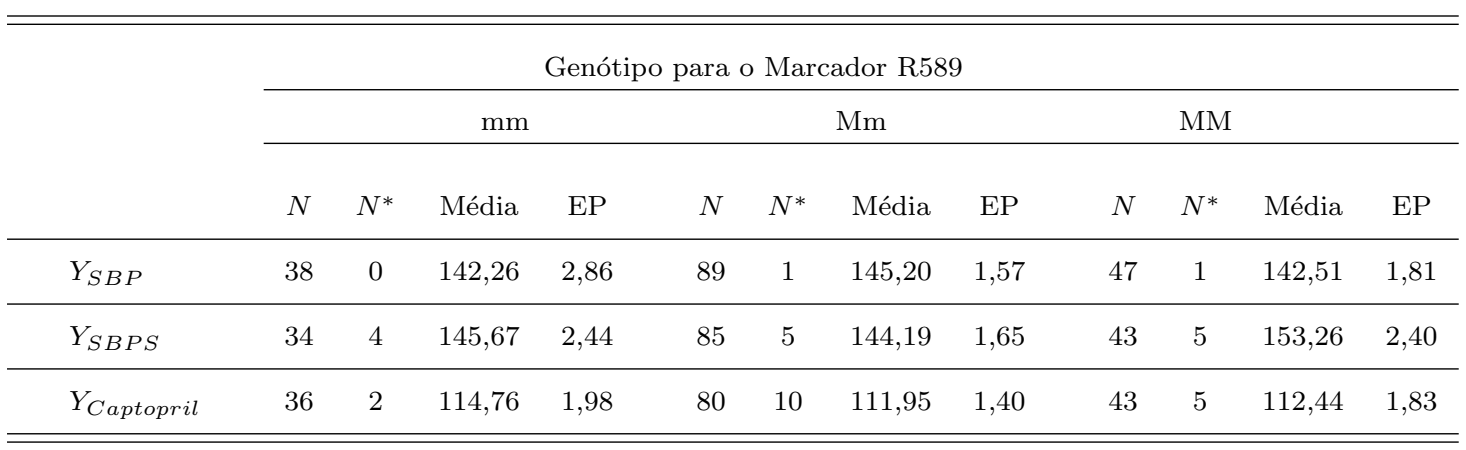


Na MANOVA a hipótese de interesse, neste caso, é:

$$
H_{0}: \boldsymbol{\mu}_{\mathrm{mm}}=\boldsymbol{\mu}_{\mathrm{Mm}}=\boldsymbol{\mu}_{\mathrm{MM}}=\boldsymbol{\mu}
$$

onde $\mu_{i j}=\left(\mu_{S B P i j}, \mu_{S B P S i j}, \mu_{C a p t i j}\right)^{\top}$ é o vetor de médias da pressão sistólica no grupo genotípico $i, j$.

O resultado obtido para a estatística de Wilks, $W=0,8721(p=0,003)$ implica que há pelo menos uma diferença significativa entre o vetor de médias, indicando um efeito significativo do genótipo do marcador R589 sobre as médias de pressão sistólica $\left(Y_{S B P}, Y_{S B P S}, Y_{\text {Captopril }}\right)$. Para o estudo destas diferenças foram calculados intervalos de confiança simultâneos os quais são apresentados nas Tabelas 6.15 e 6.16 .

Na Tabela 6.15 são apresentados os intervalos de confiança simultâneos para os contrastes entre as médias genotípicas para cada medida de pressão $\left(Y_{S B P}, Y_{S B P S}, Y_{\text {Captopril }}\right)$. Percebe-se que existe diferença significativa só em 2 contrastes dentro das classes genotípicas para $Y_{S B P S}$ especificamente. Pode-se concluir que $\mu_{S B P S_{M M}}>\left(\mu_{S B P S_{m m}}=\mu_{S B P S_{M m}}\right)$. Estes resultados indicam que após a exposição ao sal as médias da pressão sistólica para animais $F 2$ com genótipo $M M$ é significativamente maior que para animais no grupo genotípico $m m$ e $M m$. O loco R589, nas condições basal e pós-medicamento não mostrou efeito significativo.

Na Tabela 6.16 apresentam-se os intervalos de confiança para os contrastes entre as variáveis $\left(Y_{S B P}, Y_{S B P S}, Y_{\text {Captopril }}\right)$ considerando cada genótipo do marcador R589. Os resultados indicam que para animais F2, qualquer que seja o genótipo do indivíduo, o QTL próximo do loco R589 tem efeito significativo na diminuição da média da pressão sistólica (quando ingerido o captopril). Isso indica uma sensibilidade deste loco ao medicamento. Comparando a situação basal e pós-sal verifica-se que o efeito deste loco protege os animais $(F 2)$ com genótipo $m m$ e $M m$, que não tiveram sua média de pressão alterada com a dieta de sal (intervalos destacados em negrito); contudo, animais com genótipo $M M$ são sensíveis ao sal no sentido de terem um aumento significativo na média da pressão. 
Tabela 6.15 Intervalos de confiança para contrastes entre médias genotípicas para cada variável.

\begin{tabular}{ccccccc}
\hline \hline & \multicolumn{7}{c}{ Variável } \\
\cline { 2 - 7 } Contrastes & \multicolumn{2}{c}{$y_{S B P}$} & \multicolumn{2}{c}{$y_{S B P S}$} & \multicolumn{2}{c}{$y_{\text {Captopril }}$} \\
\cline { 2 - 7 } & LI & LS & LI & LS & LI & LS \\
\hline \multirow{2}{*}{ mm-Mm } & $-10,33$ & 4,45 & $-6,04$ & 9,00 & $-3,26$ & 8,88 \\
mm-MM & $-7,64$ & 7,14 & $\mathbf{- 1 5 , 1 1}$ & $\mathbf{- 0 , 0 7}$ & $-3,75$ & 8,39 \\
Mm-MM & $-4,70$ & 10,08 & $\mathbf{- 1 6 , 5 9}$ & $\mathbf{- 1 , 5 5}$ & $-6,56$ & 5,58 \\
\hline \hline
\end{tabular}

Tabela 6.16 Intervalos de confiança para contrastes entre médias dentro do grupo genotípico.

\begin{tabular}{ccccccc}
\hline \hline & \multicolumn{6}{c}{ Genótipo } \\
\cline { 2 - 7 } Contrastes & \multicolumn{2}{c}{ mm } & \multicolumn{2}{c}{ Mm } & \multicolumn{2}{c}{ MM } \\
\cline { 2 - 7 } & LI & LS & LI & LS & LI & LS \\
\hline$Y_{S B P}-Y_{S B P S}$ & $\mathbf{- 8 , 8 7}$ & $\mathbf{2 , 0 5}$ & $\mathbf{- 3 , 0 5}$ & $\mathbf{5 , 0 7 0}$ & $-16,43$ & $-5,07$ \\
$Y_{S B P}-Y_{\text {Capt }}$ & 21,07 & 33,93 & 30,33 & 36,17 & 26,47 & 36,67 \\
$Y_{S B P S}-Y_{\text {Capt }}$ & 25,88 & 35,94 & 28,06 & 36,42 & 35,36 & 46,28 \\
\hline \hline
\end{tabular}




\section{Capítulo 7}

\section{Considerações finais}

O interesse por desenvolvimento de metodologias estatísticas multivariadas na área de genética está sendo cada vez maior, já que são ferramentas fundamentais para o mapeamento genético de doenças complexas. Neste trabalho, foram consideradas diversas metodologias univariadas e multivariadas juntamente com algumas abordagens gráficas para o estudo do efeito de pleiotropia e interação gene $\times$ ambiente.

Com o intuito de mapeamento de QTL's que afetam a pressão arterial foram aplicadas as metodologias descritas ao conjunto de dados de ratos $F 2$ coletados no Laboratório de Cardiologia e Genética Molecular InCor/USP e as seguintes conclusões foram obtidas:

- Superioridade do modelo Multivariado nas análises, além de permitir testar efeitos de pleiotropia e interação gene×ambiente;

- Como alternativa a dificuldades de ajuste do modelo de mapeamento multivariado, a aplicação de métodos univariados envolvendo, por exemplo, a medida resumo diferença entre fenótipos, métodos da teoria espectral e o ajuste por covariáveis, foi eficiente para esclarecer diferentes padrões de regulação genéticos e mostraram-se concordantes com resultados da análise multivariada. Também os gráficos de perfis sugeridos para o estudo da interação gene $\times$ ambiente foram eficientes para detectar e analisar pontos informativos sobre a regulação da pressão arterial.

- Os resultados das análises permitiram identificar QTLs com diferentes padrões de regulação da pressão arterial sistólica nos cromossomos 2, 4, 5, 8 e 16. As posições dos QTL's detectados são próximas da região dos marcadores descritos para cada cromossomo na Tabela 7.1 . 
Tabela 7.1 Posições aproximadas dos genes que regulam a pressão arterial sistólica.

\begin{tabular}{clc}
\hline \hline Cromossomo & Nome do marcador & Posição em M \\
\hline & R155 & 0,13 \\
2 & FIBG & 0,71 \\
\hline 4 & R514a & 0,53 \\
\hline 5 & R589 & 0,43 \\
\hline 8 & R19a & 0,0001 \\
\hline 16 & R762 & 0,0001 \\
\hline \hline
\end{tabular}

-Conclui-se que os QTL's encontrados nos cromossomos 2, 4, 8 e 16 estão associados à variabilidade da pressão arterial sistólica entre indivíduos independente da resposta ao sal. O fato destes locos terem sido detectados somente na situação pós-sal $\left(Y_{S B P S}\right)$ deve ser interpretada como uma condição apropriada que induz a uma maior variabilidade entre indivíduos, conduzindo à detecção de efeitos significativos dos genes em uma população. Já o QTL encontrado no cromosssomo 5 atua na diminuição da pressão arterial sistólica diretamente em resposta a este stress específico (dieta com sal), principalmente nos indivíduos com genótipos $m m$ e $M m$ comparados com os de genótipo $M M$. Quando administrado o medicamento antihipertensivo este QTL contribui para abaixar a pressão independente da categorização genotípica. As conclusões com respeito à regulação diferencial do gene no cromosssomo 5 foram obtidas por meio dos modelos alternativos que permitiram o esclarecimento dos resultados do ajuste do modelo multivariado e mediante o estudo dos pontos atípicos sobre a regulação da pressão arterial.

Ressalta-se que todas as análises estatísticas consideradas neste estudo, apesar de terem sido aplicadas especificamente ao problema de interação gene×ambiente, podem ser adaptadas à identificação de genes pleiotrópicos.

A seguir destaca-se alguns tópicos de pesquisas futuras a serem exploradas nas análises de mapeamento genético multivariado:

- Continuidade da análise para o esclarecimento do sinal de ligação de alguns possíveis 
QTL's encontrados como por exemplo, no cromossomo 1, 8 e sexual do genoma dos ratos $F 2$;

- Implementação de testes mais gerais entre classes de médias sob o modelo MANOVA utilizando os recursos do aplicativo Cartographer no mapeamento de genes;

- Considerando que os pontos atípicos podem fornecer informação genética importante na identificação de genes, é necessário desenvolver metodologias estatísticas específicas na análise de dados genéticos que tratem do problema de diagnóstico de pontos aberrantes informativos ao mapeamento de QTL's, bem como da forma mais apropriada de inclusão de tais pontos nos ajustes dos modelos envolvidos.

- Já que o mapeamento de QTL's é basicamente um procedimento de múltiplos testes, o problema de encontrar um nível de significância global permanece em aberto. Sabese que múltiplos testes simultâneos implicam na necessidade de correção do nível de significância global. A correção do nível de significância mais indicada, dentre as diversas abordagens existentes na literatura, deve levar em conta a possível estrutura de dependência entre os vários locos no genoma. Além disso, o problema de múltiplos testes está relacionado à densidade de pontos nos mapas de marcadores. O presente estudo baseou-se em um mapa com 182 marcadores moleculares distribuídos nos 21 cromossomos do rato e é importante salientar que um mapa com este número de marcadores é considerado pouco denso, sendo comum atualmente o uso de mapas bastante densos que cobrem o genoma de muitas espécies com marcadores que distam entre si $1 \mathrm{cM}$. Tais avanços levam a prever que futuramente não haja necessidade de se proceder com o mapeamento genético intervalar (preditivo), mais sim o de se testar o próprio loco.

- O mapeamento genético da maioria das doenças humanas e de fenótipos relevantes a agricultura e agropecuária envolve a modelagem de múltiplos traços e múltiplos genes. Deste modo, a utilização de modelos de equações estruturais tem sido in- 
troduzida como uma ferramenta útil (Li et al. 2006) e merece ser explorada para finalidade de estudo das redes fisiológicas de regulação. 


\section{Apêndice A}

\section{Banco de Dados do Delineamento F2}

O banco de dados do projeto InCor contém variáveis genotípicas e fenotípicas mensuradas em 221 ratos obtidas de um delineamento F2. As variáveis genotípicas referem-se à informação conhecida sobre os genótipos de um mapa de marcadores moleculares para cada um dos ratos. A informação sobre o mapa de marcadores do genoma do rato pode ser obtida em: http://rgd.mcw.edu/, http:ratmap.gen.gu.se e http://www.genome . wi.mit.edu/rat/public. As variáveis fenotípicas referem-se a 23 fenótipos entre os quais estão as medidas de pressão arterial sistólica e diastólica.

\section{A.1 Delineamento $F 2$}

A Figura A.1 apresenta o esquema do delineamento $F 2$ adotado no projeto do InCor, (Instituto do Coração, São Paulo). O estudo é baseado em 221 ratos $F 2$ resultantes do cruzamento entre uma linhagem de animais normotensos Brown-Norway $(B N)$, e outra de animais hipertensos, Spontaneously hipertensive rat $(S H R)$, desenvolvidas de forma que a geração de filhos possuam características idênticas, excentuando-se apenas a pressão arterial. No esquema, $B B$ representa o genótipo de animais normotensos e $S S$ o genótipo dos animais hipertensos. Na obtenção da geração $F 2$ um indivíduo da geração $F 1$ é cruzado com outro indivíduo da geração $F 1(B S \times B S)$ e assim são obtidos os três possíveis genótipos $(B B, B S, S S)$ na razão 1:2:1. Maiores detalhes sobre este delineamento encomtram-se em Schork et al. (1995).

\section{A.2 Banco de dados dos Marcadores Moleculares e Variáveis Genotípicas}

A Tabela A.1 especifica o número de marcadores disponíveis em cada um dos 21 cro- 


\section{A.2 Banco de dados dos Marcadores Moleculares e Variáveis Genotípicas 113}

Figura A.1 Delineamento F2. Projeto InCor.

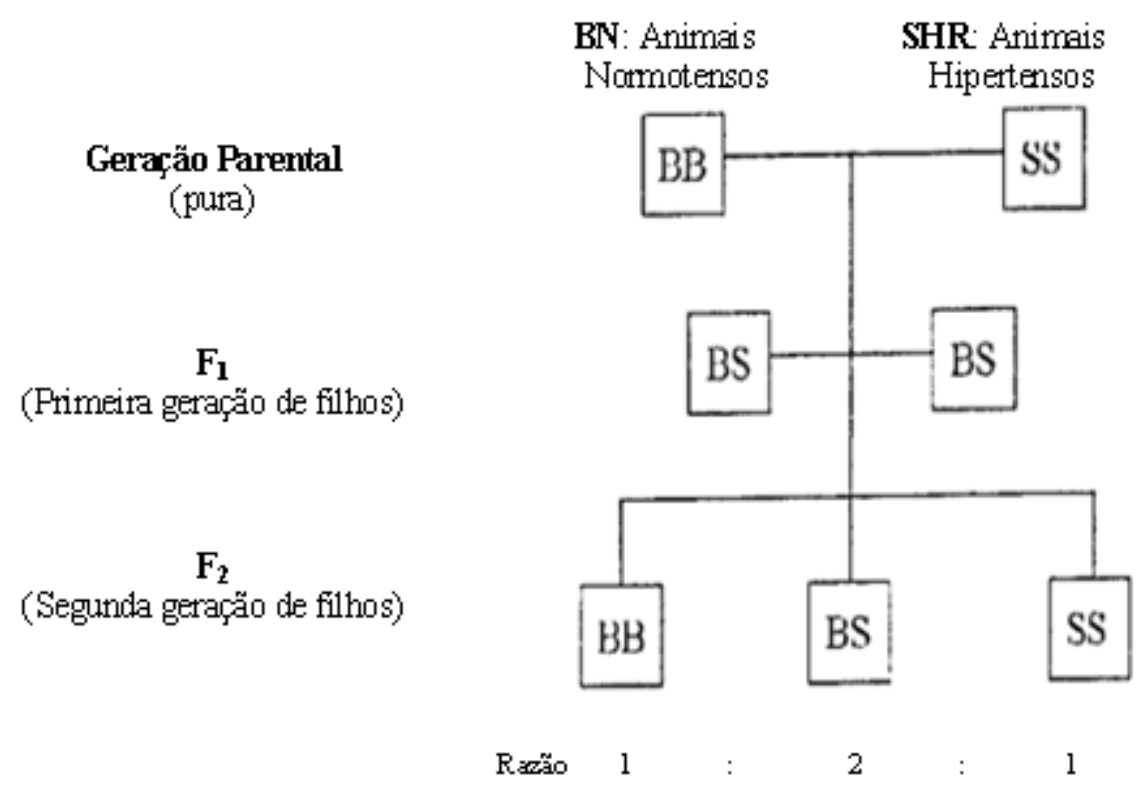

mossomos do genoma do rato. O mapa genético com os nomes dos marcadores e distâncias entre eles foi apresentada na Figura 3.1.

Tabela A.1 Número de marcadores moleculares em cada um dos 21 cromossomos.

\begin{tabular}{cc}
\hline \hline Cromossomo & No de Marcadores \\
\hline 1 & 15 \\
2 & 23 \\
3 & 18 \\
4 & 17 \\
5 & 12 \\
6 & 7 \\
7 & 8 \\
8 & 10 \\
9 & 5 \\
10 & 8 \\
11 & 5 \\
12 & 8 \\
13 & 6 \\
14 & 7 \\
15 & 2 \\
16 & 5 \\
17 & 4 \\
18 & 9 \\
19 & 2 \\
20 & 3 \\
21 & 11 \\
\hline \hline
\end{tabular}


Nota-se na Tabela A.1 que, por exemplo, no cromossomo 5 o número de marcadores moleculares são 12. Na Tabela A.2, para este cromossomo, ilustra-se os dados dos genótipos dos marcadores para cada indivíduo. A codificação utilizada para os genótipos dos Marcadores Moleculares da Tabela A.2 está descrita na Tabela A.3. Por exemplo, para o animal 2 o genótipo para o marcador 8 (R589) é 1 o qual corresponde ao genótipo homozigoto $a a$.

Para cada um dos 21 cromossomos tem-se uma tabela semelhante à apresentada em A.2 sendo que cada cromossomo contém uma quantidade diferente de marcadores moleculares.

Tabela A.2 Localização dos marcadores moleculares e dados genotípicos dos ratos para o cromossomo 5.

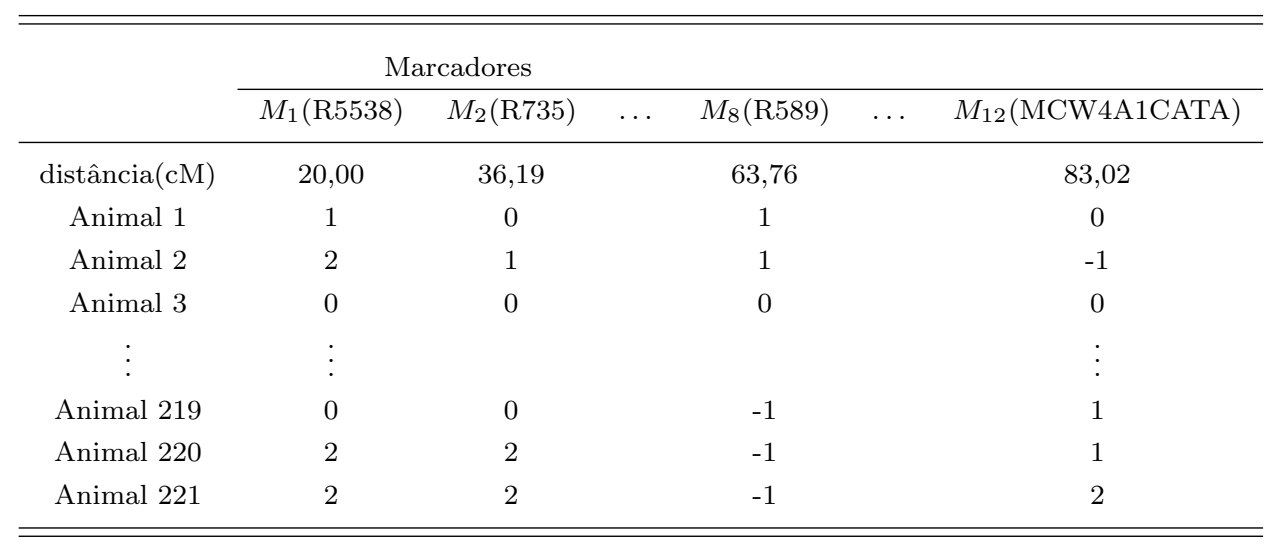

Tabela A.3 Codificação para os genótipos dos Marcadores Moleculares.

\begin{tabular}{cc}
\hline \hline Genótipo do marcador & Código \\
\hline AA & 2 \\
Aa & 1 \\
aa & 0 \\
A- & 12 \\
a- & 10 \\
- & -1 \\
\hline \hline
\end{tabular}

\section{A.3 Banco de dados das variáveis Fenotípicas}

Na Tabela A.4 ilustram-se os dados das variáveis fenotípicas dos 221 ratos. 
Tabela A.4 Dados fenotípicos para os 221 ratos.

\begin{tabular}{|c|c|c|c|c|}
\hline & \multicolumn{2}{|c|}{ Fenotipos } & \multirow[b]{2}{*}{$\begin{array}{c}\text { Fenótipo } 6 \\
\text { SBP }\end{array}$} & \multirow[b]{2}{*}{$\begin{array}{c}\text { Fenótipo } 23 \\
\text { M }\end{array}$} \\
\hline & $\begin{array}{c}\text { Fenótipo } 1 \\
\text { Baseline }\end{array}$ & $\begin{array}{c}\text { Fenótipo } 2 \\
\text { Captropil }\end{array}$ & & \\
\hline Animal 1 & 122 & 119 & 152 & missing \\
\hline Animal 2 & 126 & 119 & 137 & missing \\
\hline Animal 3 & 126 & 128 & 136 & missing \\
\hline$\vdots$ & $\vdots$ & & & $\vdots$ \\
\hline Animal 219 & 116 & 103 & 147 & 8314 \\
\hline Animal 220 & 124 & 110 & 145 & 2338 \\
\hline Animal 221 & 124 & 107 & 145 & 7128 \\
\hline
\end{tabular}




\section{Apêndice B}

\section{Enfoques referentes ao problema de múltiplos testes}

A análise de QTL's é um problema de múltiplos testes. O número de análises repetidas inclui o número de marcadores e o número de segmentos (por exemplo de $1 \mathrm{cM}$ ) mapeados do genoma ou algumas combinações dependendo do método utilizado para o mapeamento de QTL's.

As análises repetidas não são independentes, porque alguns dos marcadores ou segmentos estão ligados ou existem interações epistáticas. Nos dois extremos, todos os marcadores e segmentos estão "ligados" ou são independentes, sendo assim o nível de significância ${ }^{1}$ global pode ser simplesmente determinado utilizando a teoria da probabilidade total sob indepêndencia ou então, se todos os marcadores e segmentos são ligados, possivelmente seja necessário um único teste como alternativa ao critério do produto de testes independentes. No entanto, na prática, para análises de QTL's as situações estão sempre entre os dois extremos (Liu, 1998).

Assim, por exemplo, considerando $t$ marcadores, ao se realizar a varredura pelo genoma à procura de QTL's, serão realizados $t$ testes (no caso de mapeamento considerando um marcador por vez). Sendo adotado um nível de significância $\alpha$ para cada teste, tem-se que o nível de significância conjunto ou genômico (sob independência), denotado por $\alpha^{*}$, será: $\alpha^{*}=$ probabilidade de rejeitar uma hipótese nula verdadeira, ou também, $\alpha^{*}=1$ - probabilidade de não rejeitar nenhuma hipótese nula verdadeira, isto é, $\alpha^{*}=1-(1-\alpha)^{t}$

Nota-se que o nível de significância conjunto cresce á medida que aumenta o número de testes realizados. Por exemplo, realizando-se dois testes, adotando-se $\alpha=0,05$ em cada um, o nível de significância conjunto (sob independência) será $\alpha^{*}=0,097$; com 10 testes,

${ }^{1}$ Nivel de significância é definido como a probabilidade de se cometer um erro tipo I (rejeitar uma hipótese nula verdadeira). 
esse valor será de 0,401 e com 50 testes 0,923 . Assim para a obtenção de um limite de significância para todo o experimento é preciso ajustar o nível de significância de cada teste individual.

\section{B.1 Correção de Bonferroni}

Uma alternativa é utilizar a correção de Bonferroni que, de acordo com Province (1999), consiste em determinar o valor do nível de significância individual $\alpha$, que proporcionará o nível de significância conjunto $\alpha^{*}$. O problema de usar esta correção, é que ela é muito conservadora e é obtida considerando-se $t$ testes independentes, o que não ocorre no mapeamento de QTL's, pois muitos marcadores podem estar localizados em uma mesma região de ligação.

\section{B.2 Teste de Permutações}

Outra alternativa para determinar o valor crítico global que permite declarar a existência de um QTL associado ao marcador é o teste de permutações (Churchill \& Doerge, 1994; Doerge \& Churchill,1996). Para a realização deste teste, indexam-se os indivíduos de 1 até $n$. Os valores fenotípicos das características são tomados ao acaso e atribuídos aos indivíduos conforme forem sendo retirados. Assim, o primeiro valor retirado da amostra de dados fenotípicos é atribuído ao indivíduo 1, e assim sucessivamente, até que todos os indivíduos tenham um valor associado. Os dados permutados são então submetidos à análise para detectar a presença de QTL's. Os resultados desta análise são então armazenados e o procedimento todo (permutação, análise de QTL's e armazenamento dos resultados) é repetido $N$ vezes.

Dessa forma, qualquer associação entre marcadores e valores fenotípicos é destruída, e as análises realizadas correspondem aos resultados esperados sob a hipótese nula. Ao final desse procedimento, terão sido armazenados os resultados das $N$ análises com os dados permutados.

Com esses dados, três tipos de valores críticos podem ser obtidos:

- O valor crítico para cada teste (comparisonwise);

- O valor crítico para todos os testes dentro de um grupo de ligação (cromossomewise); 
- O valor crítico para todos os testes do genoma (genome wise).

Neste teste são armazenados os valores máximos da razão de verossimilhanças $(L R)$ dentro de cada intervalo de ligação; ao final das $N$ análises, estes valores são ordenados por ordem de magnitude, permitindo estimar o valor crítico para cada teste.

O valor crítico de cada intervalo para um nível $\alpha$ de significância é o valor de magnitude $N(1-\alpha)$, ou seja, após 1.000 permutações o valor crítico para um nível de significância de $5 \%$ é o valor ordenado número 950. Cada intervalo terá um valor crítico próprio, porém, como os valores são estimados a partir da mesma amostra de permutação, eles tendem a ser correlacionados. Para evitar essa correlação deve-se realizar uma nova permutação após a análise de cada ponto, mas isso pode ser computacionalmente inviável.

O valor crítico para para cada grupo de ligação é obtido armazenando-se o valor máximo de $L R$ de cada grupo de ligação, após cada permutação. O valor crítico é obtido da mesma forma (ordenando-se os valores obtidos e encontrando o valor de ordem $N(1-\alpha)$ ). Cada grupo de ligação possuirá um valor crítico próprio, o qual serve para todos os testes dentro do grupo de ligação. As mesmas observações sobre estimativas correlacionadas se aplicam também neste caso.

O valor crítico para o genoma todo é obtido armazenando-se, a cada permutação, o valor máximo de $L R$ obtido entre todos os testes realizados. O resultado de ordem $N(1-\alpha)$ é o valor crítico para todos os testes, sendo comumente o valor adotado para determinar a presença de um QTL. Quanto maior o número de permutações, maior será a precisão do valor crítico global.

Doerge \& Rebaï (1996), testando diferentes níveis de significância, concluíram que para o nível de significância estável de 10 e $5 \%$ são necessárias cerca de 1.000 permutações (o desvio padrão do valor obtido após inúmeros testes é baixo), mas para o nível de significância de $1 \%$ o número de permutações deverá ser de aproximadamente 10.000.

\section{B.3 FDR}

Benjamin \& Hocheberg (1995) propuseram controlar a "razão de falsas descobertas" FDR (do inglês, False Discovery Rate), definida como sendo a proporção de hipóteses nulas $H_{0}$ verdadeiras, entre as hipóteses nulas rejeitadas, ou seja, a proporção de erros devidos à falsa rejeição de $H_{0}$, também chamada proporção de falsos positivos.

Para melhor compreensão desse teste, considere-se que sejam testadas $t$ hipóteses $H_{0}$ 
das quais um determinado número $\left(t_{0}\right)$ seja verdadeira, e que $R$ das $t$ hipóteses foram rejeitadas. A Tabela B.1 resume a situação apresentada. Nessa tabela, $R$ e $t$ são variáveis observáveis, $U, V, S, W$ e $t_{0}$ são variáveis aleatórias não observáveis. Em termos dessas variáveis aleatórias, o nível de significância genômico, ou FWER (do inglês, familywise error rate), como definido pelos autores, é $P(V \geq 1)$, onde:

$t$ : número total de hipóteses;

$R$ : número de hipóteses rejeitadas;

$t_{0}$ : número de hipóteses nulas verdadeiras;

$t-t_{0}$ : número de hipóteses nulas não verdadeiras;

$V$ : número de falsos positivos;

$W$ : o número de falsos positivos. Para obter o critério FDR, considere $Q$ uma variável aleatória tal que:

$$
\mathrm{Q}=\left\{\begin{array}{l}
\frac{V}{V+S}=\frac{V}{R}, \quad \text { se } R>0 \\
0, \text { se } R=0
\end{array}\right.
$$

A proporção de erros devidos à falsa rejeição de $H_{0}$ (proporção de falsos positivos) é dada pela variável aleatória $Q$, a qual é uma variável aleatória não observável. Assim, define-se a FDR $Q e$, como sendo a esperança matemática de $Q$, isto é, $Q e=E[V / R]$.

Duas propriedades dessa razão de erros decorrem imediatamente (Benjamin \& Hocheberg, 1995):

Se todas as hipóteses $H_{0}$ forem verdadeiras, a FDR é equivalente a FWER, nesse caso, $S=0$ e $V=R$. Portanto, se $V=0 \rightarrow Q=0$ e se $V>0 \rightarrow Q=1$, ocasionando $P(V \geq 1)=E(Q)=Q e$. Desse modo, controlar a FDR implica, a grosso modo, controlar a FWER.

Quando $t_{0}<t$, a FDR é menor ou igual a FWER; neste caso, se $V>0$ decorre que $V / R \leq 1$, ocasionando $\chi_{v} \geq Q$. Aplicando o operador Esperança em ambos os lados, tem-se: $P(V \geq 1) \geq Q e$. Resulta daí, que qualquer procedimento que controle a FWER também controlará a FDR. No entanto, se um procedimento controlar apenas a FDR, ele poderá ser menos restritivo, e um ganho em poder deverá ser esperado. Em particular, quanto maior o número de hipóteses falsas, maior tende a ser $S$, e, conseqüentemente, a diferença entre as razões de erros (FDR e FWER). Decorre, pois, que o potencial de aumento do poder é tanto maior quanto maior for o número de hipóteses falsas. Em análise 
de QTL's, isso equivale a dizer que quanto maior o número de QTL's segregando, maior será o poder.

Tabela B.1 Número de erros cometidos ao se testarem t hipóteses

\begin{tabular}{lccc}
\hline \hline & Não Rejeitadas & Rejeitadas & Total \\
\hline$H_{0}$ verdadeiras & $\mathrm{U}$ & $\mathrm{V}$ & $t_{0}$ \\
$H_{0}$ Falsas & $\mathrm{W}$ & $\mathrm{S}$ & $t-t_{0}$ \\
\hline Total & $t-R$ & $\mathrm{R}$ & $\mathrm{t}$ \\
\hline \hline
\end{tabular}




\section{Referências Bibliográficas}

[1] Almasy, L. \& Blangero, J. (2000). Challenges for genetic analysis in the 21st century: localizing and characterizing genes for common complex diseases and their quantitative risk factors. GeneScreen. 1, 113-116.

[2] Amabis, J.M. \& Martho, G.R. (1994). Biologia das populações. São Paulo: Ed Moderna.

[3] Amos, C.I., de Andrade M. \& Zhu, D. (2001). Comparison of Multivariate Tests for Genetic Linkage. Human Heredity. 51, 133-144.

[4] Arya, R., Lehman, D., Hunt, K.J., Schneider, J., Almasy, L., Blangero, J., Stern, M.P. \& Duggirala, R. (2003). Evidence for bivariate linkage of obesity and HDL-C levels in the Framingham Heart Study. BMC. Genet. [Suppl] 4, 52.

[5] Balding, D.J. (2002). Discussion on the meeting on "Statistical modelling and analysis of genetic data". J.R. Statist. Soc. B. 64, 737-775.

[6] Balding, D.J., Bishop, M. \& Cannings, C. (2003). Handbooks of statistical genetics. England: John Wiley \& Sons Ltd.

[7] Basten, C. J., Weir, B. S. \& Zeng, Z.B. (1994). Zmap-a QTL cartographer. In Smith, C., Gavora, J. S., Chesnais, B. B., Fairfull, J. W., Gibson, J. P., Kennedy, B. W. \& Burnside E. B. (Eds.), Proceedings of the 5th World Congress on Genetics Applied to Livestock Production: Computing Strategies and Software, Volume 22, Guelph, Ontario, Canada. Organizing Committee, 5th World Congress on Genetics Applied to Livestock Production.

[8] Bearzoti, E. (2000). Análise de QTL no Melhoramento de Plantas. 2a jornada em genética e melhoramento de plantas. FUNAPE, 63-209. 
[9] Benjamin, Y. \& Hocheberg, Y. (1995). Controlling the false discovery rate: a practical and powerful approach to multiple testing. Journal of the Royal Statisftics Society. 21, 557-566.

[10] Carter, T.F. \& Falconer, D.S. (1951). Stocks for detecting linkage in the mouse and the theory of their designs. Journal Genet. 50, 307-323.

[11] Chambers, J.M., Cleveland, W.S., Kleiner, B. \& Tukey, P.A. (1983). Graphical methods for data analysis. Nova York: Chapman \& Hall.

[12] Churchil, G.A. \& Doerge, R.W. (1994). Empirical threshold values for quantitative trait mapping. Genetics. 138, 963-971.

[13] Cordell, H.J. (2002). Epistasis:What it means, what it doesn't mean, and statistical methods to detec it in humans. Human Molecular Genetics. 11, 2463-2468.

[14] Cui, X. \& Churchill, G.A. (2003). Statistical Test for Differential Expression in cDNA Microarray Experiments. Genome Biology. 4, 201.

[15] Curtis, O. \& de Andrade, M. (2003). Localization of genes involved in metabolic syndrome using multivariate linkage analysis. BMC Genetics. 4, S57.

[16] Doerge, R.W. \& Rebaï, A. (1996). Significance thresholds for QTL interval mapping test. Heredity. 76, 459-464.

[17] Doerge, R.W. \& Churchill, G.A. (1996). Permutation test for multiple loci affecting a quantitative character. Heredity. 142, 285-294.

[18] Doerge, R.W., Zeng, Z.B. \& Weir, B.S. (1997). Statistical issues in the search for genes affecting quantitative traits in experimental populations. Statistical Science. 12, 195-219.

[19] Draper, N.R. \& Smith, H. (1981). Applied regression analysis. New York: John Wiley Sons.

[20] Evans, D.M. (2002). The power of multivariate quantitative-trait-loci linkage analysis is influenced by the correlation between the variables. Am J Hum Genet. 70, 15991602 . 
[21] Falconer, D.S. (1952). The problem of environment and selection. Am. Nat. 86, 293298.

[22] Falconer, D.S. (1964). Introduction to quantitative genetics. London: Oliver and Boyd Ltd.

[23] Farah, S.B. (1997). DNA segredos e mistérios. São Paulo: Sarvier.

[24] Haldane, J.B.S. (1919). The combination of linkage values, and the calculation of distance betwen the loci of linked factors. Journal of Gentics. 8, 299-309.

[25] Haley, C.S. \& Knott, S.A. (1992). A simple regression method for mapping quantitative trait loci in line crosses using flanking markers. Heredity. 69, 315-324.

[26] Hartl, D.L. \& Clark, A.G. (1997). Principles of Population Genetics. Sinauer.

[27] Hastie, T., Tibshirani, R. \& Friedman, J. (2001). The Elements of Statistical Learning Data Minning, Inference and Prediction. New York: Springer.

[28] Jansen, R.C. (1992). A general mixture model for mapping quantitative trait loci by using molecular markers. Theoretical and Applied Genetics. 85, 252-260.

[29] Jansen, R.C. (1993). Maximum likelihood in a generalized linear finite mixture model by using the EM algorithm. Biometrics. 49, 227-231.

[30] Jansen, R.C. \& Stam, P. (1994). High resolution of quantitative traits into multiple loci via interval mapping. Genetics. 136, 1447-1455.

[31] Jiang, C. \& Zeng, Z.B. (1995). Multiple trait analysis of genetic mapping for quantitative trait loci. Genetics. 140, 1111-1127.

[32] Johnson, R.A. \& Wichern, D.W. (1998). Applied Multivarite Statistical Analysis, 4 ed. Upper Saddle River: Prentice Hall.

[33] Kao, C. H. \& Zeng, B. Z. (1999). Modelling Epistasis of Quantitative Trait Loci Using Cockerham's Model. Genetics. 160, 1243-1261.

[34] Kao, C. H., Zeng, B. Z. \& Teasdale, R.D. (2002). Multiple interval mapping for quantitative trait loci. Genetics. 152, 1203-1216. 
[35] Karlin, S. (1984). Theoretical aspects of genetic map function in recombination processes. In A. Chakravarti (Ed.) \& Human population genetics The Pittsbugh Symposium, 209-228.

[36] Knapp, S.J., Bridges, W.C. \& Birkes, C. (1990). Mapping quantitatives traits using molecular linkage maps. Theoretical and Applied Genetics. 79, 583-592.

[37] Knott, S.A. \& Haley, C.S. (2000). Multitrait least squares for quantitative trait loci detections. Genetics. 156, 899-911.

[38] Kosambi, D.D. (1944). The estimation of map distances from recombination values. Annals of Eugenics. 12, 172-175.

[39] Kraft, P. \& de Andrade, M. (2003). Group 6. Pleiotropy and multivarate analysis (suplement 1). Genetic Epidemiology. 25, 550-556.

[40] Lander, E.S. \& Botstein, D. (1989). Mapping mendelian factors underlying quantitatives traits using RFLP linkage maps. Genetics. 121, 185-199.

[41] Lange, K. (1997). Mathematical and statistical methods for genetic analysis. New York: Springer.

[42] Li, R., Tsaih, S.W., Shockley, K., Stylianou, I.M., Wergedal, J. \& Paigen B. (2006). Structural Model Analysis of Multiple Quantitative Traits. PLoS Genetics. 2, 10461056.

[43] Lincon, S., Daly, M. \& Lander, E. (1992a). Constructing genetic maps with MAPMAKER/EXP3.0 $3^{a}$ ed. Whitehead Institute Technical Report.

[44] Liu, B.H. (1998). Statistical Genomics: Linkage, Mapping, and QTL Analysis. Boca Raton FL: CRC Press.

[45] Lynch, M. Walsh, B. (1998). Genetics and analysis of quantitative traits. Massachusetts: Sinauer Sunderland.

[46] Mangin, B., Touquet, P. \& Grimsley, N. (1998). Pleiotropic QTL analysis. Biometrics. 54, 88-99.

[47] Montgomery, D.C. (1984). Design and analysis of experiments. New York: Wiley. 
[48] Moore, J.H. (2005). A global view of epistasis traits. Nature Genetics. 37, 13-14.

[49] Morgan, T.H. (1928). The Theory of Genes. Nev Haven, CN: Yale University Press.

[50] Neter, J.H., Kutner, M., Nachtsheim, C.J. \& Wasserman, W. (1996). Applied linear statistical models. Chicago: McGraw-Hill.

[51] Osorio, F. A. (2006). Diagnóstico de influência em modelos elípticos com efeitos mistos. Tese para obtenção do grau de Doutor em Ciências. Área de concentração: Estatística. Instituto de Matemática e Estatística da Universidade de São Paulo. São Paulo.

[52] Ott, J. (1991). Analysis of Human Genetic linkage. London: Johns Hopkins.

[53] Paula, G.A. (2004). Modelos de regressão com apoio computacional. São Paulo: IMEUSP.

[54] Province, M.A. (1999). Sequential Methods of analysis for genome scan. In: RAO, DC; PROVINCE, M.A. Dissection of complex traits. San Diego: Academic Press.

[55] Rao, D.C., Morton, N.E., Lindsten, J., Hulten, M. \& Yee, S.A. (1977). A mapping funtion for man. Hum. Hered. 27, 99-104.

[56] Samani, N.J. (2003). Genome scans for hypertension and blood pressure regulation. Am J Hypertens. 16, 167-171.

[57] Schork, N.J., Krieger, J.E., Trolliet, M.R., Franchini, K.G., Koike, G., Krieger, E.M., Lander, E.S., Dzau, V.J. \& Jacob, H.J. (1995). A biometrical genome search in rats reveals the multigenetic basic of blood pressure variation. Genome Research. 5, $164-172$.

[58] Sham, P. (1998). Statistics in human genetics. London: Arnold Applications of Statistics.

[59] Shimomura, K., Low-Zeddies, S.S, King, D.P., Steeves, T.D.L. Whiteley, A., Kusla, J., Zemenides, P.D., Lin, A. Vitaterna, M.H., Churchill, G.A. \& Takahashi, J.S. (1991). Genome-Wide Epistatic Interaction Analysisi Reveals Complex Genetic Determinants of Circadian Behaviour in Mice. Genome Researchs. 11, 959-980. 
[60] Soler, J.M.P., Pereira, A., Krieger, J.E. \& Tôrres, C.H. (2006). Gene by environment QTL mapping trough Multiple Trait Analysis in Blood Pressure Salt-Sensitivity: Identification of a novel QTL in rat chromosome 5. BMC Med Genet. 7, 47.

[61] Tanksley, S.D. (1993). Mapping polygenes. Ann. Rev. Genet. 27, 205-233.

[62] Tukey, J.W. (1977). Exploratory data analysis. Reading: Addison-Wesley.

[63] Turner et al. (2004). Multivariate linkage analysis of blood pressure and body mass index. Genetic Epidemiologic. 27, 64-73.

[64] Venter (2001). The independent, Feb. 12th.

[65] Wang S., Basten, C. J., \& Zeng Z.B. (2007). Windows QTL Cartographer 2.5. Department of Statistics, North Carolina State State University, Raleigh, NC. http://statgen.ncsu.edu/qtlcart/WQTLCart.htm

[66] Weir, B.S. (1996). Genetics data analysis II. Sunderland: Sinauer Associates.

[67] Weller, J.I., Wiggans, G.R. \& VanRaden, P.M. (1996). Application of a canonical transformation to detection of quantitative trait loci with the aid of genetic markers in multitrait experiment. Theoretical and Applied Genetics. 92, 998-1002.

[68] Wolfinger, R.D., Gibson, G., Wolfinger, E.D., Hamadeh, H., Bushel, P., Afshari, C. \& Paules, R. S. (2001). Assessing gene significance from cDNA microarray expression data via mixed models. Comput Biol. 6, 625-637.

[69] Yang, X. (2003). Optimal Design of single Factor cDNA Microarray Experiments and Mixed Models for Gene Expression Data. Dissertation for degree of Doctor in Statistics to the Faculty of the Virginia Polytechnic Institute and State University, Virginia.

[70] Zeng, Z.B. (1993). Theoretical basis for separation of multiple linked gene effects in mapping quantitative trait loci. Procedures of the Natinal Academics Science USA. 90, 10972-10976.

[71] Zeng, Z.B. (1994). Precision mapping quantitative trait loci. Genetics. 136 , 14571468. 